The Marginal Cost of Electricity 1980-1995: An Approximation Based on the Cost of New Coal and Nuclear Generating Plants

L. A. Nieves

W. P. Patton

B. J. Harrer

J. C. Emery

July 1980

Prepared for the U.S. Department of Energy under Contract DE-AC06-76RLO 1830

Pacific Northwest Laboratory

Operated for the U.S. Department of Energy

by Battelle Memorial Institute 


\title{
NOTICE
}

This report was prepared as an account of work sponsored by the United States Government. Neither the United States nor the Department of Energy, nor any of their employees, nor any of their contractors, subcontractors, or their employees, makes any warranty, express or implied, or assumes any legal liability or responsibility for the accuracy, completeness or usefulness of any information, apparatus, product or process disclosed, or represents that its use would not infringe privately owned rights.

The views, opinions and conclusions contained in this report are those of the contractor and do not necessarily represent those of the United States Government or the United States Department of Energy.

\author{
PACIFIC NORTHWEST ! ABORATORY \\ operated by \\ BATTELLE \\ for the \\ UNITED STATES DEPARTMENT OF ENERGY \\ Under Contract DE-AC06-76RLO 1830
}

\author{
Printed in the United States of America \\ Available from \\ National Technical Information Service \\ United States Department of Commerce \\ 5285 Port Royal Road \\ Springfield, Virginia 22151
}

Price: Printed Copy s.

$\therefore$ Microfiche 53.00

$\begin{array}{cc}\text {-Pages } & \begin{array}{c}\text { NTIS } \\ \text { Selling Price }\end{array} \\ & \\ 001-025 & \$ 4.00 \\ 026-050 & \$ 4.50 \\ 051-075 & \$ 5.25 \\ 076-100 & \$ 6.00 \\ 101-125 & \$ 6.50 \\ 126-150 & \$ 7.25 \\ 151-175 & \$ 8.00 \\ 176-200 & \$ 9.00 \\ 201-225 & \$ 9.25 \\ 226-250 & 59.50 \\ 251-275 & \$ 10.75 \\ 276-300 & \$ 11.00\end{array}$


PNL -3458

UC-95d

33679000552259

THE MARGINAL COST OF ELECTRICITY 1980-1995:

AN APPROXIMATION BASED ON THE COST OF NEW

COAL AND NUCLEAR GENERATING PLANTS

L. A. Nieves

W. P. Patton

B. J. Harrer

J. C. Emery

JuTy 1980

Prepared for the U.S. Department of Energy under Contract DE-AC06-76RLO 1830

Pacific Northwest Laboratory

Richland, Washington 99352 


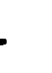

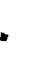




\section{EXECUTIVE SUMMARY}

In energy conservation-related investment decisions, the price of electricity used in the decision analys is should equal the cost of generating an additional unit. That is, the marginal cost or change in total production cost due to increasing production by one unit is the relevant electricity cost measure. This report presents estimates of the average cost of electricity (in 1979 dollars) generated by new coal and nuclear baseload units which are either currently under construction or planned by electric utility companies. This report also discusses the approach used to estimate the average costs of electricity from new baseload generating units and how the average cost of electricity from those units can be used to approximate the marginal cost of electricity in a region.

The objectives of this study are to develop a simple method to estimate the marginal cost of electricity at the state and regional level, and to use that method to project state and regional marginal electricity costs over the period 1980 through 1995.

The approach taken in this study is to use historical data to estimate the relationships between the costs of electricity from new coal and nuclear baseload generating units and the factors which influence those costs. The cost of electricity from a new baseload unit is estimated from five distinct cost components: 1) capital costs, 2) fuel costs, 3) operation and maintenance costs, 4) transmission and distribution costs, and 5) general and administrative costs.

Capital cost, which includes expenses incurred in the finance, purchase and construction of $\mathrm{plant}$ and equipment, represents a major component of the cost of electricity from a baseload generating unit. This cost comprises approximately $36 \%$ of the cost of electricity from coal baseload units and $63 \%$ of the cost of electricity from nuclear units (see Table 1). Therefore, the major emphasis in this study is on estimating structural capital cost equations which are capable of predicting capital costs of new coal and nuclear baseload generating units. 

TABLE 1. Cost Components as a Percentage of Tota 1
Generating Cost

Cost Component

Fue 1

Operation and maintenance

Capital
Percent of Total

Generating Cost

Coal Nuclear

54

20

10

17

36
63

Source: Congressional Research Service 1979 , p. 22.

Note: Cost proportions are averages for 62 nuclear units and 34 multiunit coal plants operating as of 1977.

The parameters of the coal and nuclear capital cost equations are estimated from historical data using ordinary least squares regression techniques. The nuclear capital cost equation specifies total capital cost of a baseload nuclear generating unit as a function of size of the unit, location, year commercial operation begins, whether or not the unit is subsidized on a partial turnkey basis, and whether or not the unit has a cooling tower. Data used to estimate the nuclear capital cost equation consists of observations on 39 nuclear plants which began commercial operation over the period from 1968 through 1977.

The coal capital cost equation specifies total capital cost of a coal baseload generating unit as a function of size of the unit, location, year commercial operation begins, and whether or not the unit has a flue-gas desulfurization system. Data used to estimate the coal capital cost equation consists of observations on 110 coal plants which began commercial operation over the period from 1968 through 1978.

Coal cost estimates are based on regional fuel characteristics and delivered costs of fuel used to generate electricity. Fuel costs for coal-fired 
generating units are derived from Energy Information Administration (EIA) delivered-coal price projections for 1985, 1990 and 1995 (DOE/EIA 1979a). Since coal prices vary significantly between Department of Energy (DOE) Regions, fue 1 costs are calculated separately for each of the 10 DOE Regions. The baseline fuel cost used in this study for coal generating units is derived from the EIA mid-range coal price scenario. The EIA high and low coal price scenarios are used in parametric analyses to illustrate the impact of coal prices on the busbar cost of electricity.

Baseline fuel costs for nuclear generating units are projected to 1995 using the uranium price escalation rate reported by Electric Power Research Institute (EPRI) (EPRI 1979). The high and low price scenarios used in parametric runs are, respectively, equal to plus and minus $12.5 \%$ times the baseline fuel cost scenario. A fourth fuel cost scenario is developed to show the effect of nuclear fue 1 reprocessing. Unlike coal fuel costs, nuclear fuel costs do not vary substantially over regions and a national average cost estimate is used.

Operation and maintenance (0\&M) costs are those production related costs, other than fue 1 costs, expended to keep a generating plant running and in good repair. O\&M costs for both coal and nuclear generating plants are projected using O\&M cost in a base year and the average real annual escalation rate over the relevant period of time. For coal plants, 1977 O\&M costs are compounded at the average real annual escalation rate for the period 1971 to 1977 . For nuclear plants, 1978 0\&M cost is compounded at the average real annual escalation rate for the period 1969 to 1978 .

Additional $0 \& M$ costs are incurred by a coal-fired generating plant which has a flue-gas desulfurization (FGD) system. The 0\&M cost associated with a $F G D$ system is estimated using ordinary least squares regression on historical FGD O\&M cost. The regression equation specifies FGD O\&M cost as a function of sulfur content of the coal used at a plant, average sulfur removal efficiency of the FGD system, plant size, and whether the FGD system was original or retrofitted.

Transmission and distribution (T\&D) cost is cost incurred in transmitting and distributing electricity from the generating plant to the final 
consumer. T\&D cost is assumed to be the same for both coal and nuclear generating plants. This cost is projected by compounding T\&D cost in 1978 by the average real annual escalation rate estimated for the period from 1969 to 1978.

General and administrative (G\&A) costs are mainly overhead expenses. G\&A costs are assumed to be the same for both coal and nuclear generating plants since they pertain to utility operations. These costs are projected by compounding G\&A costs in 1978 by the average real annual escalation rate estimated for 1969 through 1978.

In order to calculate state-level marginal cost estimates for 1980 to 1995 several assumptions are required. The major assumptions made are listed below:

- The annual levelized carrying charge is $16.5 \%$ of capital costs.

- The average capacity factor for both coal and nuclear plants is $65 \%$.

- Mid-range coal and nuclear fuel cost scenarios are used.

- The planned capacity additions reported in the Inventory of Power Plants in the United States - April 1979 (DOE/EIA 1979b), when corrected for announced cancellations and schedule changes, accurately forecast future plant construction patterns.

The resulting state-level estimates based on the baseline assumptions are presented in Appendices $A, B$, and $C$. Appendix $A$ shows the capital costs per kilowatt for coal and nuclear units, Appendix $B$ shows busbar costs of electricity from those units, and Appendix $C$ displays retail costs of electricity by state.

Three things should be noted regarding the state-level estimates. First, the marginal cost of electricity in all states tends to increase over time. Second, both coal and nuclear unit cost estimates are quite sensitive to size of the unit. In some states, the effects of size on the cost of electricity is great enough that large units offset the general trend towards higher prices on a year-to-year basis. Third, the cost of electricity from nuclear units is not predicted to be substantially different from the cost of electricity from coal units in the near future. However, over time, the cost of 
electricity from nuclear units increases at a faster rate than that from coal plants so that electricity from nuclear units is more expensive than that from coal plants after 1990.

The cost estimates for DOE Regions using the baseline assumptions are presented in Table 2. The retail cost of electricity in 1980 ranges from $\$ 11.96 / \mathrm{MBtu}$ in Region 8 to $\$ 15.72 / \mathrm{MBtu}$ in Regions 1 and 2 . In 1985 , this cost ranges from $\$ 14.02 / \mathrm{MBtu}$ in Region 8 to $\$ 17.80 / \mathrm{MB}$ tu in Region 5 . For 1990 , the cost varies from $\$ 17.14 / \mathrm{MBtu}$ in Region 8 to $\$ 19.54 / \mathrm{MBtu}$ in Region 4. By 1995, the retail cost of electricity ranges from $\$ 19.50 /$ MBtu in Region 8 to $\$ 21.48 /$ MBtu in Regions 1 and 2.

The cost of electricity in Region 8 (Colorado, Utah, Wyoming, Montana, North Dakota, and South Dakota) is consistently lower than that in other regions, 1 argely because almost all capacity planned consists of 1 arge coalfired generating units. These units use inexpensive, low-sulfur western coal and, thus, have a comparative advantage in coal fuel costs relative to other regions in the nation.

Regions 1 and 2 tend to have high relative costs of electricity. This is due, in part, to the fact that capital cost for nuclear units is higher in the northeastern United States than elsewhere and most of the capacity $p l$ anned for that region is nuclear.

TABLE 2. Estimates of Marginal Costs of Electricity at the Retail Level by DOE Region, 1980-1995(a)

\begin{tabular}{|c|c|c|c|c|c|c|c|c|c|}
\hline \multirow[b]{2}{*}{ Year } & \multicolumn{9}{|c|}{ DOE Region } \\
\hline & $1 \& 2$ & 3 & 4 & 5 & 6 & 7 & 8 & 9 & 10 \\
\hline 980 & 15.72 & 14.12 & 13.92 & 13.55 & 12.44 & 13.73 & 11.96 & 13.61 & 13.60 \\
\hline 985 & 16.72 & 16.51 & 15.70 & 17.80 & 15.42 & 15.59 & 14.02 & 16.45 & 15.69 \\
\hline $1990^{(b}$ & 17.71 & 18.73 & 19.54 & 18.77 & 17.17 & 18.05 & 17.14 & 17.09 & 18.34 \\
\hline $1995^{(c)}$ & 21.48 & 21.11 & 20.68 & 20.64 & 20.33 & 20.41 & 19.50 & 21.18 & 20.59 \\
\hline
\end{tabular}

(a) $1979 \$$ per $10^{6}$ Btu (MBtu).

(b) Estimates for Regions 3, 7, 8, and 10 are an average of costs for generic $600 \mathrm{MN}$ coal and $1200 \mathrm{MN}$ nuclear plants.

(c) Estimates for all regions are an average of generic coal and nuclear plant costs. 
The relatively high cost of electricity for Region 5 in 1985 is an example of the effect of plant size on electricity cost. The high cost is partially due to a small (504 MW) nuclear unit planned for Michigan in that year.

In addition to the baseline cases, alternative cases are analyzed to determine the effects of capacity factor, levelized carrying charge rate and fue 1 cost assumptions on the cost estimates for electricity from coal and nuc lear plants. As part of this analysis the cost of electricity from a $600 \mathrm{MW}$ coal plant is compared to the cost from a 1200 MW nuclear plant.

In general, the cost of electricity from a nuclear plant is higher than that from a coal plant at low capacity factor levels because of the high capita: investment required. At high capacity factors, electricity from nuclear plants is less expensive than that for coal. The cost cross-over points for four representative states in 1985 are $60 \%$ in Alabama, 59\% in Illino is, $63 \%$ in Arizona, and $56 \%$ in Massachusetts.

At relatively low levelized carrying charge rates, nuclear electric costs are lower than coal electric costs. At high levelized carrying charges the reverse is true. The cost cross-over points for four states in 1985 are $18 \%$ in Alabama, 19\% in Illinois, $17 \%$ in Arizona, and 19.5\% in Massachusetts.

The effects of the high, medium, and low coal fuel cost scenarios are examined. While busbar cost is sensitive to variation in coal prices, the high and low price scenarios result in less than a $10 \%$ change from the estimate based on the mid-range scenario. Busbar cost for nuclear plants was relatively insensitive to nuclear fuel cost variation. 


\section{ACKNOWLEDGMENTS}

This report built on the efforts of Richard Mazzucchi, who had taken a perceptive first cut at estimating costs of new generating capacity. Technical information and criticism were provided at various stages of the research by Vijay Mathur, Bryan Mohler, Alvaro Nieves, Thomas Secrest, Jeffrey Fang, Jack Tawil, Thomas Williams, Jack Eisenhauer and James Haskins.

In addition to the input from these Pacific Northwest Laboratory staff members, there was substantial critical review and information input from John Grossman, Mark Sawyer and their colleagues at Energy and Environmental Associates. Their efforts to assist us in producing a rigorous and solidly based analysis in spite of time limitations were extremely constructive and are very much appreciated.

Leslie A. Nieves

Project Manager 
$-$ 


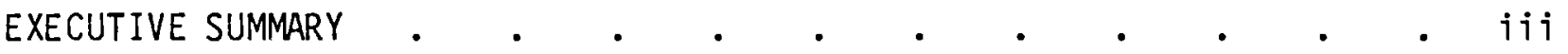

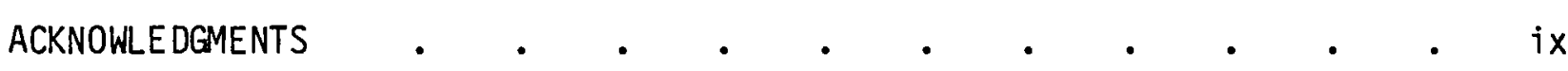

INTRODUCTION

MARGINAL COSTS OF ELECTRICITY •

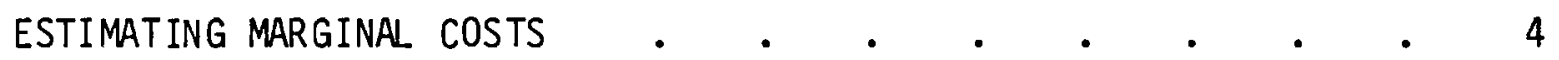

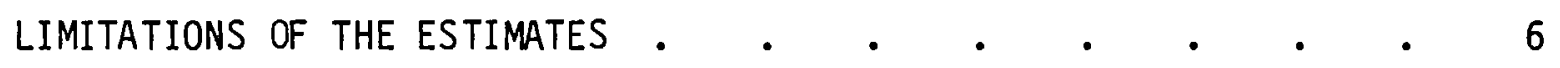

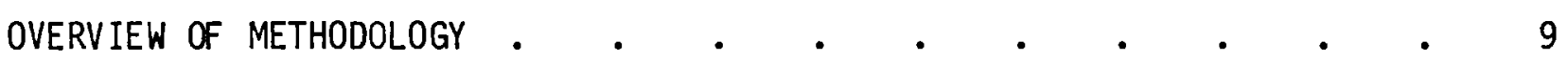

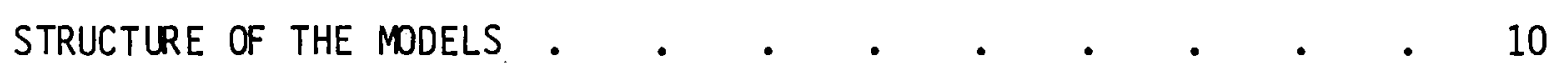

Capital Cost . $\quad . \quad$. $\quad . \quad$. . . . 10

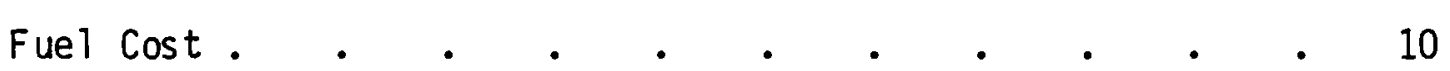

Operating and Maintenance Cost $\quad . \quad$. $\quad . \quad$. $\quad . \quad$. 11

Transmission and Distribution Cost . $~ . \quad$. $\quad . \quad$. 11

General and Administrative Cost $\quad$. $\quad$. $\quad$. 12

GENERAL ASSUMPTIONS

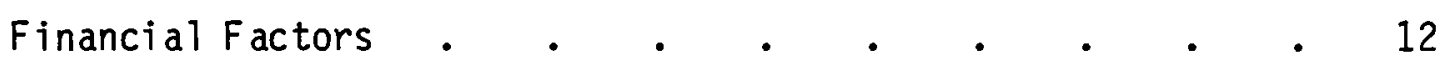

Treatment of Inflation . . . . . . . . . . 14

DEVELOPMENT OF REGIONAL MARGINAL COST ESTIMATES • • • • • • 15

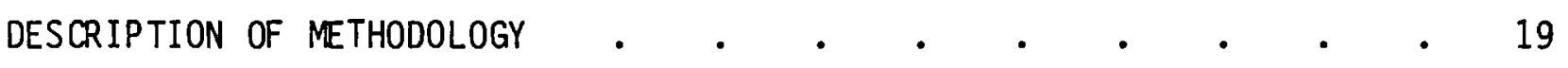

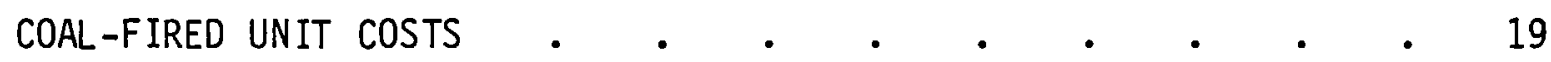

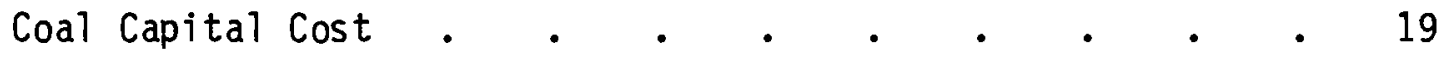

Capital Cost Per kWh $\quad$. . . . . . . . . . . 24

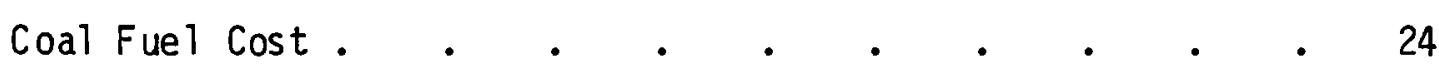

Coal Plant Operating and Maintenance Cost . . . $\quad$ • 26 
FGD Operating and Maintenance Cost . . . . . . 28

Coal-Fired Unit Busbar Cost . . . . . . . 30

NUCLEAR UNIT COSTS •

Nuclear Capital Cost . . . . . . . . . . . 31

Decommissioning Cost . . . . . . . . . . 34

Capital Cost Per kWh . . . . . . . . 35

Nuclear fuel Cost . . . . . . . . . . 35

Nuclear Unit Operation and Maintenance Cost . . . . 37

Nuclear Unit Busbar Cost . . . . . . . . . 38

TRANSMISSION AND DISTRIBUTION COST •

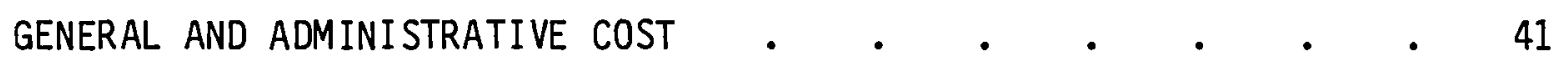

STATE AND REgIONAL RETAIL COST ESTIMATION • • • • • • 41

ANALYSIS AND INTERPRETATION

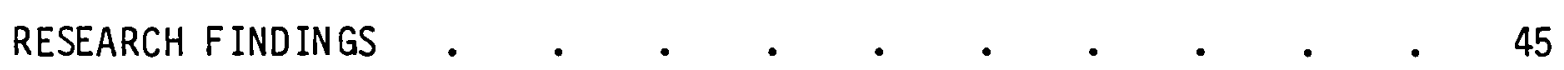

Regional Marginal Cost Estimates . . . . . . . 45

Capital Cost Estimates . . . . . . . . . . 46

Busbar Cost Estimates . . . . . . . . . 47

Retail Cost Estimates . . . . . . . . 50

SENSITIVITY ANALYSIS $\quad . \quad+\quad . \quad \cdot \quad \cdot \quad \cdot \quad \cdot 50$

Carrying Charge Rates . . . . . . . . 50

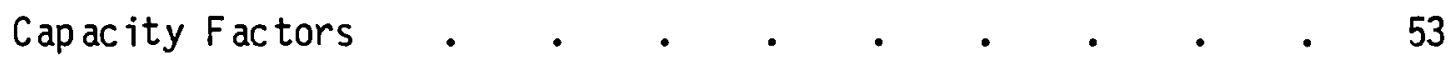

Fuel Prices . $\quad . \quad$. $\quad . \quad$. $\quad$. 53

$\mathrm{NO}_{\mathrm{x}}$ Scrubbers $\quad . \quad \cdot \quad \cdot \quad \cdot \quad \cdot \quad \cdot \quad \cdot \quad \cdot \quad \cdot 61$

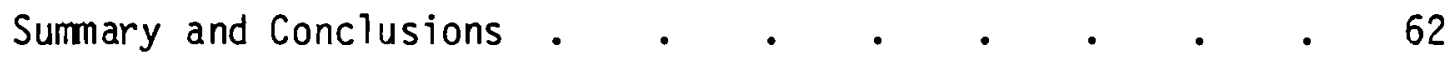

BIBLIOGRAPHY $\cdot$. 
APPENDIX A - ESTIMATES OF NEW GENERATING CAPACITY COST PER KW FOR COAL AND NUCLEAR

UNITS BY STATE

APPENDIX B - ESTIMATES OF BUSBAR COST PER MBTU FOR ELECTRICITY FROM NEW COAL AND NUCLEAR CAPACITY BY STATE

APPENDIX C - STATE AND REGIONAL RETAIL MARGINAL COST ESTIMATES $• . \quad \cdot \quad \cdot \quad \cdot \quad \cdot \quad \cdot \quad \cdot \quad \cdot \quad \cdot \quad C-1$ 



\section{INTRODUCTION}

This report presents estimates of the costs of new coal and nuclear baseload generating capacity which is either currently under construction or planned by utilities to meet their load growth expectations during the period from 1980 to 1995. These capacity cost estimates are used in conjunction with announced plant capacities and commercial operation dates to develop statelevel estimates of busbar ${ }^{(a)}$ costs of electricity. From these projected busbar costs, aggregated estimates of electricity costs at the retail level are developed for DOE Regions. The remainder of the introduction explains the rationale for using the cost of electricity from baseload plants to approximate the marginal cost of electricity. The next major section of the report outlines the methodology and major assumptions used. This is followed by a detailed description of the empirical analysis, including the equations used for each of the cost components. The fourth section presents the resultant marginal cost estimates.

\section{MARGINAL COSTS OF ELECTRICITY}

The marginal cost of electricity is critical to energy conservation investment decisions. Economic theory asserts that resources are used most efficiently when all commodities are priced at their marginal cost of production. This means that a unit of a commodity should have a price equal to the change in the total cost of production which results from production of an additional unit. Marginal cost pricing occurs in competitive markets. Electric utilities however, tend to operate as regulated monopolies. For this reason, electricity pricing is almost universally based on the average costs of production.

Estimating the marginal cost of producing electricity is complicated by the difficulty in defining an "additional unit" of electricity. Utilities may increase the quantity of power generated in several ways. In the short-run, they can make more intensive use of existing capacity and delay the retirement

(a) The conductor between the generating plant and the transmission system. 
of older, less efficient plants. In the long-run, utilities may expand capacity by adding baseload, intermediate or peaking units. New baseload plants represent the lower limit of long-run marginal cost for a utility system. Since baseload capacity is added in large, discrete units, it is not realistic to calculate the change in system cost attributable to the last unit of electricity generated. However, the marginal cost of electricity can be approximated by calculating the change in total system cost divided by the change in capacity.

$$
\text { Thus, if } \begin{aligned}
\Delta T C_{i} & =T C_{i j}-T C_{i j} \\
\Delta Q_{i} & =Q_{i j}-Q_{i j} \\
M C_{i} & \approx \frac{\Delta T C_{i}}{\Delta Q_{i}}
\end{aligned}
$$

and

then

where

$$
\begin{aligned}
T C_{i j}= & \text { total cost of electricity from company } i \text { in year } j \\
\Delta T C_{i}= & \text { change in total cost of electricity from company } i \text {, when new } \\
& \text { baseload capacity is added } \\
Q_{i j}= & \text { total capacity of company } i \text { in year } j \\
\Delta Q_{i}= & \text { change in capacity of company } i \text {, when new baseload capac } i t y ~ i s \\
& \text { added } \\
M C_{i}= & \text { approximate marginal cost of electricity from company } i .
\end{aligned}
$$

The change in the total cost of electricity produced by an electric utility company and attributable to a new baseload unit is approximately equal to the total cost of electricity from the new unit. The change in system capacity of the company is equal to the capacity of the new unit. Thus, the marginal cost of electricity for that company is approximately equal to the average cost of electricity from the new baseload unit.

The electricity cost estimates presented in this report are derived from the average cost of electricity generated by new plants and, hence, are only approximations of long-run marginal cost. As Figure 1 shows, at any point in time the long-run marginal cost estimates may be either higher than, lower 


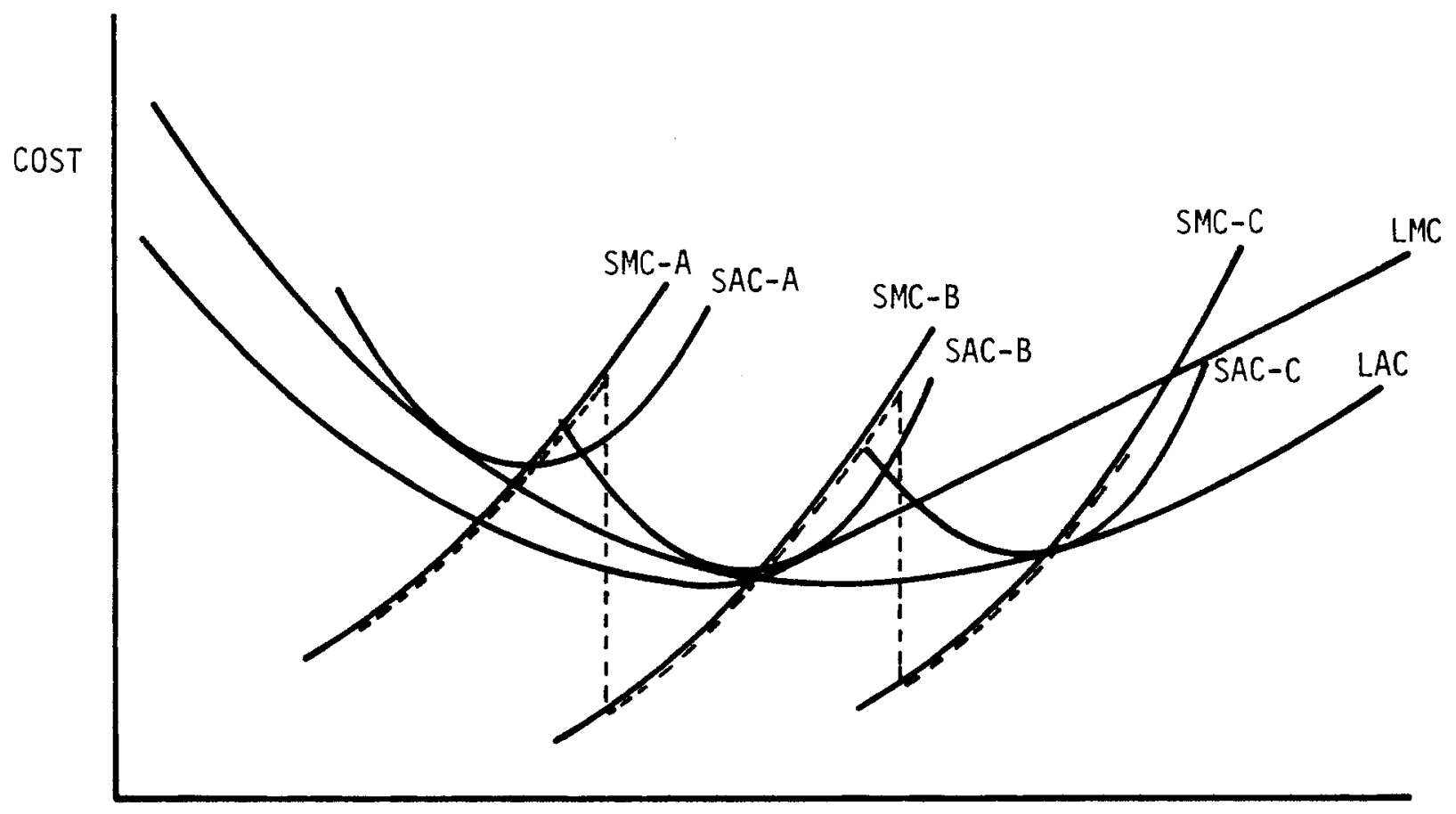

QUANTITY OF ELECTRICITY

FIGURE 1. Utility Short-Run and Long-Run Cost Curves

than, or equal to short-run average costs (which most closely represent prices consumers are charged) depending on system capacity and the quantity of electricity generated. In Figure 1 , the average costs of production for a utility in 1980 are represented by the short-run cost curve SAC-A. With the capacity it has on line, the utility moves along the short-run marginal cost curve SMC-A making increased use of high variable cost facilities as load growth occurs. The addition of new capacity shifts average costs to the curve SAC-B where the load growth and capacity expansion process is repeated. Because of the discrete nature or "lumpiness" of the capacity expansion process, the costs to utilities of meeting increases in demand may vary considerably from long-run marginal cost. In addition, the fact that long-run marginal costs of electricity are found to be increasing in all DOE Regions does not necessarily mean that either the shortrun or the long-run average costs of generating power are increasing. When marginal costs are increasing, average costs can still be 
decreasing but at a decreasing rate. Another possibility is that both marginal and average cost curves are shifting upward due to increasing input factor costs.

\section{ESTIMATING MARGINAL COSTS.}

Actual costs of electricity generated to meet new demand will depend on the type of capacity used, which is in turn a function of the time pattern of demand. To minimize the cost of production, utilities use the ir lowest variable cost units (generally coal and nuclear) to meet their constant or baseload demand. Intermediate load, which varies from season to season, is usually met by units with higher variable costs. Units with the highest variable costs and/or the shortest start-up times are used to meet seasonal or daily peak loads.

The pattern of demand incidence and the mix of generating capacity used to meet it varies considerably among utilities and even more among regions of the country. While nuclear units are almost universally baseload, coal units may be either baseload or intermediate. Gas turbines are used primarily for generating peak power, but there are a few utilities which use them for both peakloads and baseloads. Diesel generators, generally used to supply peak and intermediate power, have also been used in multiples for baseload generation. Hydro facilities are also commonly used for both baseload and peakload generation. The complexity of the production alternatives, compounded by the possibility of inter-utility purchases of power to meet both peak and baseload demands, makes precise estimation of marginal costs extremely difficult.

Since actual marginal cost cannot be estimated without information regarding new generating capacity, future load curves and load durations, this study estimates the incremental cost of new baseload capacity and resultant costs of power production. The approximations of marginal cost developed for DOE Regions represent the likely lower limits of the incremental costs of meeting electricity demand growth. The upper limits of marginal cost are subject to great uncertainty and may be determined by the costs of gas- and oil-fired turbines in some regions and by the cost of solar or other noncon-ventional technologies in other regions. 
While the degree to which estimates of baseload capacity costs understate actual marginal costs during the period 1980 to 1995 varies among the DOE Regions, (a) there is ample justification for use of baseload capacity cost estimates. Table 3 shows the percentage of net generation of electricity by load category. Across the DOE Regions, baseload capacity accounts for $60 \%$ or more of net generation. If marginal cost estimates were based on weighted average output of new capacity, baseload cost estimates alone would be a fair approximation due to the major contribution of baseload units to total production. In addition, it is clear that in present utility plans for capacity

TABLE 3. Percentage of Net Generation of Electricity by Load Category and Region, 1978

\begin{tabular}{ccccc} 
DOE Region & \multicolumn{3}{c}{ Load Category } \\
\cline { 1 - 2 } \cline { 5 - 5 } \cline { 5 - 5 } \cline { 5 - 5 } \cline { 5 - 5 } & Base & Intermediate & Peak \\
2 & 63 & 22 & 35 & 01 \\
3 & 72 & 27 & 02 \\
4 & 63 & 35 & 01 \\
5 & 62 & 36 & 02 \\
6 & 64 & 35 & 01 \\
7 & 60 & 37 & 03 \\
8 & 88 & 11 & 01 \\
9 & 59 & 39 & 02 \\
10 & 79 & 20 & 01
\end{tabular}

Source: Murphy 1980, pp. 99 to 107.

(a) Region 1: Connecticut, Maine, Massachusetts, New Hampshire, Rhode Island, Vermont; Region 2: New Jersey, New York; Region 3: Delaware, Maryland, Pennsylvania, Virginia, West Virginia; Region 4: Alabama, Florida, Georgia, Kentucky, Mississippi, North Carolina, South Carolina, Tennessee; Region 5: Illinois, Indiana, Michigan, Minnesota, Ohio, Wisconsin; Region 6: Arkansas, Louisiana, New Mexico, Oklahoma, Texas; Region 7: Iowa, Kansas, Missouri, Nebraska; Region 8: Colorado, Montana, North Dakota, South Dakota, Utah, Wyoming; Region 9: Arizona, Câlifornia, Hawaii, Nevada; Region 10: Alaska, Idaho, Oregon, Washington. 
additions through 1990, coal and nuclear units predominate. Table 4 summarizes the number and type of units and total capacity expected to begin commercial operation each year. Roughly $90 \%$ of the planned capacity additions between 1980 and 1990 are either coal or nuclear units. Hence, their costs represent a useful approximation of the long-run marginal cost of electricity production.

TABLE 4. Committed New Generating Units and Capacity(a) by Type, 1980 to 1990.

\begin{tabular}{|c|c|c|c|c|c|c|c|}
\hline \multirow[b]{2}{*}{ Year } & \multicolumn{2}{|c|}{ Nuc lear } & \multicolumn{2}{|c|}{ Coal (b) } & \multicolumn{2}{|c|}{ Other $(c)$} & \multirow{2}{*}{$\begin{array}{c}\text { Coal and Nuclear } \\
\% \text { of Total } \\
\text { New Capacity }\end{array}$} \\
\hline & No. & MW & No. & MW & No. & $\mathrm{MW}$ & \\
\hline $\begin{array}{l}1980 \\
1981 \\
1982 \\
1983 \\
1984 \\
1985 \\
1986 \\
1987 \\
1988 \\
1989 \\
1990\end{array}$ & $\begin{array}{r}8 \\
12 \\
13 \\
16 \\
11 \\
8 \\
8 \\
11 \\
4 \\
7 \\
5\end{array}$ & $\begin{array}{r}8,372 \\
12,345 \\
11,988 \\
16,724 \\
12,395 \\
9,080 \\
9,017 \\
12,529 \\
4,355 \\
8,064 \\
6,045\end{array}$ & $\begin{array}{r}36 \\
22 \\
16 \\
19 \\
19 \\
22 \\
20 \\
36 \\
19 \\
19 \\
8\end{array}$ & $\begin{array}{r}17,301 \\
9,699 \\
7,375 \\
10,915 \\
10,265 \\
12,146 \\
10,704 \\
19,479 \\
10,630 \\
11,143 \\
4,433\end{array}$ & $\begin{array}{r}20 \\
10 \\
10 \\
20 \\
12 \\
15 \\
12 \\
10 \\
12 \\
7 \\
2\end{array}$ & $\begin{array}{r}4,701 \\
2,430 \\
1,787 \\
4,305 \\
2,436 \\
4,403 \\
596 \\
1,255 \\
2,698 \\
2,881 \\
576\end{array}$ & $\begin{array}{l}85 \\
90 \\
92 \\
87 \\
90 \\
83 \\
97 \\
96 \\
85 \\
87 \\
95\end{array}$ \\
\hline
\end{tabular}

(a) Based on "net dependable capacity" of generating units rather than nameplate capacity.

(b) Including lignite.

(c) Including oil, gas, hydro, pumped storage, geothermal, wood chips, and multifuel generating capacity.

Source: Berman 1980, pp 70 to 73 .

\section{LIMITATIONS OF THE ESTIMATES}

The capacity cost estimates developed in this study represent construction cost trends which are common to generating units in each region of the country. The actual cost of unit construction will differ from these estimates due to factors such as siting and licensing difficulties and delays, construction stoppages and delays, component design, climate, construction contractor and the quality of utility management. Thus the results may be used to estimate the cost of constructing a typical coal or nuclear generating unit in each state but not what it would cost to construct a particular unit on a specific site. 
In addition to the cost variation related to specific plant designs and locations, there is uncertainty about the construction cost trends themselves. It is clear, both from the generating unit cost data and from current events, that we are in a period of rapid technological change. To some extent this is incorporated in the marginal cost estimates, but major changes in design requirements and associated costs for either coal or nuclear units should cause actual costs to differ from those estimated. The impact of such changes on costs cannot be estimated from time series data such as that used in this study, unless the rates and direction of these changes are similar to those which have occurred during the study period. 


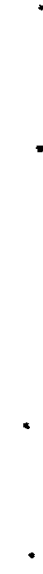


There are essentially two ways to forecast the cost of electricity from new baseload generating units. The first way is to calculate the cost of production based on actual engineering designs. Interest, labor and materials expenses are estimated on a site-specific basis from detailed engineering specifications and projections of the rate of inflation, regulatory delays, and other contingencies. These costs are then summed over the expected construction period of the plant to estimate the capital cost of the new generating plant. The cost of fuel, operation and maintenance, and transmission and distribution are also estimated from engineering specifications and assumptions regarding future changes in these costs.

The second way to project the cost of electricity from new baseload generating units is to examine historical cost data for capital, fuel, operation and maintenance, administration, and transmission and distribution. From this data statistical estimates are derived for the factors that have influenced electricity generating costs and for the cost escalation rates. Using the information generated in this manner, it is possible to forecast the cost of electricity by assuming that the structural relationships underlying the observed historical data will continue for a specified length of time.

Regardless of whether the cost of electricity from new baseload generating units is projected from engineering or historical data, the accuracy of the projections is limited by uncertainties associated with future events. When detailed site-specific information is not required for planning purposes, the cost of electricity can best be approximated by estimating cost relationships from historical data. This may result, however, in relatively large variations between the costs predicted for units in a specific state and actual unit costs when construction takes place, even though the predictions may accurately represent the average structure of costs for units in general.

The approach used here is to approximate the marginal cost of electricity in each state by using historical data to project the real cost (in 1979 dollars) of electricity from coal and nuclear baseload units which are scheduled to come on line in each year between 1980 and 1990. The cost projections 
are based on public information regarding the construction plans of utilities. We assume that utilities $\mathrm{plan}$ to add baseload capacity only when it is less expensive to add such capacity than it is to add additional peaking or intermediate capacity, purchase electricity on contract, or delay retirement of older, less efficient units. Due to the present regulatory uncertainties affecting nuclear plant licensing, it appears likely that most, if not a11, baseload units coming on line between 1990 and 1995 will be coal-fired. While there are still a few nuclear plants planned for completion during that period, most originally scheduled units have been cancelled.

\section{STRUCTURE OF THE MODELS}

The retail cost of electricity generated by new coal or nuclear baseload units is determined by five basic cost components: 1) capital and related $\cos t, 2)$ fue 1 cost, 3) operation and maintenance cost, 4) transmission and distribution cost, and 5) general administrative cost. The following is a description of the cost components examined in this study. The definitions are determined not by economic theory, but by the actual aggregation of cost elements in the data bases used.

Capital Cost

Capital cost includes all expenses incurred in the finance, purchase and construction of plant and equipment or incurred due to ownership of the unit. Thus, the capital cost component is determined by the data rather than by the economic definition of capital. For new coal and nuclear units, capital cost is a major component of the cost of generating electricity.

\section{Fuel Cost}

Fuel cost is the expense for fuel purchased to generate electricity. This cost component includes only production and transportation costs for an estimate of the delivered fuel cost. Fuel cost varies directly with the amount of electricity generated from each unit. 


\section{Operating and Maintenance Cost}

Operating and maintenance cost is that production related cost, other than fuel cost, which is expended to keep a generating unit running and in good repair. Operating and maintenance cost includes wages, supplies and, for nuclear units, liability insurance.

Transmission and Distribution Cost

Transmission and distribution cost is the operation and maintenance expense incurred in transmitting and distributing electricity from the generating unit to the final consumer, plus a fixed capital charge for the capital cost of the transmission and distribution facilities. This cost includes such things as the cost of transmission lines, substation transformers, and meters. Transmission and distribution cost varies with the distance of consumers from the generating unit, the number of consumers and their power and voltage requirements. An average value for transmission and distribution cost is used in this study because regional data was unavailable.

General and Administrative Cost

General and administrative cost is composed of utility system overhead items including customer account expenses such as meter reading; customer service expenses; sales expenses; and administrative expenses such as salaries, property insurance, employee pensions, and costs of administrative buildings. This cost varies with the level of electricity generation in the sense that generation is a measure of the size of the utility. An average utility charge to recover this cost is used in this study.

In the analysis that follows, the cost of electricity generated by new baseload coal and nuclear power units is discussed in terms of capital cost, busbar cost and retail cost. Capital cost is reported in 1979 dollars per rated $\mathrm{kW}$ of installed capacity. The busbar cost reported represents the cost of power at the generating plant boundary and is the sum of levelized carrying charges for capital cost, fuel cost, and operating and maintenance cost. Busbar and retail costs are reported in $1979 \$ / M B$ tu. (a) Retail cost estimates

(a) MBtu is used to represent $10^{6} \mathrm{Btu}$. 
presented are the cost of electricity delivered to the final consumers and are the sum of busbar cost, transmission and distribution cost, and general and administrative cost.

The structures of the retail electricity cost models for coal and nuclear units are shown in Figure 2. As indicated, the coal cost model requires development of both capital cost and operating and maintenance cost estimates which are sums of both unit and flue-gas desulfurization system costs. Delivered coal cost is added to these cost components to estimate busbar costs. Retail cost estimates are then developed from the busbar costs by adding transmission and distribution and general and administrative costs.

\section{GENERAL ASSUMPTIONS}

The estimation of electricity marginal costs requires a number of assumptions relating to factors which affect the expenses that utilities face. These include such items as inflation, interest rates, taxes, and the expected operating life of new generating facilities. Where assumptions are made that are specific to either coal or nuclear plants or to individual cost components, they are discussed in context. The general assumptions upon which this study is based are discussed below.

\section{Financial Factors}

Generating facilities are built either by investor-owned or public utilities. In 1977 over 75\% of all facilities were owned and operated by investor-owned utilities, but that may be changing since $37.5 \%$ of capacity added in that year was added by public utilities (EEI 1977). The revenue requirements of public utilities are approximately $30 \%$ lower than their investor-owned counterparts because their power revenues are non-taxable and they have access to federally subsidized financing. Neither taxes nor subsidies are, strictly speaking, costs. They are transfer payments between rate payers and taxpayers. This study is based on payment of market interest rates and taxes. The cost estimates represent the costs of generating power for investor-owned utilities.

For the purpose of cost estimation, new generating units are assumed to have a 30-year operating life and capital costs are allocated to each year of 


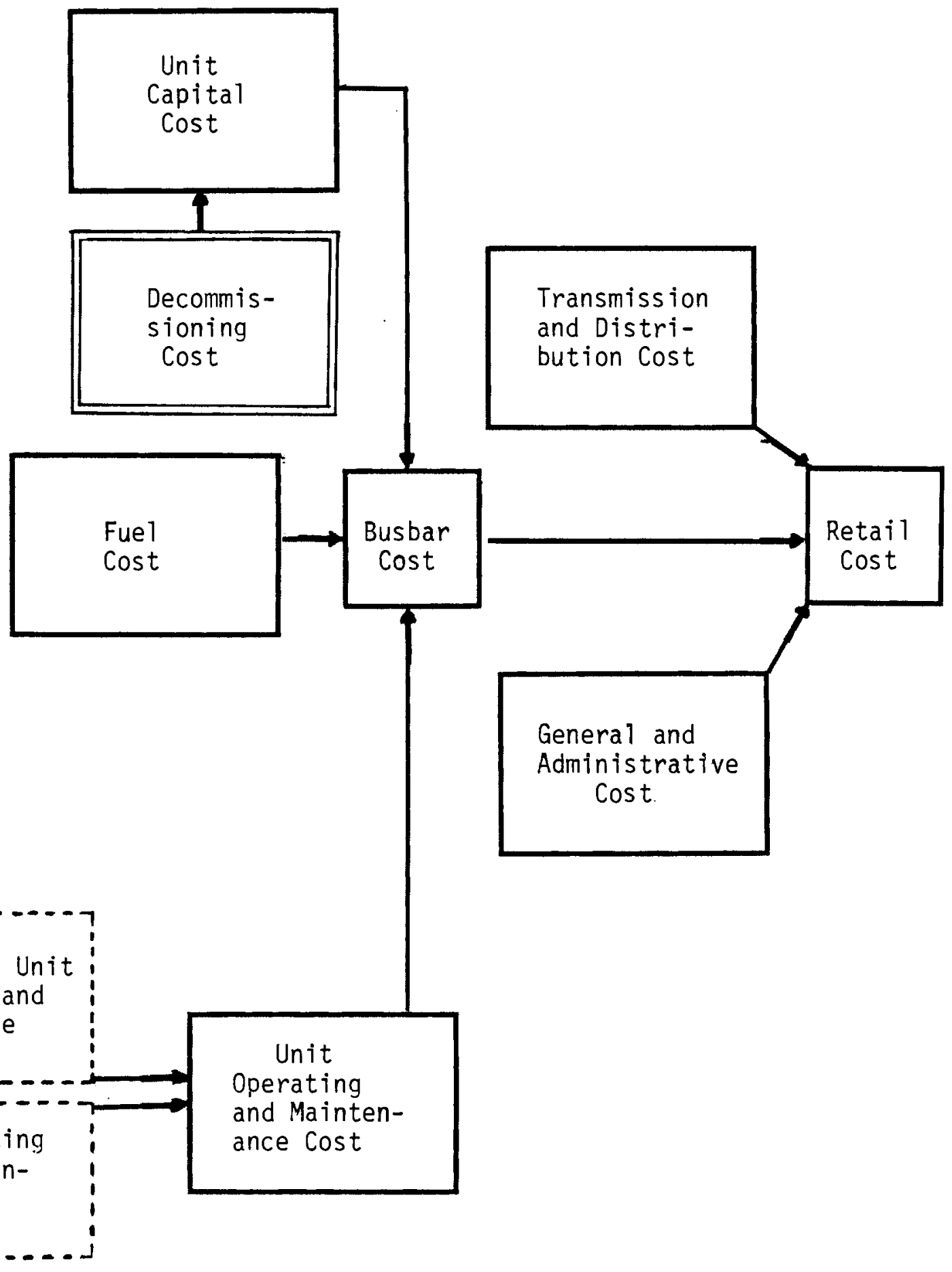

\section{FIGURE 2. Coal and Nuclear Cost Mode1}

Note: Cost elements which only occur in the coal generating cost model are shown with a dotted line. Those which only pertain to the nuclear model are shown with a double line 
unit operation. Thus, the expense of plant and equipment is amortized over a thirty year period to obtain a levelized carrying charge. The levelized carrying charge for a baseload unit represents the uniform stream of payments which will, over 30 years, exactly cover the cost of capital investment, depreciation, property insurance, property taxes, a normal return on investment and income taxes. Typically, for investor-owned utilities, this figure is higher than for publicly-owned utilities that have access to low interest federal loans and whose power revenues are nontaxable. In this study a fixed charge rate of $16.5 \%(a)$ of capital cost is assumed for all units regardless of ownership.

Once the total capital-related cost for a unit has been calculated, the capital cost per kilowatt-hour ( $k$ Wh) of electricity can be estimated. In this step of the analysis the total capital cost is divided by the product of the capacity factor times 8760 (hours in a year) times the unit capacity in kilowatts $(\mathrm{kW})$. The capacity factor is a measure of performance of a generating unit expressed as a ratio of actual output to potential output. This study assumes a constant capacity factor of $65 \%$ over the operating lives of both coal and nuclear units. While actual capacity factors may vary from $40 \%$ to over $70 \%$ for an individual unit, sensitivity analysis has shown that use of a $65 \%$ capacity factor over the entire generating unit life leads to roughly the same conclusions as does use of a more realistic variation in capacity factors over the unit's operating period (Roberts et al. 1978, Appendix 0). Nationally, capacity factors for baseload units have varied between $67.8 \%$ and $63.8 \%$ during the period from 1970 to 1978 (Murphy 1980).

Treatment of Inflation

Since about 1970, the treatment of inflation has become an increasingly important element in cost estimation methodology. If the costs which occur in different time periods are not all converted to the same year's dollars, changes in the real cost of producing electricity relative to other goods may

(a) In studies published since 1978, assumed carrying charge rates have varied from $16 \%$ to $20 \%$. Most studies reviewed used $16 \%$ to $17 \%$ (Bergstrom and Brandfon 1979; Perl 1978; Reichle 1979; Roberts et al. 1978). 
be obscured by changes in the value of the dollar. This is particularly important with power plants since construction may require 5 years or more.

All capital-related costs for generating units are converted to 1979 dollars using the Handy-Whitman Index for steam-electric generating plants (Whitman et a1. 1979). Use of this index permits measurement of changes in the real cost of steam-electric plant construction materials and labor. There are costs (such as interest) included in the capital cost data used in this study for which use of the Handy-Whitman Index is inappropriate, but disaggregation of the data was deemed infeasible.

The Producer Price Index, formerly called the Wholesale Price Index, was used to convert all other costs to 1979 dollars. The rationale for use of this index is succinctly stated by Uri (1975, p. 51), "The wholesale price index was chosen as the factor price deflator because the inputs into the electrical energy generation process are so varied that even if price indices for each input existed, the computational burden of factor-specific deflation would be prohibitive."

\section{DEVELOPMENT OF REGIONAL MARGINAL COST ESTIMATES}

The development of regional marginal cost estimates proceeds from the estimation of capital costs for planned coal and nuclear units, to state-level estimates of electricity busbar costs for each type of unit in each year, to marginal retail cost estimates for each state and, finally, to marginal retail cost estimates for each DOE Region. The four steps in the cost estimation are shown in Figure 3. In the first step, the capital investment related costs are estimated for each plant scheduled to begin commercial operation in a given year. The capital, decommissioning, fuel, and operating and maintenance costs are then summed to produce state busbar cost estimates. In some states, in some years, more than one coal or nuclear unit is scheduled to come on line. Where this is the case, the state-level estimates of busbar costs for coal and for nuclear plants are based on a capacity weighted average of unit costs. Then, in the third step, either the average of busbar costs for coal or nuclear when both come on line, or the busbar cost of the only type coming on 


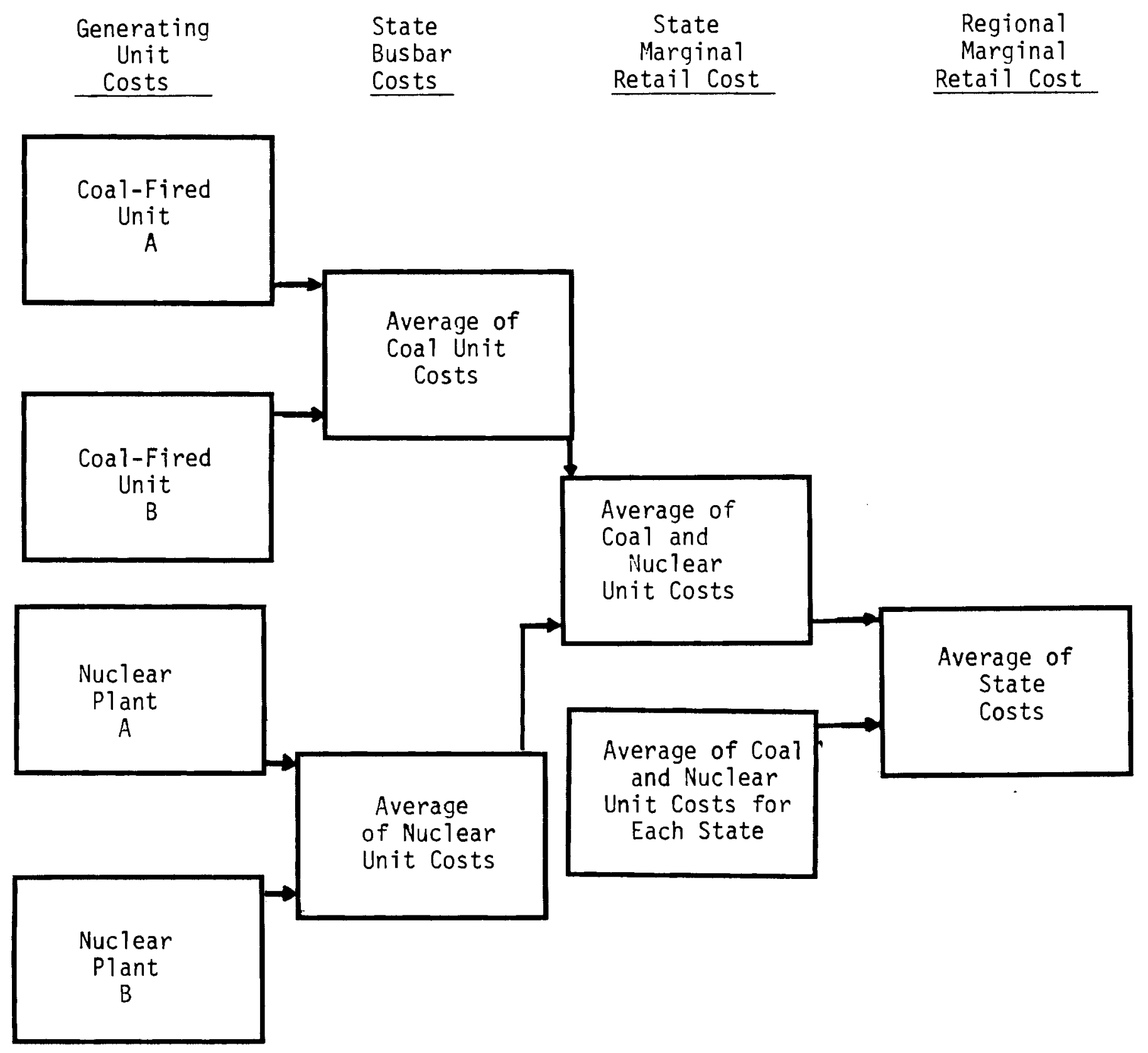

FIGURE 3. Derivation of Regional Marginal Cost Estimates 
line are added to transmission and distribution and general administrative cost to develop state marginal retail cost estimates. The marginal retail cost estimates for all of the states in a Region are averaged to develop the cost estimates for each DOE Region, so that busbar and retail cost estimates represent the average cost of power from each incremental expansion of generating capacity. This approach to estimation of regional marginal cost produces estimates which are approximations of the long-run marginal cost of electricity. 
. 
DESCRIPTION OF METHODOLOGY

In this section the procedures used to estimate the major components of the marginal cost of electricity production are discussed. The coal facility capital and operating cost equations are described first, followed by the equations for nuclear units. The methods used to estimate transmission and distribution cost, which applies to both types of units, are presented, and in the subsequent section the general and administrative cost estimates are discussed. Finally, the procedure used to develop marginal cost estimates for each DOE Region is described.

\section{COAL-FIRED UNIT COSTS}

In the following sub-sections the major cost components affecting the busbar cost of electricity from coal-fired units are discussed. First, the procedure used to estimate the capital cost of the generating unit and flue gas desulfurization (FGD) system is explained. This is followed by a discussion of cost estimation procedures for delivered coal in each region of the country, and a description of the estimation procedure for operating and maintenance cost of the generating units. Finally, the operating and maintenance cost of FGD systems is presented.

\section{Coal Capital Cost}

Capital cost for coal-fired units constitutes a significant portion (about 36\%) of the cost of the electricity generated (Congressional Research Service $1979, p .22$ ). Hence, examination of the relationship between the capital cost of coal-fired units and important factors which influence cost is a primary emphasis of this study.

\section{$\underline{\text { Data }}$}

The capital cost equations for coal-fired units are estimated by ordinary least-squares regression using a data set from a previous PNL study (Haskins, et a1. 1980). This data set includes observations on 110 coal generating units which began comercial operation between 1969 and 1977 . The data was assembled primarily from the Steam-Electric Plant Construction Cost and Annual 
Production Expenses reports for 1975-1977 (Haskins, et a1. 1980, p. 4) Supplemental information and data corraboration was provided by Electric Wor ld, Power, and Power Engineering magazines' steam-electric power plant design surveys. Additional data for the average capital cost of FGD systems was obtained from a publication entitled EPA Utility FGD Survey:

August-September 1978 (EPA 1978) and a report entitled The Status of Flue Gas Desulfurization Applications in the United States: A Technological Assessment Report in Full (FPC 1977).

\section{Assumptions}

In addition to the general assumptions identified in the Overview of Methodology section, some assumptions pertaining specifically to our coal capital cost analysis were necessary. These assumptions are:

- The regional construction cost differential for coal-fired units built in the South continues unchanged (Haskins, et al. 1980).

- As of 1980, all new coal-fired units will have FGD systems.

- An equal proportion of total cost occurs in each year of the licensing and construction period for each unit. That is, the relationship between cumulative capital cost incurred and time is assumed to be linear. This assumption allows allocation of construction costs to each year of the construction period so that the effects of general inflation can be removed.

- The Handy-Whitman cost index for steam generating plants is an appropriate measure of the real capital cost changes that occurred between 1969 and 1979 .

This last assumption is important because the cost data from the previous PNL study include observations from 1969 to 1977 and is reported in 1976 do 11 ars using the Handy-Whitman cost index for steam generating plants. In the present study, the capital cost regressions are estimated in 1976 do 11 ars and the resulting estimates are then inflated to 1979 dollars by multiplying by a factor of 1.22 . The factor 1.22 is obtained by dividing the 1979 Handy-Whitman cost index by the cost index for 1976 . 


\section{Equations}

The capital cost of coal-fired baseload units is a function of a variety of plant characteristics. The previous PNL study (Haskins, et al. 1980) analyzing the economic impact of regulation on coal generating units, identified several factors as contributing significantly to the total capital costs of coal-fired units. These factors include 1) plant location (i.e., whether it is in the South or not), 2) unit capacity, 3) length of construction and licensing period, 4) joint ownership, 5) boiler-turbine generator efficiency, 6) unit efficiency (heat rate), 7) year commercial operation begins and 8) presence or absence of cooling towers.

For the purposes of the current study, several variables were deleted from the equations specified in the previous PNL study. The variable for length of construction and licensing period was dropped from the equation because it was felt that year of initial operation would pick up much of the cost influence of length of construction and licensing period since the two variables are highly correlated (Haskins et al. 1980). In addition, the construction and licensing period variable lacks predictive relevance in the present study, since such time estimates are not available for future plants. The variables for joint ownership and unit efficiency were also deleted from the equation because observations on these variables were not readily available for future plants. Analysis of the historical data revealed little variation in the boiler temperature of coal-fired units, so this variable was also dropped.

Finally, the cooling tower dumy variable was deleted from the coal cost equation because examination of the cost data revealed that identification of the units for which cooling towers were included in the costs as of the date of commercial operation was not consistent. Expansion of the data base to permit use of a dumy variable for cooling towers is highly desirable because such towers are a major component of total capital cost. Indeed, further definition of the data to allow differentiation between use of wet and dry cooling systems might substantially improve predictions of capital cost. As the model is presently specified, the increase in coal plant capital costs due to cooling towers is only reflected in the cost escalation rate over time. 
An additional difference stems from the fact that the previous study (Haskins et al. 1980) did not include information on FGD systems. These systems are necessary to comply with current air pollution emission standards for new coal-burning units. Estimates indicate that a FGD system unit will comprise about $17 \%$ of the total capital cost of a 1000 MW unit (PEDCO 1978). Corraborating evidence of the magnitude of FGD system costs is found in a study undertaken by Budwani (1980) which stated that compliance with overall pollution control requirements will increase unit capital costs by 25 to $30 \%$.

In this study the capital cost of FGD systems is estimated using two data sources. These are the EPA Utility FGD Survey: August-September 1978 and the U.S. Department of Commerce Status of Flue Gas Desulfurization Applications in the United States: A Technological Assessment Report in Ful1. These data sources yielded 118 independent observations on FGO systems that were planned, under construction, or in operation as of 1978. Those coal-fired units with new FGD systems included in the PNL (Haskins et al. 1980) data were identified from the two FGD data sources. For the ten units which were so identified, coding was added to the PNL data to indicate inclusion of an FGD system. This modification of the data set allows use of a FGD dummy variable in the coal capital cost equation.

When the remaining variables from the previous PNL study and the FGD dummy variable are regressed on total capital cost per unit, the following results are obtained: (numbers in parentheses represent $F$ statistics)

$$
\begin{aligned}
& \operatorname{CCOSTC}(\$)=-2904780.5+251078.76 \times \text { SIZE }+8114121.7 \times \text { YEAR } \\
& (.056) \quad(191.575) \quad(23.195) \\
& -39717924 . \times \text { SOUTH }+ \text { 19455169. } \times \text { FGD } \\
& (18.556) \quad(1.623)
\end{aligned}
$$

$$
R 2=0.725
$$

where:

$$
\operatorname{CCOSTC}(\$)=\text { total capital cost for coal-fired generating units }
$$




$$
\begin{aligned}
\text { SIZE = } & \text { unit capacity (MW) } \\
\text { YEAR = } & \text { initial year of commercial operation minus } 1968 \\
\text { SOUTH = } & 1,0 \text { dumy indicating whether or not the plant is located } \\
& \text { in the South. The South is defined as Texas, Oklahoma, } \\
& \text { New Mexico, Arkansas, Louisiana and all the states in DOE } \\
& \text { Region } 4 . \\
\text { FGD }= & \begin{array}{l}
\text { 1,0 dummy indicating whether or not a FGD system was } \\
\text { installed when the plant was built. }
\end{array}
\end{aligned}
$$

In Equation 1, the coefficient on the $F G D$ dummy variable is significant only at the .20 level using a one-tailed test. The FGD variable is retained in the equation because the improvement in the overall explanatory power of the equation (as measured by $R^{2}$ ) due to inclusion of the variable is significant. It is expected that the addition of cost data for plants completed since 1977 to the data base would raise the significance level of the FGD variable. The coefficient on the FGD dummy variable indicates the amount added to total unit cost by inclusion of a FGD system. It does not indicate the cost of a FGD system independent of other capital costs.

The information in the coal plant capital cost equation is converted from 1976 dollars into 1979 dollars by multiplying the coefficients in the equation by 1.22 , derived from the Handy-Whitman steam generating plant cost index. This yields the following conclusions (in 1979 dollars):

- Total capital cost for coal-fired units tends to increase about $\$ 9,900,000$ for each additional year after 1980 that a unit begins commercial operation.

- Coal generating units located in the South tend to cost approximately $\$ 48,460,000$ less than units located elsewhere.

- Each additional MW of capacity increases total unit capital cost by approximately $\$ 310,000$.

- A FGD system adds approximately $\$ 23,740,000$ to the total capital cost of a coal-fired unit. 
Capital Cost Per kWh

Once the total capital cost of a generating unit is calculated from Equation 1, the capital cost per kWh of electricity generated in a given state and a given year is determined by dividing the capital costs for a state in that year by the total associated energy production for that year. The annual capital cost is found by multiplying total statewide capital cost by the assumed carrying charge rate of $16.5 \%$ per year and converting the product to mills. The total annual energy production is determined by multiplying the number of hours in a year times the assumed capacity factor, 65\%, times the incremental statewide capacity in $\mathrm{kW}$ 's. The equation is as follows:

$$
\operatorname{CCOSTC}(\mathrm{mi11 \textrm {s }} / \mathrm{kWh})=\frac{\operatorname{ccosTC}(\$) \times 0.165 / \mathrm{yr} \times 1000 \mathrm{mi11 \textrm {s } / \$}}{8760 \mathrm{hr} / \mathrm{yr} \times 0.65 \mathrm{hr} / \mathrm{hr} \times \mathrm{kW} \text { capacity }}
$$

\section{Coal Fuel Cost}

For a coal plant operating in 1977, fuel cost represented approximately $85 \%$ of the variable production cost and $54 \%$ of the total generating cost (Congressional Research Service 1979, p. 22). This indicates the significance of the effect of coal price in determining the cost of electricity from coalfired generating $p l$ ants.

The delivered price of coal is a function of many variables. For example, the price of delivered coal must cover the costs of capital, labor, supplies, power, benefit payments, coal preparation, reclamation activities, taxes, and royalty payments for the coal mining operation plus the cost of transporting the coal. Due to cost differentials between underground and open pit mining, differences in coal characteristics, and varying distances from the coal mines to the generating plants, the delivered price of coal is subject to considerable regional variation. The 1977 delivered price of coal to the electric utility sector ranged from $\$ 0.48$ to $\$ 1.40 / \mathrm{MBtu}(1978 \$)$ in the 10 DOE demand regions (DOE/EIA 1979a, p. 233).

Several estimates of future delivered coal prices have been made. The two most recent forecasts were performed by the Electric Power Research Institute (EPRI 1979, pp. 6.2-6.7) and the Energy Information Administration 
(DOE/EIA 1979a, p. 233). The projections made by EPRI were for delivered coal prices through the year 2030 for 8 coal consuming regions. The EIA projections were made through the year 1995 for 10 regions.

The projected coal prices used in this study are developed from the EIA delivered coal price projections. Several factors led to use of EIA data instead of the EPRI data. This study derives estimates of the cost of electricity at the state level and since state level projections of delivered coal prices were unavailable, the EIA data for a 10 region level of aggregation are more appropriate than the data for EPRI's 8 region level. EIA estimated coal prices under several scenarios, of which two are used in this study as the basis for a sensitivity analysis. No alternative scenarios are available in the EPRI study. Also of significance is the fact that EPRI made no attempt to factor in short-term price fluctuations in their projections whereas EIA did. (a)

Using the EIA delivered-coal price projections (DOE/EIA 1979a, p. 233) for 1985, 1990, and 1995, and the actual 1977 price as data points, an equation is estimated to predict the annual trend in delivered-coal prices for each of the 10 DOE Regions. It was found that a logarithmic curve fit the EIA data best. The estimated equation is of the form:

$$
\text { Coal Price }{ }_{i r}=a_{r}+b_{r}\left[\ln \left(\text { year }_{i}-1976\right)\right]
$$

where

$$
\begin{aligned}
& i=\text { year in which the coal price is to be estimated } \\
& r=\text { region } 1, \ldots, 10 .
\end{aligned}
$$

The estimated values of the intercept (a) and slope (b) for each of the 10 regional equations are presented in Table 5. The EIA data used to generate these estimates was given in $1978 \$$ MBtu. The data are inflated to 1979 dollars using the Producer Price Index (PPI) and converted into mills/kWh with the

\footnotetext{
(a) For example, the EPRI projected coal price for 1980 was derived from the estimated 1985 and 1990 coal prices. It is interesting to note that the average EPRI projections for 1985 and 1990 were $31 \%$ and $26 \%$ lower, respectively, than the EIA average projections for the same years.
} 
use of a heat rate factor of $10,400 \mathrm{Btu} / \mathrm{kWh}$. (a) Therefore, the estimated values for $a$ and $b$ in Table 5 estimate the cost of coal per kWh generated in $1979 \mathrm{mills} / \mathrm{kWh}$.

TABLE 5. Coal Price Equation Yariables Estimated Using a Logarithmic Form(a) (1979 mills/kWh)

\begin{tabular}{llrl}
\multicolumn{1}{c}{ DOE Region } & & $\frac{a^{(b)}}{b}$ & \\
\hline 1. New England & 16.27 & 3.62 \\
2. New York/New Jersey & 15.56 & 3.27 \\
3. Mid Atlantic & 13.22 & 3.62 \\
4. South Atlantic & 13.57 & 3.86 \\
5. Midwest & 12.05 & 3.27 \\
6. Southwest & 6.91 & 5.50 \\
7. Central & 10.42 & 3.40 \\
8. North Central & 5.74 & 3.16 \\
9. West & 6.55 & 6.78 \\
10. Northwest & 9.36 & 4.92
\end{tabular}

(a) Developed from EIA data (1979a, p. 233).

(b) This term is an estimated 1977 coal cost per $k$ Wh generated and should not equal 1977 delivered coal prices.

Coal Plant Operating and Maintenance Cost

The other variable production cost besides fuel cost is operation and maintenance (O\&M) cost. During 1977, O\&M cost accounted for $15 \%$ of the variable production cost and $10 \%$ of the total generating cost for a coal-fired plant (Congressional Research Service 1979, p. 22).

(a) The heat rate of $10,400 \mathrm{Btu} / \mathrm{kWh}$ represents a national average value. The EIA (1978, pp. XVII-XIX) indicates that the number of Btus needed or used to generate a kilowatt-hour of electricity varies between plants and consequently, between regions. The regional heat rates presented by the EIA include those of $0 i 1$ and gas fired generating plants. Because of the difficulties of identifying heat rates for coal-fired plants alone on a regional basis, the national average heat rate is applied to all regions. 
Operating cost includes the cost of operating the steam and electric plant, and operation supervision and engineering. Maintenance cost includes supervision and engineering, and the cost of maintaining the plant structure, boiler plant, and the electric plant. (a) The principal cost component of O\&M is labor. Since 1948, the average monthly pay for power plant employees has more than tripled in nominal terms (DOE/EIA 1978, p. XIV). However, because of automation and technological advances, the number of 0\&M employees for the average plant has decreased and the total wage bill has not increased as rapidly. The other major cost components of O\&M are plant operation supplies including lubricants and chemicals, office and other incidental expenses, and maintenance parts and materials (DOE/EIA 1978, p. XIV).

Data from the Steam-Electric Plant Construction Cost and Annual Production Expenses 1977 (DOE/EIA 1978) were used to estimate future 0\&M cost for coal plants. The average 0\&M cost during the period from 1971 through 1977 was used to determine historical trends. Only those plants that burn coal exclusively were included in the 0\&M cost calculation. Those plants that burn coal and gas and/or oil were omitted because the plant 0\&M cost could not be allocated by fuel type. There was little or no overlap between the data base used to project plant $0 \& M$ cost and that used to project FGD system O\&M cost.

From 1971 through 1977, coal plant 0\&M cost in current dollars increased from 1.20 to $2.37 \mathrm{mills} / \mathrm{kWh}$. In real terms, this represents an average annual rate of increase of $3.32 \%$. Based on this information, the equation used to estimate future coal plant 0\&M cost is:

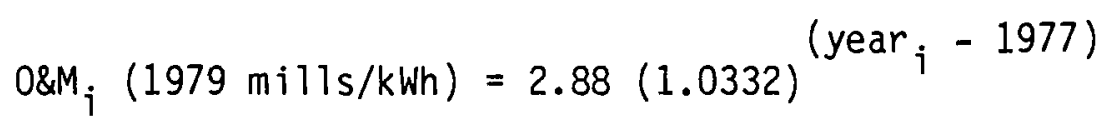

(a) O\&M cost is sometimes defined to include a fixed cost portion related to the interest on debt, dividend or other return charges, depreciation or amortization expenses, and allocated general and administrative expenses. For this study, general and administrative expenses are estimated separately and the other capital related fixed charges are included in the capital carrying charges. 
where

$i=$ year in which the $0 \& M$ cost is to be estimated

$2.88=1977$ O\&M cost in $1979 \mathrm{mills} / \mathrm{kWh}$

1.0332 = escalation factor with an annual real escalation rate of $3.32 \%$.

This specification of coal plant 0\&M cost neglects the issues of regional variation in 0\&M cost and increasing returns to plant scale in 0\&M cost.

Because of regional variation in the price of labor, which is the largest component of O\&M cost, there is certain to be some variation in 0\&M cost between regions. Empirical estimates of the historic regional variations in 0\&M cost were not made because the necessary data base was unavailable. There is also some doubt concerning the absolute magnitude of the variation and its overall impact.

Scherer (1977, p. 145) and Uri (1975, p. 53) both indicate that there is a relationship between $\mathrm{plant}$ size and 0\&M cost. However, the amount of labor necessary to operate and maintain a plant does not increase at the same rate as plant size. Scherer notes that the relationship between plant size and 0\&M cost is barely significant and assumes they are independent (Scherer 1977, p. 145).

FGD Operating and Maintenance Cost

In addition to their considerable capital cost, FGD systems have operation and maintenance cost which contributes significantly to the overall operating cost of a coal-fired generating unit.

Data from the Utility FGD Survey (EPA 1978) is used in a regression analysis to estimate the cost of operating and maintaining FGD systems. Various characteristics of the FGD systems and the units where they are being used are given in this data. The relationship between these characteristics and the FGD operation and maintenance cost in mills/kWh is examined.

Preliminary analysis of the EPA data revealed that the sulfur content of the coal, the startup date of the FGD system, whether the system was original or retrofitted, the chemical process used in the FGD system, the efficiency of $\mathrm{SO}_{2}$ removal by the system, and the size of the plant may be important factors in determining the operation and maintenance costs of the FGD systems. 
Because the data set included only 34 FGD systems and many of the chemical processes used in these systems were represented by only one or two observations, process type was not included as a variable in the FGD operating and maintenance cost equation.

The equation for the relationship between the characteristics listed above and FGD operating and maintenance cost is as follows ( $F$ test statistics are in parentheses):

$$
\begin{aligned}
& \text { FGDOM }(\mathrm{mills} / \mathrm{kWh})= \frac{-0.9883}{(0.2197)}+\underset{(5.58)}{0.5248} \times \text { SULF }+\frac{0.0515}{(3.38)} \times \mathrm{EFF} \\
&-\frac{1.3709}{(4.44)} \times \mathrm{NEW}+\frac{0.0030}{(3.68)} \times \text { SIZE } \\
& R^{2}=0.547
\end{aligned}
$$

where:

FGDOM $(\mathrm{mills} / \mathrm{kWh})=$ operating and maintenance cost in mills $/ \mathrm{kWh}$

$$
\begin{aligned}
\text { SULF = } & \begin{aligned}
\text { average sulfur content of the coal in percent by } \\
\text { weight }
\end{aligned} \\
\text { EFF = } & \text { average percent } \mathrm{SO}_{2} \text { removal } \\
\mathrm{NEW} \mathrm{=} & 1,0 \text { durmy variable indicating whether the } F \mathrm{GD} \text { system } \\
& \text { was installed in a new plant, or retrofitted in an } \\
& \text { old plant } \\
\text { SIZE = } & \text { rated capacity of the } \mathrm{plant} \text { in MW. }
\end{aligned}
$$

When converted to $1979 \$$, the data reveals the following:

- For every $1 \%$ increase in the sulfur content of the coal by weight, operating and maintenance cost for the FGD system increases by about $0.64 \mathrm{mills} / \mathrm{kWh}$.

- For every $1 \%$ increase in the efficiency of the $\mathrm{SO}_{2}$ removal process, operating and maintenance cost for the FGD system increases by about $0.06 \mathrm{mills} / \mathrm{kWh}$. 
- The operating and maintenance cost for an FGD system in a new plant is about $1.7 \mathrm{mills} / \mathrm{kWh}$ less than the cost in a plant where the system has been retrofitted.

- For every $1 \mathrm{MW}$ increase in plant capacity, the operation and maintenance cost of the FGD system increases by approximately $0.004 \mathrm{mills} / \mathrm{kWh}$.

The data for future coal-fired units included information on all of the above variables except the efficiency of the $\mathrm{SO}_{2}$ removal systems and the sulfur content of the coal used. In order to estimate the future operating and maintenance costs of FGD systems, it was necessary to add information on these variables to the data base. Information on sulfur content of the coal used in the generating plants was obtained from the publication, Cost and Quality of Fuels for Electric Utility Plants - 1978 (DOE/EIA 1979b). For the plants which were not included in this data source, the average sulfur content of the coal used by utilities located in that same state is substituted. Since coal and lignite are treated separately and sulfur content did not vary greatly within states, use of average sulfur content is unlikely to bias estimates.

All new units are assumed to have FGD systems which remove $90 \%$ of the $\mathrm{SO}_{2}$ content of the coal used. This assumption is based on the requirements of the EPA New Source Performance Standards issued in 1979 (National Journal 1980). When more than one coal unit comes on line in a year, a capacityweighted average of the estimated individual unit costs is used to determine FGD operation and maintenance cost for the state.

Coal-Fired Unit Busbar Cost

The cost of power produced by coal-fired units is calculated by suming the estimates of capital cost, fuel cost and 0\&M cost. The resulting estimate of busbar cost is converted from mills per $\mathrm{kWh}$ to $\$$ per MBtu in the following equation: 


$$
\begin{aligned}
\operatorname{BCOSTC}(\$ / M B t u) & =\operatorname{CCOSTC}(\mathrm{mi} 11 \mathrm{~s} / \mathrm{kWh})+\text { FUELC (mills } / \mathrm{kWh}) \\
& +0 \& M(\mathrm{mi} 11 \mathrm{~s} / \mathrm{kWh})+F \text { GDOM }(\mathrm{mi} 11 \mathrm{~s} / \mathrm{kWh}) \times \\
\frac{\mathrm{kWh}}{3412 \mathrm{Btu}} & \times \frac{\$}{1000 \mathrm{mi} 11 \mathrm{~s}} \times \frac{10^{6} \mathrm{Btu}}{\mathrm{MBtu}}
\end{aligned}
$$

where:

$$
\begin{aligned}
\text { BCOSTC } & =\text { busbar cost of power from coal-fired units } \\
\text { CCOSTC } & =\text { capital cost per } k W h \text { generated } \\
\text { FUELC } & =\text { coal cost per } \mathrm{kWh} \text { generated } \\
\text { O\&M } & =\text { operation and maintenance cost per kWh generated } \\
\text { FGDOM } & =\text { FGD system } 0 \& M \text { cost per kWh generated }
\end{aligned}
$$

NUCLEAR UNIT COSTS

The methodology used to estimate the cost of power generation for nuclear units is described in the following section. The data, assumptions, and equation for capital cost is presented first. A discussion of decomissioning cost, fuel cost projections, and estimates of operating and maintenance cost follow.

\section{Nuclear Capital Cost}

Nuclear generating unit capital cost is estimated to account for about $63 \%$ of the total cost of supplying electricity (Congressional Research Service 1979 , p. 22), a substantially larger percentage than that for coal-fired units. Thus, accurate estimation of the capital cost of nuclear units is crucial to any analysis of the cost of supplying electricity from these plants.

\section{Data}

Nuclear cost data from a study entitled, Cost Analysis of Light Water Reactor Power Plants (Mooz 1978) is used in the nuclear capital cost equation which is estimated by ordinary least squares. This data set is composed of 39 observations on various characteristics of nuclear units which began commercial operation from 1968 to 1977. 


\section{Assumptions}

Most of the assumptions that applied to the coal-fired unit capital cost analysis also apply to the nuclear cost analysis. The differences are as follows:

- The differential from national average cost for nuclear units in the Northeast (DOE Regions 1, 2 and 3 excluding Virginia) continues unchanged.

- No new nuclear generating units are constructed on a partial turnkey (subsidized) basis.

- The FGD systems assumptions do not apply because these systems are not used in nuclear units.

- The nuclear plant data base (Mooz 1978) assumes that expenditures over the licensing and construction period for each unit occur in an S-shaped pattern (starting slowly, increasing, peaking, and decreasing).

- All new nuclear units have cooling towers since once-through cooling is no longer permitted.

\section{Equations}

Several factors have been identified which affect the capital cost of nuclear generating units, such as: 1) location, 2) length of licensing process, 3) length of construction period, 4) start of commercial operation, 5) size of the unit, 6) company building the unit, 7) learning by engineers and contractors, 8) presence or absence of cooling tolvers, 9) public or private ownership, and 10) partial turnkey subsidies (Mooz 1978).

For purposes of our analysis, some changes were made from the Mooz study in the specification of the equation. The variables for length of licensing process and length of construction period were dropped from the equation because of multicolinearity problems with the variable for year of initial commercial operation and because the influence of these omitted variables is likely to be picked up by the latter variable. Due to a lack of information for future plants, the variable for the contractor building the unit, learning 
by engineers and contractors, and type of ownership were also dropped. The est imated equation for nuclear unit capital cost is the following (F statistics are in parentheses):

$$
\begin{gathered}
\operatorname{CCOSTN}(\$)=\underset{(1.379)}{-139,341,570 .}+\underset{(15.486)}{55,934,735 .} \times \text { Year }+\underset{(7.041)}{292,781.88} \times \text { SIZE } \\
\begin{array}{c}
-164,105,890 . \\
(8.001)
\end{array} \times \text { PT }+36,696,690 . \\
R^{2}=0.653
\end{gathered}
$$

where:

$$
\begin{aligned}
\operatorname{CCOSTN}(\$)= & \text { total capital cost for nuclear generating units } \\
\text { YEAR = } & \text { calendar year beginning commercial operation minus } 1968 \\
\text { SIZE = } & \text { rated capacity of plant (MW) } \\
\text { PT = } & 1,0 \text { dummy variable indicating whether or not the plant was } \\
& \text { subsidized under a partial turnkey arrangement } \\
\text { TWR = } & 1,0 \text { dummy variable indicating presence or absence of a } \\
& \text { cooling tower } \\
\text { LOCI = } & 1,0 \text { dumy variable indicating whether or not plant is } \\
& \text { located in the Northeast (DOE Regions } 1,2 \text {, and } 3, \\
& \text { excluding Virginia). }
\end{aligned}
$$

In Equation 7 the cooling tower (TWR) and Northeast region (LOCI) durmy variable coefficients are not statistically significant. Both are retained in the equation, however, due to the relatively large effects on total capital cost and the recognized deficiencies of the data base. There are few observations available for each of these variables, and it is felt that expansion of the data base would be helpful in further investigation of the cost impacts of cooling towers and regional location.

A similar process to that described previously in the coal capital cost analysis is used to convert the coefficients of Equation 7 from $1976 \$$ to $1979 \$$ (i.e., multiply by 1.22 using the Handy-Whitman steam generating plant cost index). This yields the following information (in 1979\$): 
- Total capital cost tends to increase by about $\$ 68,240,000$ for each year into the future that a nuclear generating unit begins commercial operation.

- Each additional MW of capacity added to unit size tends to raise total capital cost by about $\$ 360,000$.

- Partial turnkey subsidies lower the total capital cost by approximately $\$ 200,210,000$.

- The presence of a cooling tower increases capital cost by about $\$ 44,770,000$.

- The total capital cost of nuclear generating units located in the northeastern United States tends to be approximately $\$ 77,990,000$ higher than for units located elsewhere.

Decommissioning Cost

The cost of decommissioning a nuclear plant and the source of revenue to cover this cost has only recently become an issue of concern. Studies by Manion and La Guardia (1976) and by Smith et al. (1978), have estimated the costs for three decommissioning alternatives: 1) mothballing, 2) entombing, and 3) immediate removal of a nuclear facility. (a) Smith et al., Ferguson (1978), and Chapman (1979) addressed the issue of the various techniques that a utility may use to recover the cost. These range from creating a tax exempt special fund, to adding the present value of the decomissioning cost to the rate base.

For the purpose of this study, the estimated cost for immediate removal of a nuclear facility from Smith et al. was used. The estimates by Manion and La Guardia are not used because no economic analysis involving the value of money over time was performed. (b) The alternative of immediate removal is selected as the most likely to be implemented given the higher costs of other

(a) The Smith et al. study sumarizes and compares five other decommissioning cost studies besides the study by Manion and La Guardia.

(b) Data from the Manion and La Guardia study was escalated and discounted for use in the Roberts et al. (1978) study. Smith et al. also escalated the Manion and La Guardia data to a time/cost basis comparable with their data and found no significant difference. 
alternatives (see Smith et a1. 1978, pp. 2-12). It was assumed that the most likely method of recovering the cost of decommissioning is the addition of a levelized annual cost to the rate base. Therefore, to recover the estimated $\$ 42.1$ million (1978\$) cost of dismantling a reference 1175 MW pressurized water reactor unit (Smith et a1. 1978, pp. 2-1, 2-6), a decommissioning charge of $\$ 38.70 / \mathrm{kW}(1979 \$)$ is added to the capital cost for each nuclear plant.

\section{Capital Cost Per kWh}

Given estimates of both total capital cost from Equation 7 and cost per $\mathrm{kW}$ for decommissioning, the capital cost per kWh of electricity generated is calculated. The procedure is similar to that used in Equation 2 for coal capital cost.

$$
\begin{aligned}
\operatorname{CCOSTN}(\mathrm{mi11 \textrm {s }} / \mathrm{kWh})= & \frac{\operatorname{CCOSTN}(\$) \times 0.165 / \mathrm{yr} \times 1000 \mathrm{mil1 \textrm {s }} / \$}{8760 \mathrm{hr} / \mathrm{yr} \times 0.65 \mathrm{hr} / \mathrm{hr}} \times \frac{\mathrm{kW} \mathrm{capacity}}{} \\
& +\operatorname{DECOM}(\$ / \mathrm{kW}) \times \frac{0.165 / \mathrm{yr} \times 1000 \mathrm{mi} 11 \mathrm{~s} / \$}{8760 \mathrm{hr} / \mathrm{yr} \times 0.65 \mathrm{hr} / \mathrm{hr}}
\end{aligned}
$$

Nuclear Fuel Cost

For a nuclear unit operating in 1970, nuclear fue 1 cost accounted for $62 \%$ of the variable production cost (Uri 1975, p. 53). By 1977, the Congressional Research Service (1979, p. 22) indicated that fuel cost had declined to $54 \%$ of the variable production cost and $20 \%$ of the total generating cost. It is evident that fue 1 cost is not as significant a factor in the cost of nuclear generated electricity as the price of coal in coal generated electricity.

The price of nuclear fuel to a nuclear generating unit depends upon the cost associated with the various stages of the fuel cycle. The fuel cycle includes underground or surface mining of the ore, milling the ore to "yellow cake," converting the "yellow cake" to gas for enrichment, enriching or concentrating the natural uranium content of the gas, converting the gas to a solid, assembling the fuel rods and elements, and either storing or disposing of the spent fue 1 or fue 1 reprocessing. The areas of significant uncertainty affecting price projections for nuclear fuel are uranium reserve data and spent fuel reprocessing policies (EPRI 1979, p. 6-1). 
The most recent projections of nuclear fuel costs were made by EPRI (1979, pp. 6.9-6.14). Nuclear fuel costs were estimated for both the reprocessing and no-reprocessing case with a cost range of $\pm 12.5 \%$ to reflect uncertainties. For the no-reprocessing case, the fuel cost was $\$ 0.44 / \mathrm{MBtu}$ (1978\$) and this price was expected to escalate at a real rate of $2.48 \%$ per year. Reprocessing was not expected to occur before 1990. The real escalation rate for the reprocessing case was $1.05 \%$ per year. The lower escalation rate occurs because plutonium gained from reprocessing has a value which offsets the overall fuel cost.

This study's nuclear fuel cost projections are based on the EPRI no-reprocessing case because reprocessing is not expected to occur before 1990 and because of the uncertainties attached to future reprocessing policies. The EPRI fuel cost of $\$ 0.44 / \mathrm{MBtu}(1978 \$$ ) is inflated to $1979 \$$ using the Producer Price Index and converted into mills/kWh using a nuclear plant heat rate of $10,769 \mathrm{Btu} / \mathrm{kWh} . \mathrm{a}^{(\mathrm{a})}$ This base price is then escalated at the real annual rate of $2.48 \%$. Based on this information, the nuclear fuel cost equation is:

$$
\text { Fue } \left.1 \text { Cost }_{i}(1979 \mathrm{mills} / \mathrm{kWh})=5.33(1.0248) \text { (year }_{i}-1978\right)
$$

where:

$i=$ year for which the nuclear fuel cost is to be estimated $5.33=1978$ fuel cost in $1979 \mathrm{mills} / \mathrm{kWh}$

1.0248 = escalation factor.

Specification of nuclear fuel cost in this manner assumes that the fue 1 cost for all nuclear reactors is the same (i.e., there are no regional variations in price). This assumption was also made in the study by Roberts et al. (1978). It is interesting to note that its nuclear fuel costs included carrying charges for the fuel as it moved through the front end of the fuel cycle.

(a) The EIA (1980, p. 103) lists nulear power heat rates ranging from 10,769 $\mathrm{Btu} / \mathrm{kWh}$ to $11,161 \mathrm{Btu} / \mathrm{kWh}$. The $10,769 \mathrm{Btu} / \mathrm{kWh}$ rate is used in this study because it represents the estimated heat rate for nuclear plants in operation during 1977 through 1980. 
Except for these carrying charges, there is little difference between its cost projections and those based on the EPRI data.

Nuclear Unit Operation and Maintenance Cost

The other portion of variable production cost, besides fuel cost, is operation and maintenance cost. For a typical nuclear unit, $46 \%$ of variable production cost and $17 \%$ of total generating cost were in the form of operation and maintenance cost during 1977 (Congressional Research Service 1979, p. 22).

Nuclear unit operation cost includes expenses for supervision and engineering, reactor coolants and water, and operation of the steam and electric plant. Maintenance cost includes expenses for supervision and engineering, maintaining the $\mathrm{plant}$ structure, the reactor plant equipment, and the electric plant. (a) A principal component of nuclear 0\&M cost is the cost for nuclear liability insurance which is directly related to unit operation. Uri (1975, p. 54) estimates that approximately $30 \%$ of nuclear 0\&M cost is for insurance. Some other components of nuclear plant 0\&M cost are labor, maintenance parts and materials, and office and other incidental expenses.

Data from the Statistics of Privately Owned Electric Utilities in the United States - 1978 (DOE/EIA 1979e, pp. 37, 44) was used to estimate nuclear unit O\&M cost. Data for privately owned utilities were selected so that no publicly owned, possibly subsidized, nuclear units would be considered. The average 0\&M cost for private nuclear units during the 1969 through 1978 period was used as the basis for 0\&M cost projections.

From 1969 through 1978, nuclear unit operation and maintenance cost in current dollars increased from 1.41 to $3.20 \mathrm{mills} / \mathrm{kWh}$. This increase, when adjusted for inflation, represents an average annual real rate of increase of $2.34 \%$. Based on this information, the equation used to estimate future nuclear plant 0\&M cost is:

(a) Like coal plant 0\&M cost, nuclear 0\&M cost does not include any general and administrative expenses nor any capital related fixed charges. 


$$
08 M_{i}\left(1979 \mathrm{mi11 \textrm {s } / \mathrm { kWh } )}=3.60(1.0234)^{\left(\text {year }_{i}-1978\right)}\right.
$$

where:

$$
\begin{aligned}
& i=\text { year in which the } 0 \& M \text { costs are to be estimated } \\
& 3.60=1978 \text { 0\&M cost in } 1979 \mathrm{mills} / \mathrm{kWh} \\
& 1.0234=\text { escalation factor with an annual real escalation rate of } 2.34 \% . \\
& \text { Like the coal-fired unit } 0 \& M \text { equation, the nuclear } 0 \& M \text { equation neglects }
\end{aligned}
$$
the issue of regional variations in O\&M cost and returns to scale. Regional variations in O\&M cost will undoubtably occur but data 1 imitations precluded their quantification. Decreasing 0\&M cost per kWh as plant size increases, seems to be more significant for nuclear facilities than for coal-fired units. Uri (1975, pp. $53 \& 54$ ) indicates that few additional personnel are needed as the size increases and when an additional unit is added to a plant, the operating cost does not rise proportionally to the increased capacity. Based on Scherer's (1977, pp. $152 \& 153$ ) data, the decreases in 0\&M cost per $\mathrm{kWh}$ from an $800 \mathrm{MW}$ unit to a $1300 \mathrm{MW}$ unit is approximately $0.5 \mathrm{mill}$. This is a small change and should not affect the estimates to any great extent. Nuclear Unit Busbar Cost

The estimates of capital, fuel and O\&M costs are sumed to calculate the busbar cost of power for each nuclear unit. The following equation converts the busbar cost from mills per kWh to $\$$ per MBtu:

$$
\begin{aligned}
\operatorname{BCOSTN}(\$ / \mathrm{MBtu}) & =\operatorname{CCOSTN}(\mathrm{mi} 11 \mathrm{~s} / \mathrm{kWh})+\text { FUELN }(\mathrm{mi} 11 \mathrm{~s} / \mathrm{kWh}) \\
& +0 \& M(\mathrm{mi} 11 \mathrm{~s} / \mathrm{kWh}) \times \frac{\mathrm{kWh}}{3412 \mathrm{Btu}} \times \frac{\$}{1000 \mathrm{mi} 11 \mathrm{~s}} \times \frac{10^{6} \mathrm{Btu}}{\mathrm{MBtu}}
\end{aligned}
$$

where

$$
\begin{aligned}
\text { BCOSTN } & =\text { busbar cost of power from nuclear units } \\
\text { CCOSTN } & =\text { capital cost per } k \text { Wh generated } \\
\text { FUELN } & =\text { nuclear fuel cost per } k \text { Wh generated } \\
\text { O\&M } & =\text { operation and maintenance cost per } k W h \text { generated }
\end{aligned}
$$




\section{TRANSMISSION AND DISTRIBUTION COST}

The retail cost of electricity to the final consumer is a function of the busbar cost of generating the electricity (which is the sum of the levelized capital carrying cost, fuel cost, and operating and maintenance cost), the transmission and distribution (T\&D) cost, and the general and administrative cost. The items included in the busbar cost of electricity have been discussed. In this section T\&D cost is estimated. General and administrative cost is estimated in the following section.

Transmission and distribution cost is the expense incurred in transmitting and distributing electricity from the generating unit to the final consumer. Annual T\&D cost consists of fixed charges on investment as well as operation and maintenance expenses. The annual fixed charges include a return on invested capital, depreciation, taxes, and insurance. Operation expenses include the costs of load dispatching, overhead and underground line operation, supervision and engineering, customer installations, and meter expenses. Maintenance cost includes the expense of maintaining station equipment, overhead and underground lines, line transformers, meters, and supervision and engineering.

Estimates of the transmission and distribution cost per unit of electricity generated are scarce. This is mainly due to the many factors that enter into the determination of T\&D cost. For example, distribution cost varies because of differences in climate, topography, load density, load characteristics, growth rates, type of utility ownership, and the size of the utility (Uri 1975, p. 42). Transmission cost varies with voltage, whether the current is ac or dc, tower and conductor design, length of line, geographical location and terrain, labor costs, whether the line is above ground, underground, or over water, and right-of-way acquisition costs. The right-of-way acquisition costs vary with the type of 1 and, land use, transmission voltage, and the width of the right-of-way required, which in turn varies with the type of pole or tower used (Schiefelbein 1977, pp. 28-30; EPRI 1979, pp. 9.1-9.9). This 1 arge number of factors is indicative of the difficulty in determining representative T\&D cost. 
The data used to estimate T\&D expenses are from Statistics of Privately Owned Electric Utilities in the United States-1978 (DOE/EIA 1979e pp. 29, 34, $35,40,41)$. National average data for the period from 1969 through 1978 are used to determine T\&D estimates. In the first step, the annual fixed charges on investment in T\&D facilities are estimated. To arrive at an annual value, it is assumed that revenues for depreciation and amortization of the entire utility plant are allocated to the T\&D plant in proportion to the T\&D share of total utility plant investment. This value is used as an approximation of the annual T\&D fixed charge and annual operation and maintenance expenses for the T\&D system are added to it to estimate the annual T\&D cost.

From 1969 through 1978, T\&D cost increased in real terms from 2.16 to $2.88 \mathrm{mills} / \mathrm{Kwh}$ on a national average basis. This represents a real annual rate of increase of $3.28 \%$. Based on this information, the equation used to estimate future T\&D cost is:

$$
T_{\& D_{i}}(1979 \mathrm{mills} / \mathrm{kWh})=3.24(1.0328)^{\left(\text {year }_{i}-1978\right)}
$$

where:

$$
\begin{aligned}
& i=\text { year for which the T\&D cost is to be estimated } \\
& 3.24=1978 \text { T\&D cost in } 1979 \mathrm{mills} / \mathrm{kWh} \\
& 1.0328=\text { escalation factor with an annual real escalation rate of } 3.28 \% \\
& \text { Because sufficient data are not readily available to calculate regional }
\end{aligned}
$$
or state T\&D cost, this specificaton of T\&D cost assumes no regional variation. Uri (1975, p.42) says that while the unit costs for distribution facilities of individual utilities would vary from the national average, regional averages would approximate the national average so that regional estimates are unnecessary. For transmission costs both Uri and Scherer (1977, p. 54) used a cost per mile specification, with Uri (1975, pp. 39-42) estimating interregional transmission costs as the gross distance between regions, times the transmission cost per mile. Due to the lack of appropriate data, the specification of T\&D cost used in this study is an extreme simplification of a highly complex variable. 


\section{GENERAL AND ADMINISTRATIVE COST}

The final cost component estimated is general and administrative (G\&A) cost. G\&A cost includes utility expenses generally referred to as overhead which are really a fixed portion of utility operation and maintenance (O\&M) cost. Analyzing G\&A cost separately from O\&M cost however, avoids the problem of developing separate G\&A cost estimates for coal-fired and nuclear generating facilities.

G\&A cost includes customer account expenses such as meter reading and collection expenses, customer service and informational expenses; and sales expenses such as advertising, administrative and general salaries, office supplies, employee pensions, and maintenance of administrative buildings.

Data from the Statistics of Privately Owned Electric Utilities in the United States - 1978 (DOE/EIA 1979e, pp. 35, 40) is used to estimate G\&A cost. From 1969 through 1978, G\&A cost increased from 1.47 to $2.59 \mathrm{mills} / \mathrm{kWh}$. In real terms, this represents an average annual increase of $1.73 \%$. Based on this data, the equation used to project G\&A cost is:

$$
\text { G\&A }_{i}\left(1979 \mathrm{mi11 \textrm {s } / \mathrm { kWh } )}=2.91(1.0173)^{\left(\text {year }_{i}-1978\right)}\right.
$$

where:

$i=$ year for which the expenses are to be estimated, $2.91=1978 \mathrm{G} \& A$ cost in $1979 \mathrm{mills} / \mathrm{kWh}$, 1.0173 = escalation factor with an annual real escalation rate of $1.73 \%$

As with the other estimated cost elements, G\&A cost is subject to regional variation. Regional variations in the cost of 1 abor impact most of the items included in G\&A cost and there may also be regional variation in pension costs. Since data to estimate this variation are not readily available, the national average G\&A cost is applied to all regions.

STATE AND REGIONAL RETAIL COST ESTIMATION

From the busbar cost estimates for coal and nuclear units and average utility $T \& D$ and G\&A costs per $\mathrm{KWh}$, state level estimates of retail cost are 
calculated. The state-level retail cost estimates are based on nuclear and coal-fired units scheduled to begin commercial operation between 1980 and 1995. Data as to the fuel type, capacity, location and scheduled operation of these units are taken from information regarding projected coal and nuclear generating unit additions reported by utilities (DOE/EIA 1979d). (a) Using the specific information as to year, location and capacity for each scheduled unit, the capital cost per $\mathrm{kW}$ of capacity is estimated. Tables in Appendix $A$ show the average capital cost per $\mathrm{kW}$ for all coal and nuclear plants scheduled to come on line in each state in each year to 1995.

Average busbar cost is then calculated for the coal and nuclear capacity additions in each state. Estimates of busbar cost for each state and year in which capacity additions are scheduled are given in Appendix B. Since 1995 is beyond the period of plant commitments, generic plants are used to estimate busbar costs. Where busbar cost estimates for both coal and nuclear units occur in a given year (see tables in Appendix B) an average of the resulting retail costs is used in the state retail cost estimates shown in Appendix $C$. This aggregation of specific generating unit costs to estimate state marginal retail cost for a given year is illustrated in the first three columns of Figure $3(p .16)$.

It should be noted that the state-level electricity cost estimates are developed without regard for actual utility system boundaries or for the effects on retail costs of joint ownership of units by out-of-state utilities. All the costs related to a specific unit are allocated to the marginal cost estimate for that state alone. While this procedure has minimal effect on the regional estimates, it limits the accuracy of the individual state estimates.

(a) Changes, such as delays in date of commercial operation and cancellations of nuclear units, as of April, 1980, were made in this data on the basis of utility industry announcements. The "Nuclear News Briefs" columns of Nuclear News for 1979 (Volume 22, Issues 1-12) and 1980 (Volume 23, Issues 1-4) were used to update the data. Corraborating data was found in "U.S. Nuclear Power Plants: Construction Progress" (Atomic Industrial Forum 1980). 
Marginal retail cost estimates for the DOE Regions are shown in Appendix $C$ and sumarized in the discussion of results. These regional cost estimates are an average of the state-level retail cost estimates for the scheduled capacity additions in the years when additions occur and for the generic plant in 1995. 
. 


\section{ANALYSIS AND INTERPRETATION}

This section of the report discusses the research findings and the sensitivity of the marginal cost estimates to changes in the assumed values of key variables. A summary table of the marginal cost estimates for DOE Regions is included in the discussion of findings. Detail of the state-level estimates is included in the Appendices. A summary and conclusions follow the sensitivity analysis.

\section{RESEARCH FINDINGS}

The marginal cost estimates for DOE Region are presented first and are followed by a discussion of the capital, busbar and state, retail cost estimates from which they are developed.

\section{Regional Marginal Cost Estimates}

Projections of the marginal retail cost of electricity through 1995 for each DOE Region are given in Table 6. The estimates for 1980 range from a low of $\$ 11.96 / \mathrm{MBtu}$ in Region 8 to a high of $\$ 15.72 / \mathrm{MB}$ tu in Regions 1 and 2 . Costs in all Regions rise until 1995 when the range is from $\$ 19.50 / M B$ tu to $\$ 21.48 / \mathrm{MB}$ tu with the low and high costs in the same regions as in 1980 . The pattern of relative costs among the Regions does not hold during the intervening years, however. This is due to the fact that these cost estimates are

TABLE 6. Estimates of Marginal Costs of Electricity at the Retail Leve 1 by DOE Region, 1980-1995(a)

\begin{tabular}{|c|c|c|c|c|c|c|c|c|c|}
\hline & \multicolumn{9}{|c|}{ DOE Region } \\
\hline Year & $1 \& 2$ & 3 & 4 & 5 & 6 & 7 & 8 & 9 & 10 \\
\hline 80 & 15.72 & 14.12 & 13.92 & 13.55 & 12.44 & 13.73 & 11.96 & 13.61 & 13.60 \\
\hline 85 & 16.72 & 16.51 & 15.70 & 17.80 & 15.42 & 15.59 & 14.02 & 16.45 & 15.69 \\
\hline $1990^{(b)}$ & 17.71 & 18.73 & 19.54 & 18.77 & 17.17 & 18.05 & 17.14 & 17.09 & 18.34 \\
\hline $1995^{(c)}$ & 21.48 & 21.11 & 20.68 & 20.64 & 20.33 & 20.41 & 19.50 & 21.18 & 20.59 \\
\hline
\end{tabular}

(a) $1979 \$ /$ MB tu.

(b) Estimates for Regions 3, 7, 8, and 10 are an average of costs for generic $600 \mathrm{MN}$ coal and $1200 \mathrm{MN}$ nuclear plants.

(c) Estimates for all regions are an average of generic coal and nuclear plant costs. 
based on actual units being added to capacity and also due to the slight differences in coal and nuclear cost escalation rates among the regions. In addition, the escalation rates are partially a function of the scale of the units being added. For instance, the highest cost estimate in 1985 occurs in Region 5. This is due to the scheduled completion of a $500 \mathrm{MN}$ nuclear unit, resulting in a much higher estimated cost per kW than the 1100 to $1200 \mathrm{MW}$ plants generally scheduled elsewhere.

Capital Cost Estimates

Estimates of the capital cost per $\mathrm{kW}$ of installed capacity for each of the scheduled units are shown in the tables in Appendix A. The costs shown in all of the tables are estimated without the cost of $\mathrm{NO}_{\mathrm{X}}$ scrubbers. If such scrubbers are required after 1990, they would increase coal-fired unit capital costs by about $5 \%$, as well as increasing 0\&M and fuel costs.

In Appendix $A$ the table for each DOE Region indicates the cost per $\mathrm{kW}$ in the expected first year of comercial operation for all of the coal and nuclear units planned in each state. Careful inspection of these tables reveals that the capital cost escalation rates for both coal and nuclear plants differ among states and over time. This is due to variation in the size of new plants as higher demand growth or joint ownership allows some utilities in some time periods to take better advantage of economies of scale than others. The capital cost models predict substantial economies of scale for both coal and nuclear plants over the range of unit capacities currently projected. However, capital cost per $\mathrm{kW}$ predicted for coal-fired units of less than $400 \mathrm{MW}$ and nuclear units of less than $800 \mathrm{MN}$ are so much higher than those for larger units that the reliability of these estimates is suspect.

Estimates are not made for those states in which there are no announced plans for capacity additions. This lack of expansion may either be due to a low rate of demand growth or quite possibly to joint ownership of facilities which are to be constructed in an adjoining state. Hawai is a special case in that there is no coal or nuclear capacity at present and none is planned. The marginal source of power there is likely to be $0 i 1$ or gas-fired capacity. 
Because there is such variation in the capital cost estimates at the state level, the trend in capital cost per $\mathrm{kW}$ is illustrated by estimates of costs for a $600 \mathrm{MW}$ coal-fired unit and a $1200 \mathrm{MN}$ nuclear unit. Table 7 presents these estimates for four states which encompass the range of cost per $\mathrm{kW}$ predicted by the mode1. Cost estimates for nuclear units are $80 \%$ greater than the high range of costs assumed by EIA for plants coming on line by 1995 (DOE/ EIA 1979b, p. 30). Estimates that are comparable to those of this study have been developed by Bergstrom and Brandfon (1979), Kennedy and Campbel1 (1979) and Reichle (1979). The cost per $\mathrm{kW}$ for coal plants estimated by the model is in the same range as EIA estimates (DOE/EIA 1979b, p. 20).

TABLE 7. Cost Per kW for Generic Plants in Representative States, 1980 to $1995(a)$

\begin{tabular}{|c|c|c|c|c|c|c|c|c|}
\hline \multirow[b]{2}{*}{ Year } & \multicolumn{2}{|c|}{ Al abama } & \multicolumn{2}{|c|}{ Arizona } & \multicolumn{2}{|c|}{ Illinois } & \multicolumn{2}{|c|}{ Massachusetts } \\
\hline & $\overline{\mathrm{Coa}}$ & Nuc lear & $\overline{\mathrm{Coa} 1}$ & Nuclear & Coa & Nuclear & Coal & Nuclear \\
\hline 80 & 457 & 958 & 538 & 958 & 538 & 958 & 538 & 1024 \\
\hline & 539 & 1247 & 620 & 1247 & 620 & 1247 & 620 & 1312 \\
\hline & 622 & 1535 & 703 & 1535 & 703 & 1535 & 703 & 1600 \\
\hline 95 & 705 & 1823 & 785 & 1823 & 785 & 1823 & 785 & 1888 \\
\hline
\end{tabular}

(a) $1979 \$ / \mathrm{kW}$ of installed capacity.

\section{Busbar Cost Estimates}

Busbar cost estimates for coal-fired and nuclear units are shown for each state in Appendix B. While there is a general upward trend in busbar costs, it is masked in some states by the impact on generating costs of relative unit size. In some early years unusually small coal or nuclear units result in higher busbar cost estimates than in later years.

To make the underlying cost trends clear busbar costs for generic coal and nuclear units were projected. The relationship between busbar costs for the two types of units is shown in Figures 4 through 7 . In most states nuclear plants produce cheaper power in 1980 and 1985 . There are a few western coal-bearing states, such as Utah, however, in which electricity from coal-fired units is always less expensive. In most states there is a crossover between 1985 and 1990, and coal-fired unit busbar costs are lower from 


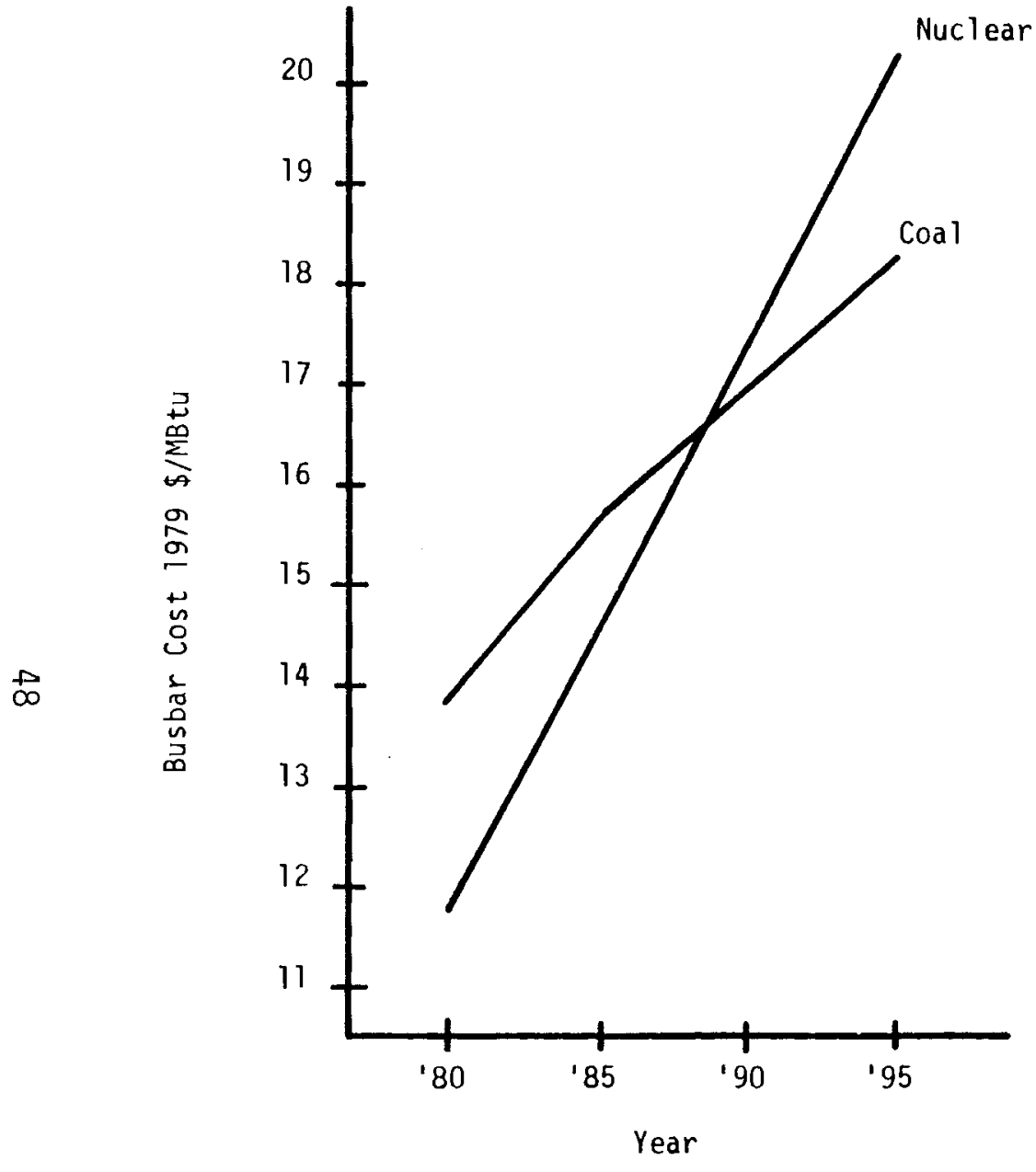

FIGURE 4. Busbar Costs for Representative Eastern State: Massachusetts

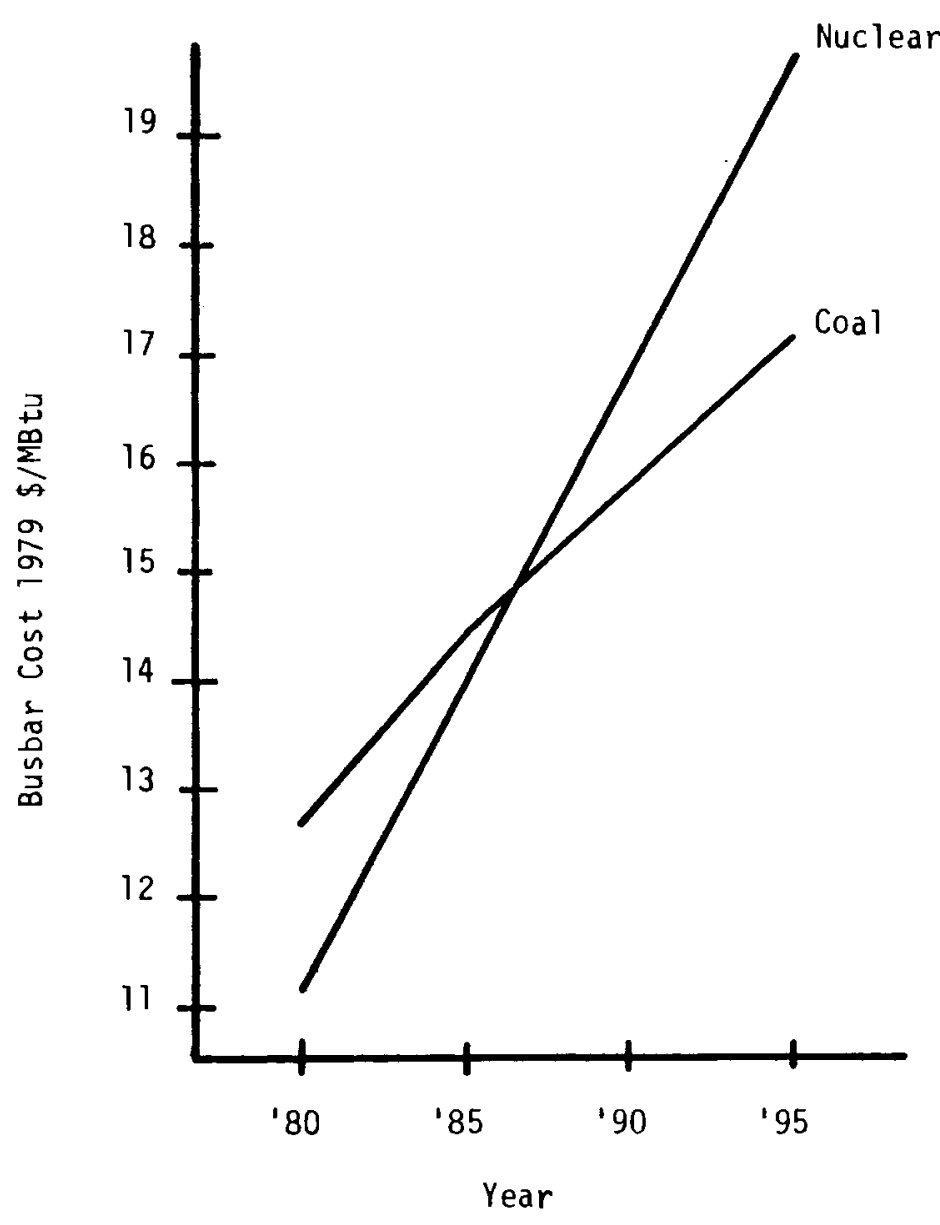

FIGURE 5. Busbar Costs for Representative Southern State: Alabama 


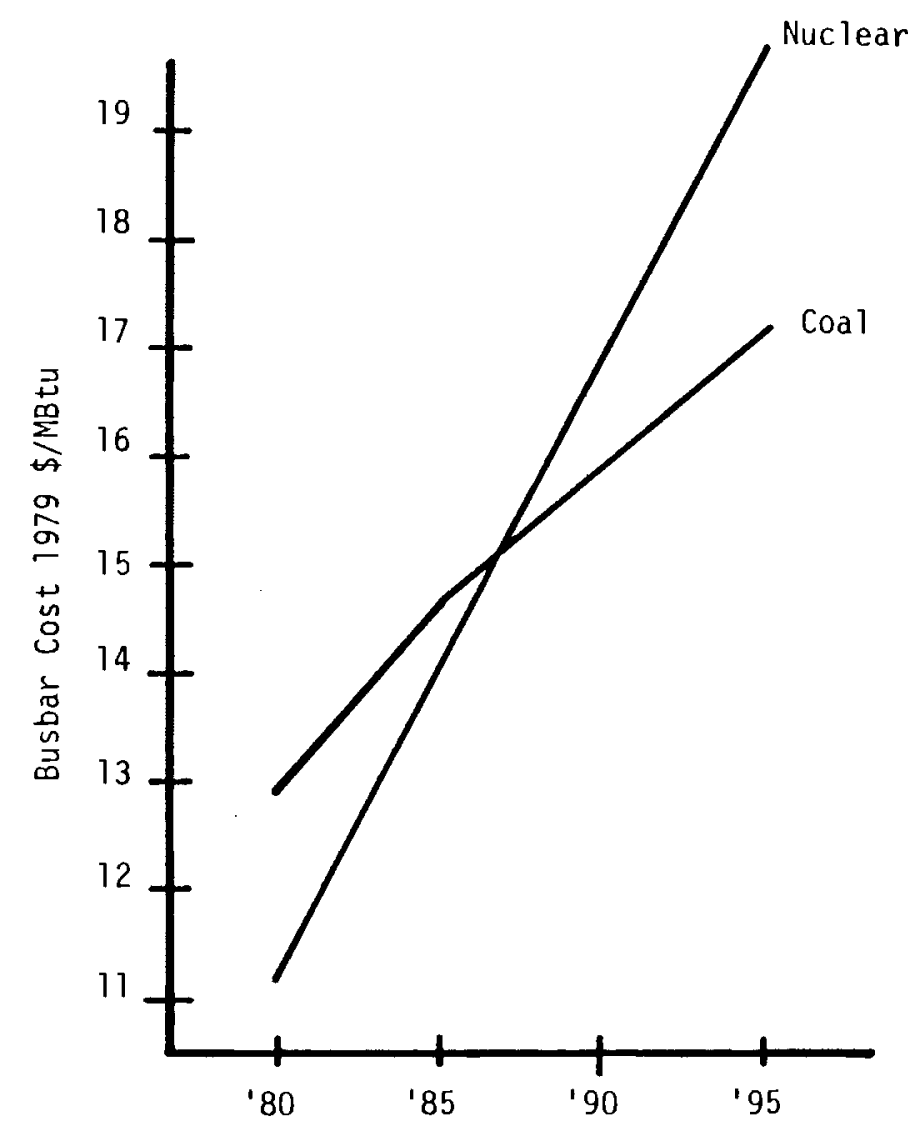

Year

FIGURE 6. Busbar Costs for Representative Midwestern State: Illino is

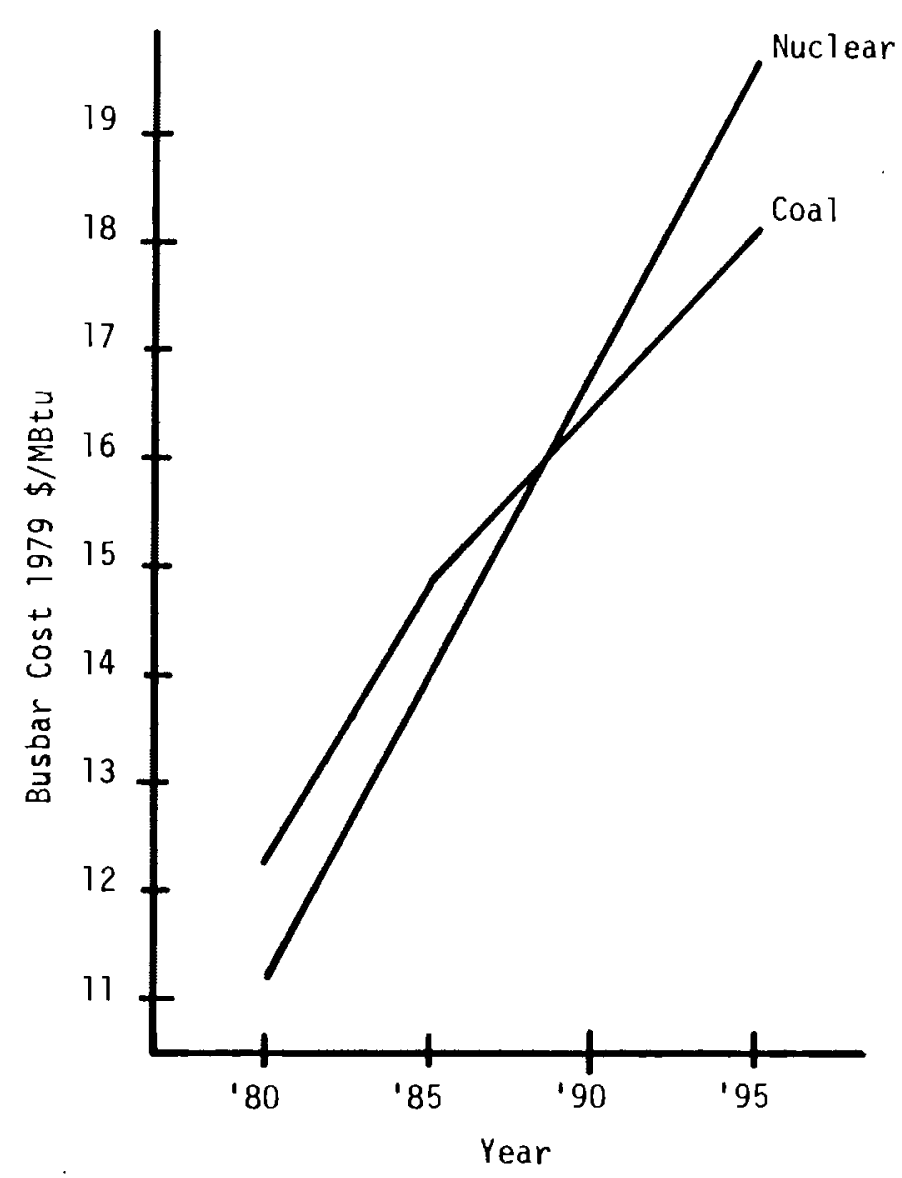

FIGURE 7. Busbar Costs for Representative Western State: Arizona 
then on. In states with a cost structure similar to Arizona (Figure 7 ) the addition of $\mathrm{NO}_{x}$ scrubbers could render coal units more costly than nuclear units after 1990 as well.

\section{Retail Cost Estimates}

Retail marginal cost estimates, for each state in which capacity is added between 1980 and 1995, are shown in Appendix C. Since so little capacity expansion is planned in New England and since the cost structure is similar to that of New York and New Jersey, DOE Regions 1 and 2 are combined to produce one regional marginal cost estimate shown in Table C.1. The marginal cost estimates are higher along the eastern coast than in the rest of the country and highest in New England. However, in those states the marginal costs are lower than the price currently charged by some utilities. This occurs because the cost of power from new coal and nuclear units is less than the cost of power from the oil-fired capacity currently in use. The lowest marginal cost estimates are found in the coal bearing western states, where large, coalfired units are being constructed and full cost is lower than in other regions.

\section{SENSITIVITY ANALYSIS}

A sensitivity analysis was carried out to examine the effect of changes in the assumed values of key variables on busbar costs. These parameters include the carrying charge rate applied to capital cost, the capacity factor, and coal and nuclear fuel cost escalation rates. Busbar costs are calculated for generating units with capacities that are typical of current construction: $600 \mathrm{MW}$ coal-fired and $1200 \mathrm{MW}$ nuclear units. Busbar costs for these generic plants are projected using the same capital, 0\&M, and fuel cost equations used to project costs for planned capacity additions. The results are presented for 1985 for four states which are representative of the major differences in costs among regions of the United States.

\section{Carrying Charge Rates}

Levelized annual carrying charges for capital are varied between $10 \%$ and $20 \%$ while other parameters are held at baseline levels. The impact of this variation on busbar costs is graphically illustrated in Figures 8 through 11. 


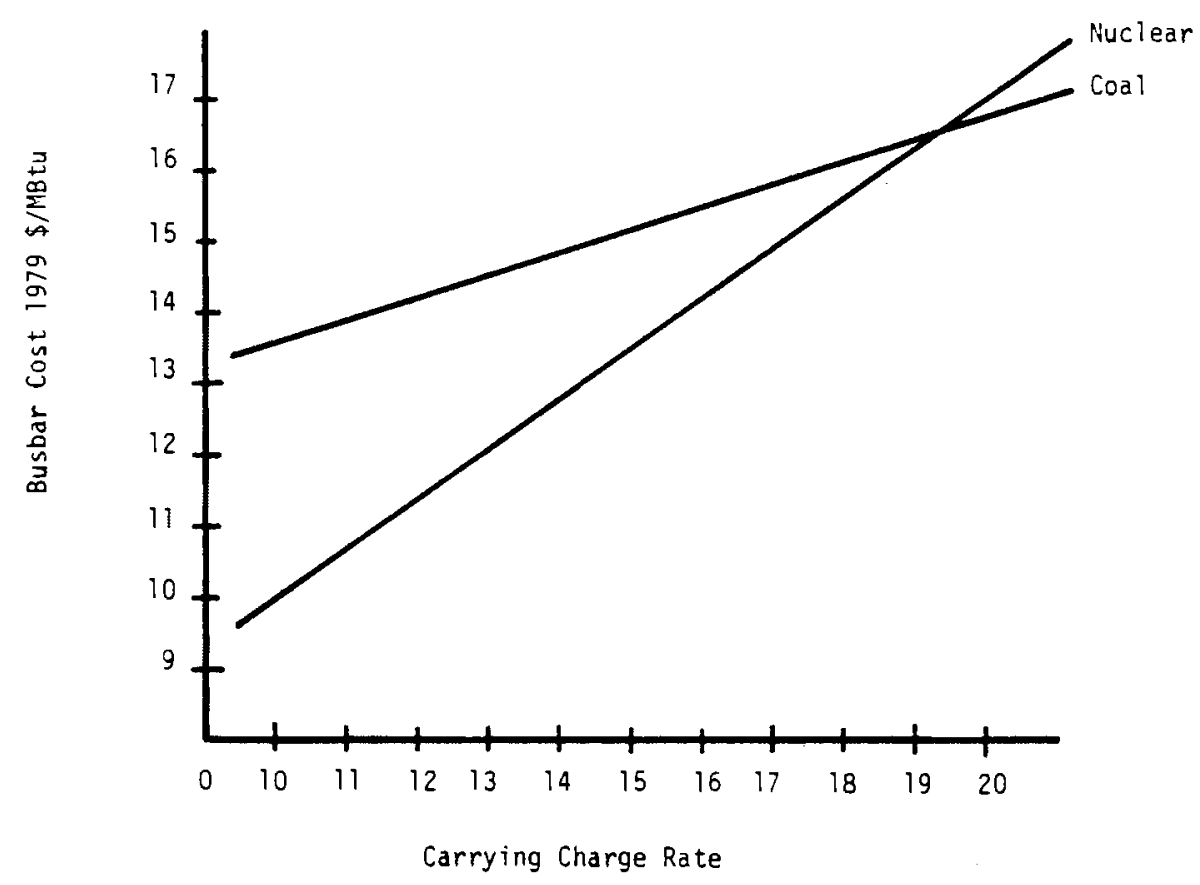

FIGURE 8. Representative Eastern State: Massachusetts (Year $=1985)$

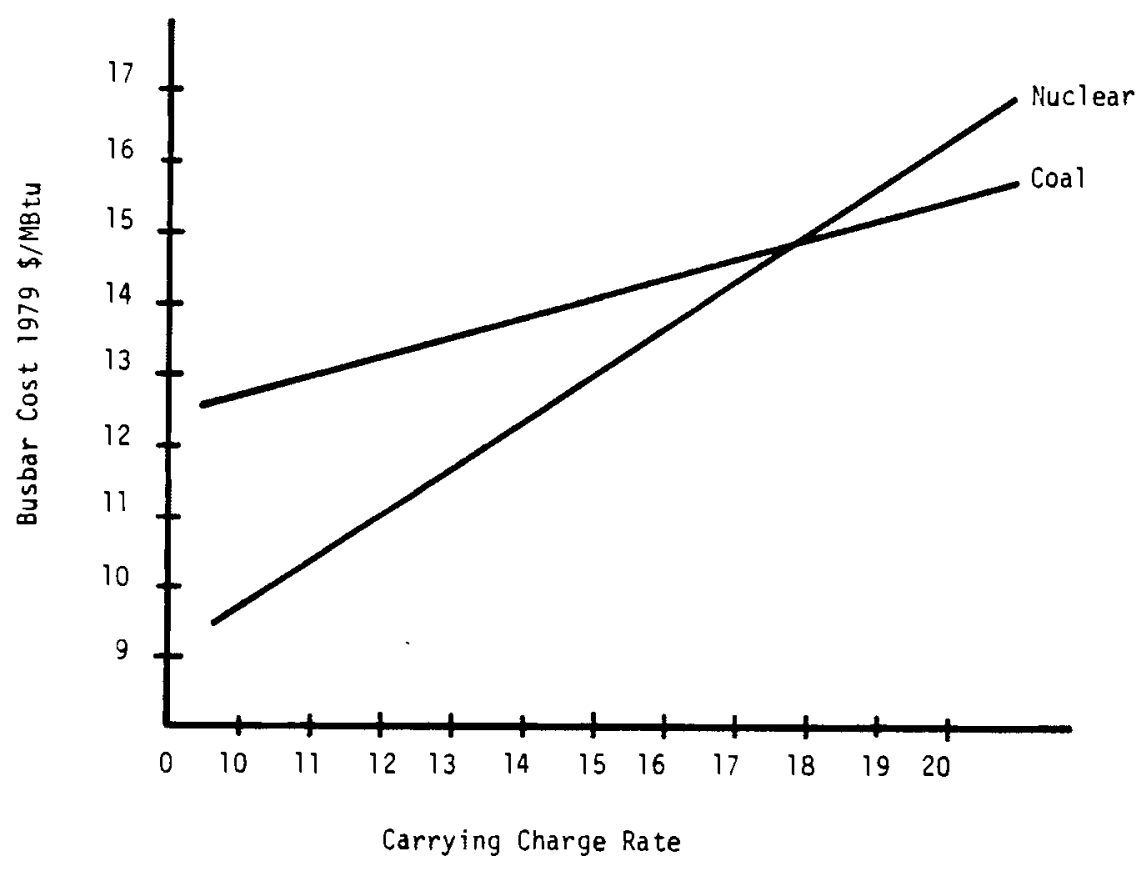

FIGURE 9. Representative Southern State:

Alabama (Year $=1985)$ 


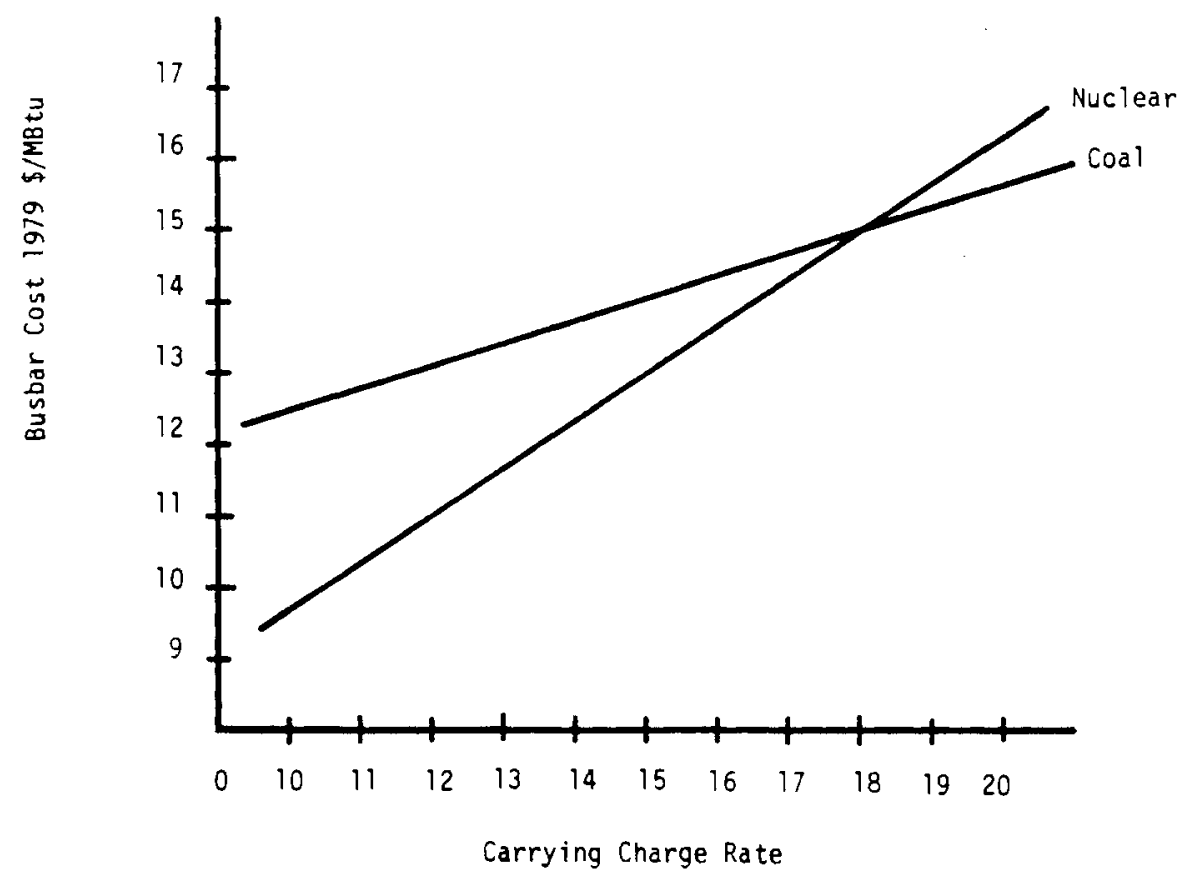

FIGURE 10. Representative Midwestern State:

Illinois (Year $=1985)$

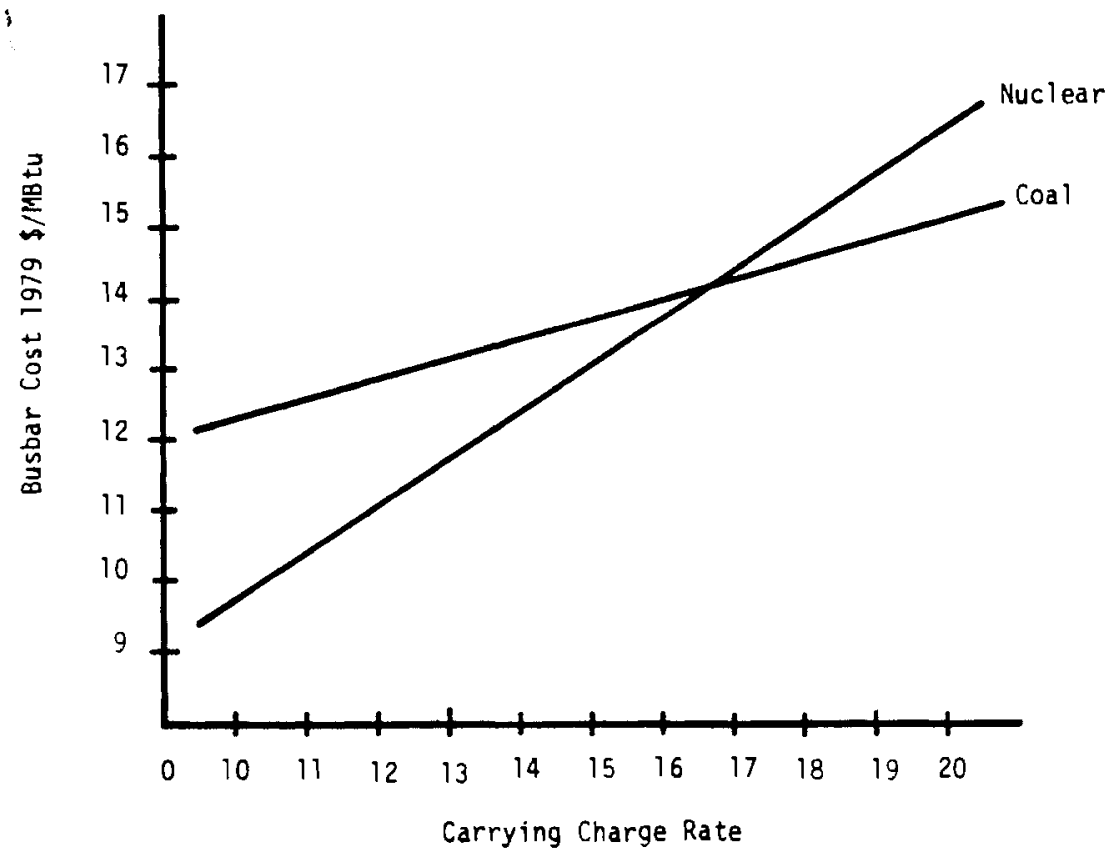

FIGURE 11. Representative Western State:

Arizona (Year $=1985)$ 
Nuclear unit busbar costs show the same response to variation in the carrying charge rate in all regions except the Northeast. In the Northeast, busbar costs increase more rapidly with increases in the carrying charge rate because capital cost is a larger portion of generating cost there than elsewhere. Coal-fired unit busbar costs increase least rapidly with increases in the carrying charge rate in the South and west. The point at which increasing the carrying charge rate results in higher busbar costs for nuclear than for coal depends both on relative capital costs and the relative cost of coal among regions. These crossover points occur at about $17 \%$ in the West, $18 \%$ in the South and Midwest and $19 \%$ in the Northeast.

\section{Capacity Factors}

To examine the effect of another key variable, the capacity factor is varied in increments of $5 \%$ between $35 \%$ and $85 \%$, while other parameter values are held at baseline values. The impact of this variation on busbar costs in 1985 is shown for the four representative states in Figures 12 through 15. While busbar costs for nuclear units are higher in the Northeast than elsewhere, the response of these costs to variation in the capacity factor does not vary significantly between regions. Busbar costs for coal-fired units are slightly less sensitive to capacity factor values in the South and West than in the Midwest and East where capital and/or fuel costs are higher. In general, nuclear costs decline much more rapidly than coal busbar costs as capacity factors increase since capital costs are a much larger component of generating costs for nuclear units. Power from coal plants is more costly than that from nuclear plants for capacity factors greater than $55 \%$ to $60 \%$ in the Midwest and Northeast. The crossover point occurs between $60 \%$ and $65 \%$ elsewhere.

\section{Fuel Prices}

High and low fuel price scenarios are used to examine the effects on busbar costs of price variation around the baseline assumptions. 

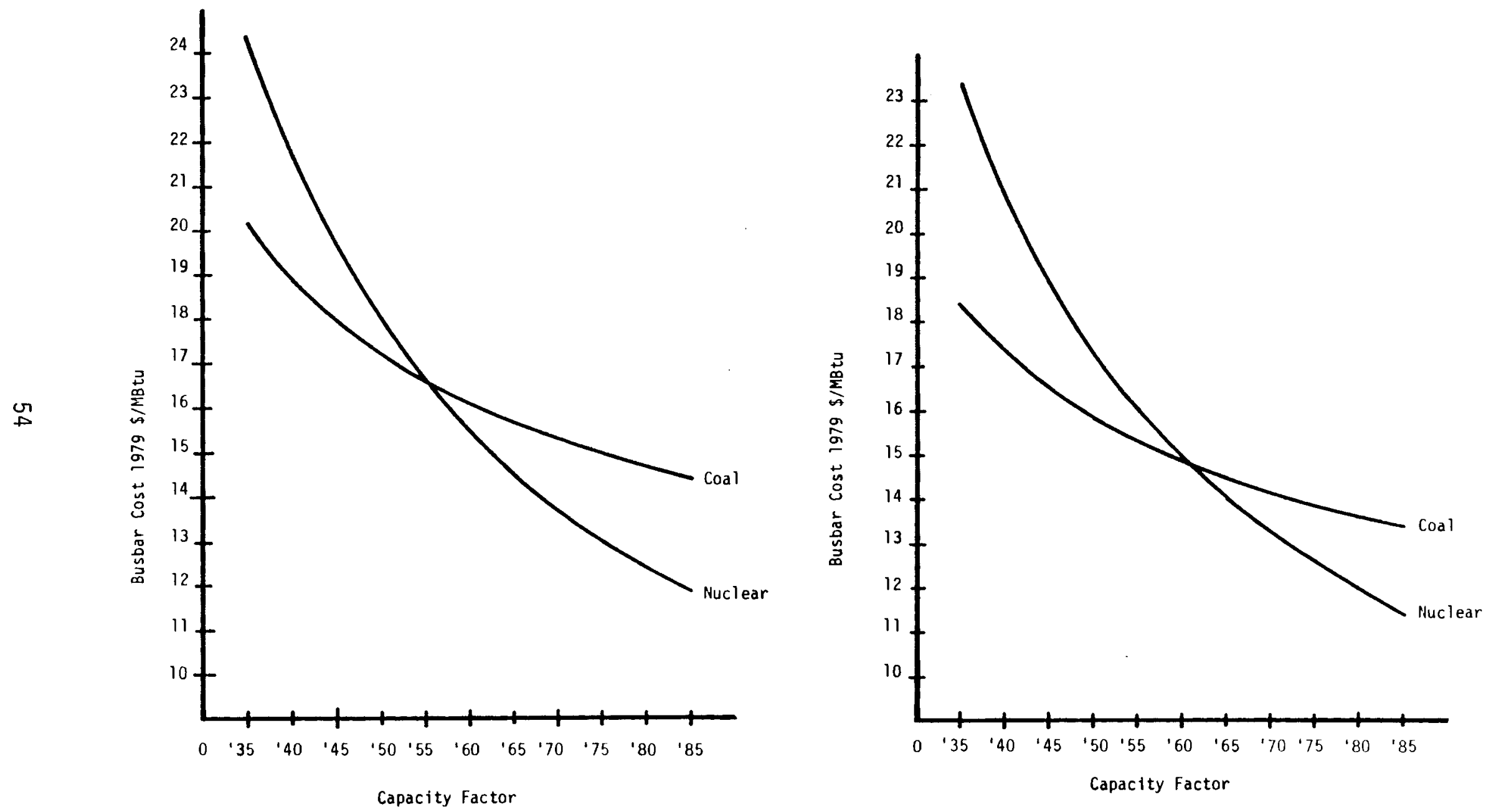

FIGURE 12. Representative Eastern State:

Massachusetts (Year $=1985)$
FIGURE 13. Representative Southern State:

Alabama (Year = 1985) 


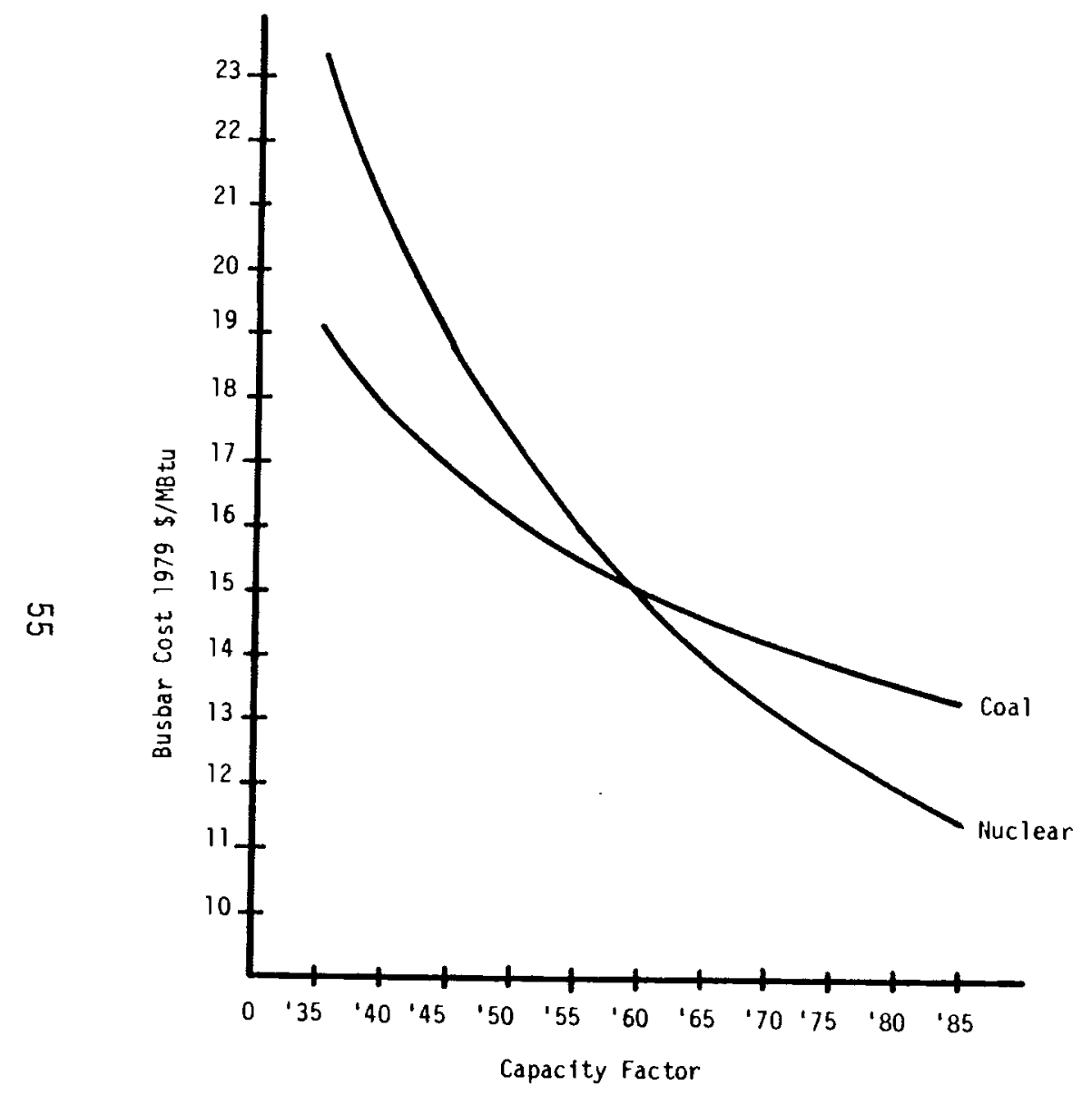

FIGURE 14. Representative Midwestern State: Illino is (Year $=1985)$

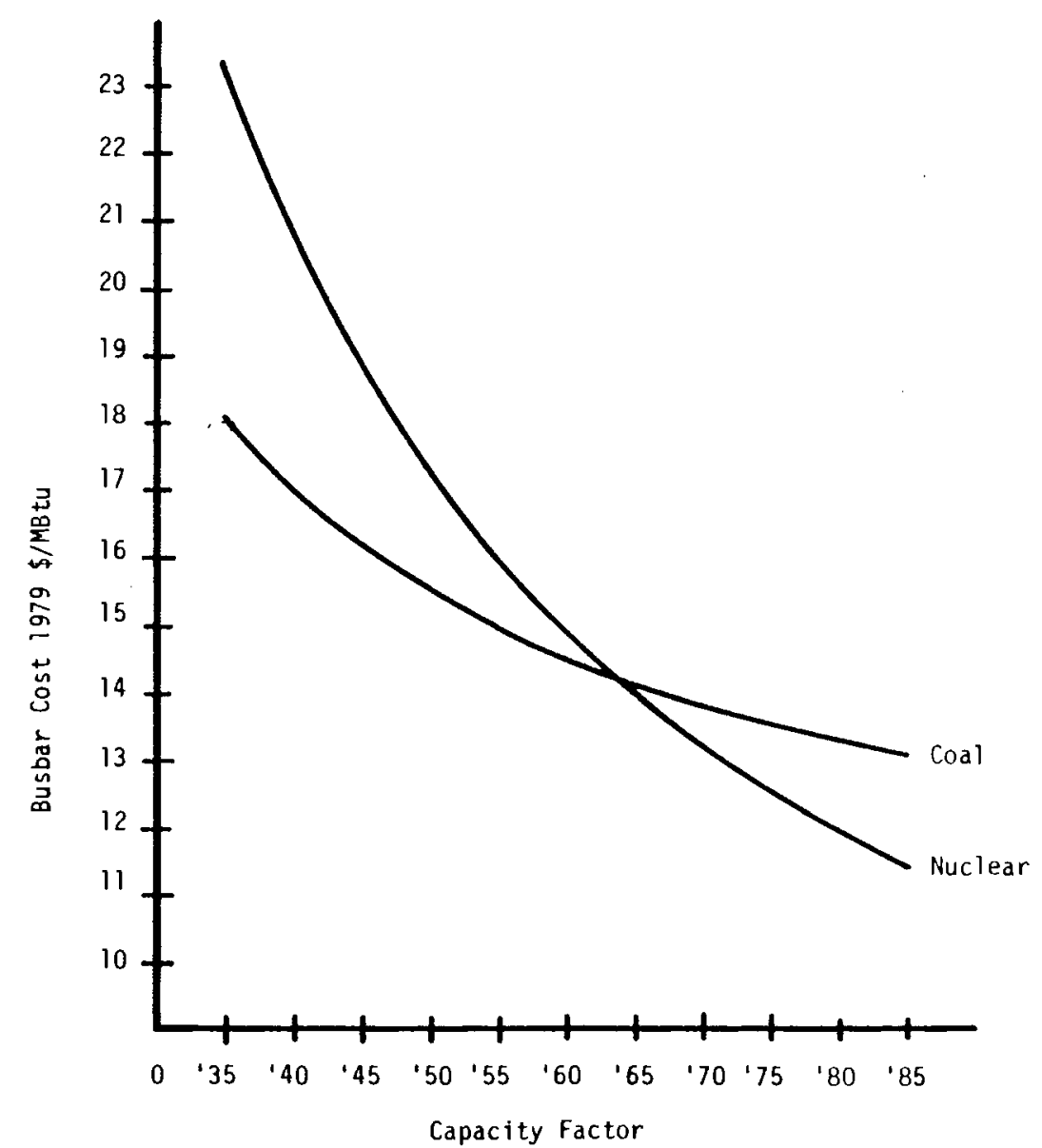

FIGURE 15. Representative Western State: Arizona (Year $=1985)$ 


\section{Alternative Coal Price Scenarios}

Two alternative estimates of delivered-coal prices are used to indicate the sensitivity of the predicted busbar costs to differing coal prices. The two scenarios represent cases of higher or lower delivered-coal prices than the mid-range case used in the marginal cost estimates.

These alternative coal price projections are developed from DOE/EIA delivered-coal price projections (1979a). The DOE/EIA projected coal prices are based on five different supply and demand configurations (Projection Series A through E). The mid-range case (Series $C$ ), corresponding to a midrange supply of and demand for coal, is used as the baseline in this study. The alternative price projections reflect a low supply of and a high demand for coal resulting in a high coal price, and a high supply of and low demand for coal which produces a low coal price. These two scenarios correspond to the DOE/EIA Projection Series $B$ and $D$, respectively.

Using the DOE/EIA Series B and D projected coal prices for 1985, 1990, and 1995 (1979b, Table 30), and the actual 1977 price (1979a, p. 233) as data points, an equation is estimated for the annual trend in each of the $10 \mathrm{DOE}$ Regions for the high and low coal price scenarios. A logarithmic curve of the same form used to project coal prices for the base case is estimated for the high and low coal price scenarios.

The estimated intercept (a) and slope (b) for each of the 10 Regional equations for the high and low price scenarios are presented in Table 8. The DOE/EIA data were inflated to 1979 dollars using the Producer Price Index and converted into mills/kWh using a heat rate of $10,400 \mathrm{Btu} / \mathrm{kWh}$. Figure 16 depicts the projected delivered coal prices for DOE Region 1 resulting from each of the three scenarios for 1980 through 1995. While each Region has different price projections for each of the scenarios, the figure indicates the relationship of projected prices for the high and low price scenarios to the base or mid-range scenario.

Alternative Nuclear Fuel Cost Projections

To analyze the sensitivity of the predicted cost of nuclear generated electricity to nuclear fuel costs, three alternative price scenarios are 
TABLE 8. Coal Price Equation Coefficients for Two Price Scenarios Estimated Using a Logarithmic Form(a) (1979 mills/kWh)

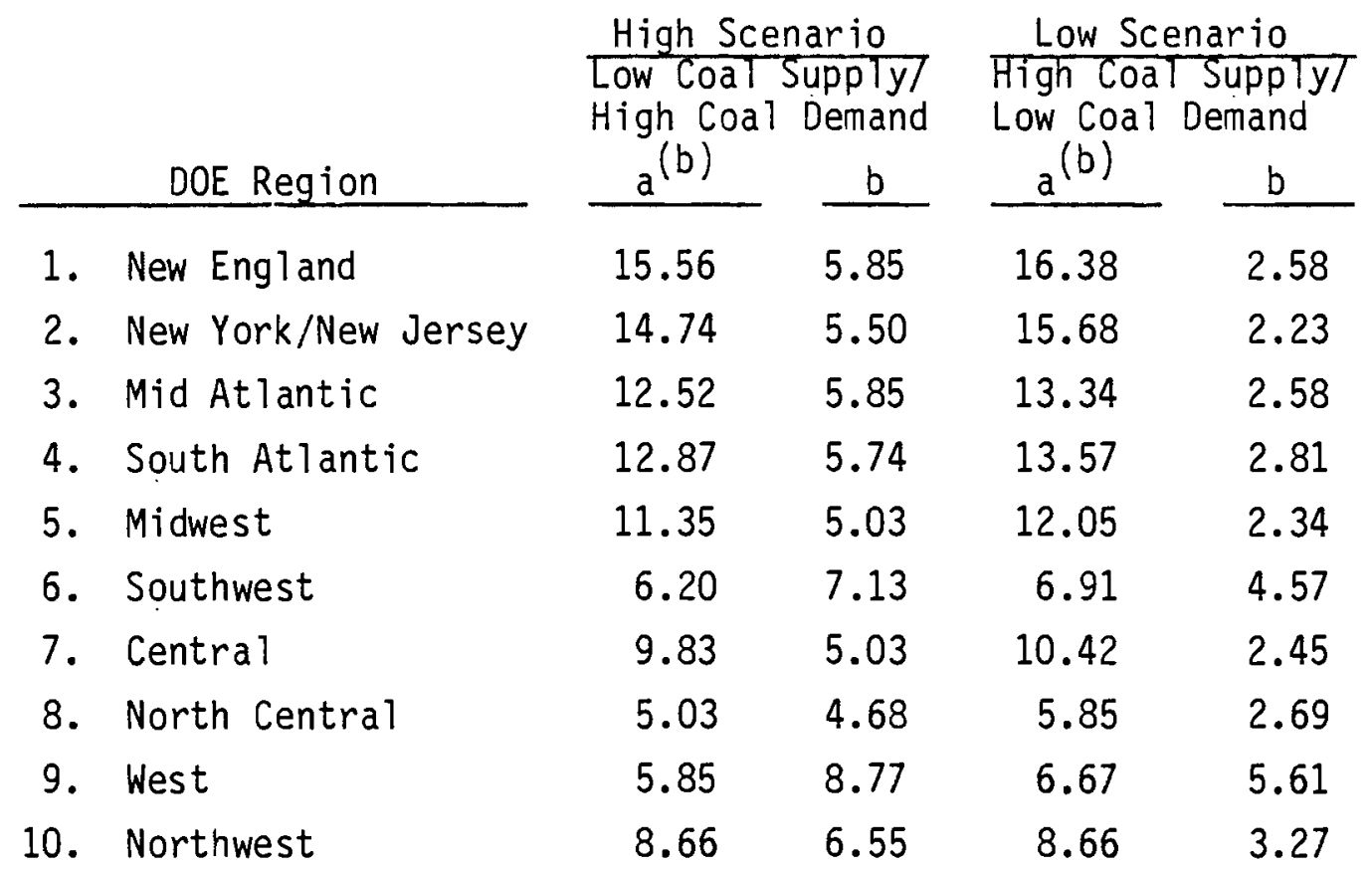

(a) Developed from DOE/EIA data (1979b, Table 30) for Projection Series B and Series D.

(b) This term is an estimated 1977 coal cost per kWh generated and should not equal the 1977 delivered coal price.

used. The three scenarios include a high and a low fuel cost, both without fuel reprocessing, and a scenario which includes fuel reprocessing.

Nuclear fuel cost projections made by EPRI (1979, pp. 6.9-6.14) are used to develop the various price scenarios. Nuclear fuel costs were estimated by EPRI for both the reprocessing and no-reprocessing cases with a cost range of $\pm 12.5 \%$ to reflect uncertainty. The mid-range nuclear fuel cost estimates without reprocessing are used as the base price projections in estimating Regional marginal costs. For the high and low fuel price scenarios, the estimated annual baseline price for nuclear fuel is increased by $12.5 \%$ or lowered by $12.5 \%$, respectively. The high, mid-range or baseline, and the low fuel price scenarios for the no-reprocessing case are depicted in Figure 17. 


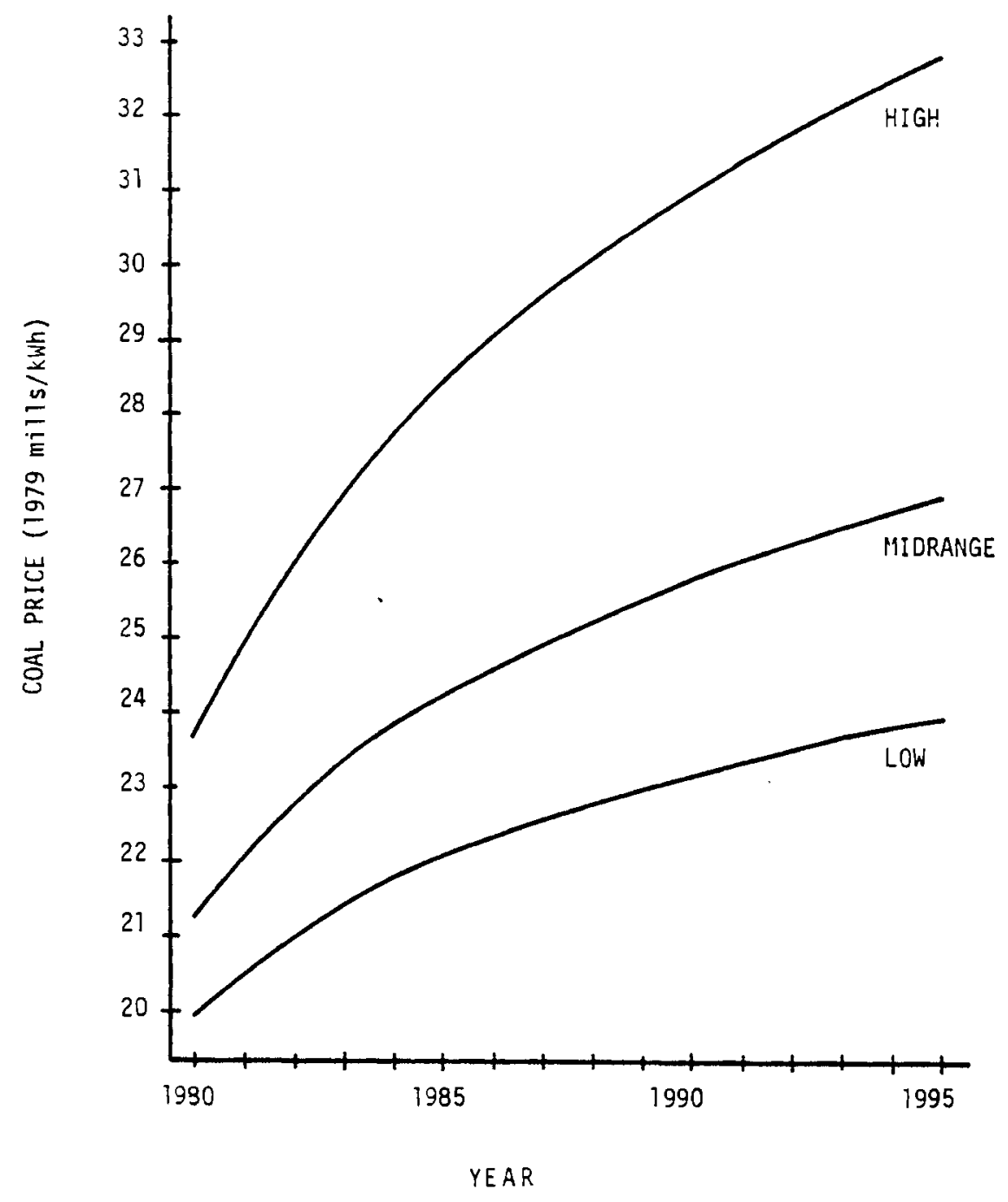

FIGURE 16. Coal Price Projections for the Three Scenarios (DOE Region 1) 
For the nuclear fuel price scenario with reprocessing, it is assumed that a nuclear plant coming on line prior to 1990 would not have a reprocessing fuel cost alternative. This assumption was made because EPRI indicated that nuclear fuel reprocessing could not occur before 1990. From 1990 on, a nuclear plant coming on line is assumed to incur the lower fuel cost associated with the availability of reprocessing. The annual price escalation rate for the reprocessing case is lower than the no-reprocessing case because the value of the plutonium gained from fuel reprocessing offsets the overall fuel cost. Consequently, the reprocessing price scenario uses the baseline nuclear fuel cost equation until 1990 and from 1990 on, the fuel cost equation is:

$$
\text { Nuc Fuel Cost }{ }_{i}(1979 \mathrm{mills} / \mathrm{kWh})=6.98(1.0105)^{\left(\text {Year }_{i}-1989\right)}
$$

where:

$i=$ year for which the nuclear fuel cost is to be estimated, 1990 through 1995
$6.98=1989$ estimated fuel cost in $1979 \mathrm{mills} / \mathrm{kWh}$
1.0105 = escalation factor with a real annual escalation rate of $1.05 \%$.

The nuclear fuel price scenario for the reprocessing case is also depicted in Figure 17. Busbar costs are approximately 2\% lower after 1990 with reprocessing than wi thout.

\section{Comparison of Coal and Nuclear Cost}

Table 9 shows the changes in nuclear busbar costs for the alternative fuel price scenarios. Because of the high rate of increase in nuclear capital costs, changes in fuel prices show a decreasing proportional effect over time. In general, nuclear busbar costs are less responsive to fuel price variation than are the busbar costs of coal which are given in Table 10. In 1985, the high and low nuclear fuel price scenarios fall within the busbar cost ranges of both the high and low coal price scenarios. In 1990, the low nuclear fuel price scenario results in higher busbar costs overall than the low coal price scenario. Then, in 1995, the low nuclear fuel price scenario 


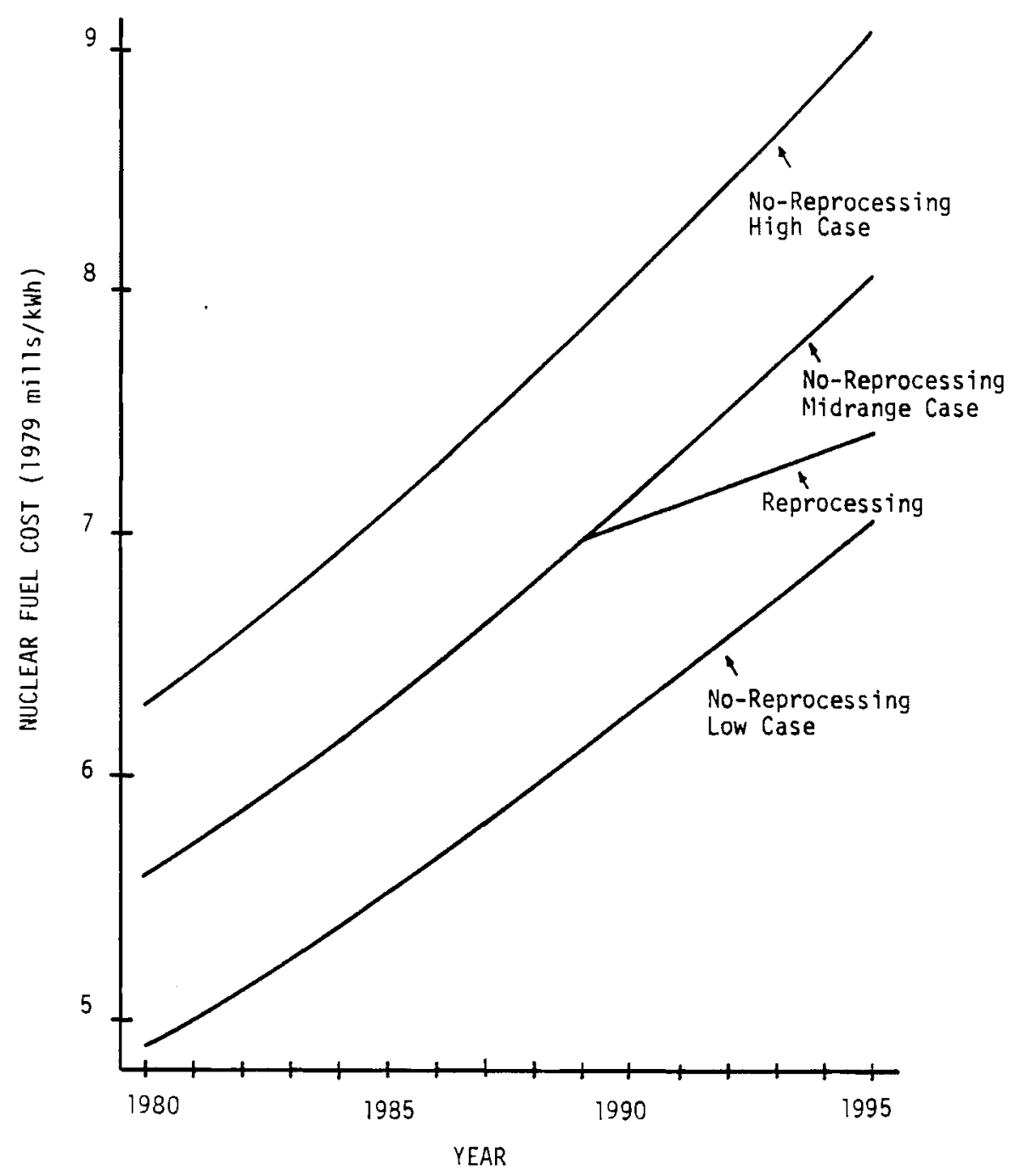

FIGURE 17. Nuclear Fuel Price Projections for the Four Scenarios (National Average) 
TABLE 9. Nuclear Busbar Cost Sensitivity to Fuel Price Scenarios (1979\$/MBtu)

$\frac{1985 \text { Price Scenarios }}{\text { Base- }} \frac{1990 \text { Price Scenarios }}{\text { Base- }} \frac{1995 \text { Price Scenarios }}{\text { Base- }}$ High line Low High line Low High line Low

$\begin{array}{llllllllll}\text { Northeast } & 14.79 & 14.56 & 14.33 & 17.66 & 17.40 & 17.14 & 20.59 & 20.29 & 20.00\end{array}$

All Other

Regions

$\begin{array}{lllllllll}14.24 & 14.01 & 13.78 & 17.11 & 16.85 & 16.59 & 20.04 & 19.74 & 19.44\end{array}$

TABLE 10. Coal Busbar Cost Sensitivity to Fuel Price Scenarios (1979\$/MBtu)

1985 Price Scenarios Base-

DOE Region

Region 1

Region 2

Region 3

Region 4

Region 5

Region 6

Region 7

Region 8

Region 9

Region 10

High line Low

16.90

16.59

16.21

15.48

15.37

14.27

14.93

13.04

15.91

15.30
15.68

15.40

14.99

14.48

14.45

13.42

14.05

12.27

14.84

14.45
1990 Price Scenarios Base-

High line Low

$\begin{array}{lll}18.54 & 17.03 & 16.26\end{array}$

$18.19 \quad 16.71$

15.93

17.86

16.35

15.57

17.11

15.87

15.05

$15.76 \quad 15.03$

13.84

16.91

15.02

12.82

16.08

13.45

16.47

15.38

12.00

14.54

14.12

17.94

13.19

17.04

13.57

14.30

14.66

16.61

13.24

15.74

15.97

14.50

1995 Price Scenarios

Base-

High line Low

$\begin{array}{lll}19.99 & 18.28 & 17.41\end{array}$

19.61

17.93

17.06

19.30

17.59

16.72

18.55

17.14

16.23

$\begin{array}{lll}18.28 & 16.97 & 16.17\end{array}$

$\begin{array}{lll}17.64 & 16.44 & 15.93\end{array}$

$\begin{array}{lll}17.85 & 16.60 & 15.80\end{array}$

$\begin{array}{lll}15.88 & 14.77 & 14.40\end{array}$

$\begin{array}{lll}19.65 & 18.14 & 17.16\end{array}$

$\begin{array}{lll}18.54 & 17.33 & 15.72\end{array}$

results in higher busbar costs than the high coal price scenario in all but three DOE Regions. Thus, the range of likely nuclear cost is moving above and out of the range of likely coal cost.

NO $x$ Scrubbers

The last parameter examined in the sensitivity analysis is $\mathrm{NO}_{x}$ scrubbers, which affect both the capital and operating costs of coal-fired units. Data for capital and operating and maintenance costs for $\mathrm{NO}_{\mathrm{x}}$ scrubbers is obtained from previous research (Rosenberg et al. 1978). This 
data is used to derive an average capital cost of $\$ 36 / \mathrm{kW}$ for $\mathrm{NO}_{\mathrm{x}}$ scrubbers and an average operating and maintenance cost of $\$ 2.55 \mathrm{mills} / \mathrm{kWh}$. When these costs are added to busbar costs (assuming $\mathrm{NO}_{x}$ scrubbers will be introduced in 1990) the results indicate that both the capital and busbar costs for coal-fired units will rise by about $5 \%$ in 1990.

Summary and Conclusions

Assumptions regarding carrying charge rates, capacity factors and fue 1 prices determine the cost of power from coal or nuclear plants in each DOE Region and time period. Because of the higher capital cost and lower operating cost of nuclear units relative to coal units, a high percentage of capacity utilization over time is necessary to make nuclear units cost competitive. This has implications for both the planning and operating phases of electricity generation. If demand is insufficient to fully utilize available capacity, utilities will reduce use of existing coal plants rather than nuclear. In planning to add additional baseload capacity, it appears that a utility faces more financial risk in installing a nuclear unit than a coal unit in that if demand growth is insufficient to fully utilize the new capacity, the financial loss would be greater for a nuclear unit. This would tend to make utility planners more cautious in installing additional nuclear baseload capacity than they would be in installing additional coal capacity. Another major impact on costs results from varying carrying charge rates. The higher capital costs of nuclear units generally cause nuclear plants to have lower busbar costs than coal at carrying charge rates of from $10 \%$ to $15 \%$. However, because of regional differences in capital costs and coal prices, the interest rate at which the crossover point occurs for nuclear and coal busbar costs varies considerably by DOE Region. Fuel costs, while potentially having important regional effects on the relative busbar costs of coal and nuclear units, are not generally as important in determining costs as the capacity factors and carrying charge rates. 


\section{BIBLIOGRAPHY}

Atomic Industrial Forum. 1980. "U.S. Nuclear Power Plants: Construction Progress." Nuclear Industry. 27(2):28-29.

Atomic Industrial Forum, Inc. 1979. "1978 Economic Survey Results." News Release, Washington, DC.

Bechtel Power Corp. 1977. Coal-Fired Power Plant Capital Cost Estimates. EPRI AF-342, Electric Power Research Institute, Palo A7to, California.

Bennett, R. R. and S. J. Kettler. 1978. "Dramatic Changes in the Cost of Nuclear and Fossil-Fueled Plants." Ebasco Services Inc.

Bergstrom, R. N. and W. W. Brandfon. 1979. "Trends in Electric Generating Costs." paper presented at WATTEC Conference, February 21, 1979, Knoxville, Tennesse.

Berman, I. M. 1980. "New Generating Capacity: When, Where and by Whom." Power Engineering. 84(4):70-78.

Budwani, R. N. 1980. "Power Plant Capital Cost Analysis." Power Engineering. $84(5): 62-70$.

Chapman, D. August 14, 1979. "Decommissioning, Taxation, and Nuclear Power Cost." Test imony before the Subcommittee on Energy, Committee on Resources, Land Use, and Energy, California State Assembly on the Economic Implications of the Three Mile Island Accident for California, Hearing, Los Angeles, California.

Congressional Research Service. 1979. Federal Government Incentives to Coal and Nuc lear Energy. A study for the Subcommittee on Energy and Power, Committee on Interstate and Foreign Commerce, U.S. House of Representatives, Committee Print 96-IFC 20, U.S. Government Printing Office, Washington DC.

Edison Electric Institute. 1977. Statistical Year Book of the Electric Utility Industry for 1976. EEI Publication No. 77-37. New York.

Electric Power Research Institute. 1979. Technical Assessment Guide. EPRI PS-1201-SR, Special Report. Palo Alto, California.

Environmental Protection Agency. 1978. EPA Utility FGD Survey: AugustSeptember 1978. EPA, Washington, D.C.

Federal Energy Administration, Energy Information and Analysis. September 1977. U.S. Commercial Nuclear Power: A Status Report. FEEA/B-77/390, NTIS, Springfield, Virginia. 
PEDCO Environmental Inc. 1978. Particulate and Sulfur Dioxide Emission Control Costs for Large Coal-Fired Boilers. PB-281 271, Environmental Protection Agency, NTIS, Springfield, Virginia.

Perl, L. J. 1978. "Estimated Costs of Coal and Nuclear Generation." Paper presented at a New York Society of Security Analysts Seminar, December 12 , 1978, New York.

Reichle, L. F. C. 1979. "The Economics of Nuclear Versus Coal." Paper presented to the Richmond Society of Financial Analysts, October 30, 1979, Richmond, Virginia.

Roberts, J.0., S. M. Davis and D. A. Nash. 1978. Coal and Nuclear: A Comparison of the Cost of Generating Baseload Electricity by Region. PB 289585 NUREG-0480, U.S. Nuc Tear Regulatory Comission, NTIS, Springfield, Virginia.

Rosenberg, H. S. et al. 1978. Control of NOx Emission by Stack Gas

Treatment. Battelle Columbus Laboratories, Columbus, Ohio.

Scherer, Charles R. 1977. Estimating Electric Power System Marginal Costs. North-Holl and Publishing Company, New York, New York.

Schiefelbein, G. F. August 1977. Alternative Electrical Transmission Systems and Their Environmental Impact. Prepared by Battelle Pacific Northwest Laboratory for the U.S. Nuclear Regulatory Cormission, NUREG-0316, NTIS, Springfield, Virginia.

Shan, K. R. 1979. "Capital Cost Escalation and the Choice of Power Stations." Energy Policy. 7(4):321-328.

Smith, R. I., G. J. Konzek, and W. E. Kennedy, Jr. June 1978. Technology, Safety, and Costs of Decommissioning a Reference Pressurized Water Reactor Power Station, prepared by the Battelle Pacific Northwest Laboratory for the U.S. Nuclear Regulatory Commission, NUREG/CR-0130, Vol. 1, NTIS, Springfield, Virginia.

U.S. Department of Energy, Economic Regulatory Administration. 1979. Interim Report on the Performance of 400 Megawatt and Larger Nuclear and Coal-Fired Generating Units. DOE/ERA-0007/2, U.S. Government Printing Office Washington, DC.

U.S. Department of Energy, Energy Information Administration. 1978. Steam Electric Plant Construction Cost and Annual Production Expenses 1977. DOE/EIA-0033/3(77), U.S. Government Printing Office, Washington DC.

U.S. Department of Energy, Energy Information Administration. 1979a. Annual Report to Congress 1978, Volume 3. DOE/EIA-0173/3, U.S. Government Printing Office, Washington DC. 
Federal Power Commission, Bureau of Power. 1976. Factors Affecting the Electric Power Supply 1980-85. FPC, Washington, DC.

Federal Power Commission, Bureau of Power. 1977. Status of Flue Gas Desulfurization Applications in the United States: A Technological Assessment Report in Full. U.S. Department of Commerce, NTIS, Washington, D.C.

Ferguson, J. S. 1978. "A Case for Funding Nuclear Plant Decommissioning Cost." Power Engineering 82(12):53-56.

Friedlander, G. D. 1977. "20th Steam Station Cost Survey." Electrical World. $188(9): 43-58$.

Gibbs and Hill, Inc. 1980. "Economic Comparison of Coal and Nuclear Electric Power Generation." Atomic Industrial Forum, Inc. Washington, DC.

Haskins, J. P., R. J. Nesse and T. J. Secrest. 1980. "Capital Cost Escalation in Coal-Fired Power Plants." Paper presented to the Western Economic Association, June 16, 1980, San Diego, California.

Hunter, S. R. 1980. "Long-run Marginal Costs Lower Than Average Costs." Public Utilities Fortnightly. 105(1):17-19.

Kennedy, W. J. L. and R. M. Campbe11. 1979. "The Economics of Nuclear Power." Paper presented at the Atomic Industrial Forum, Inc. Conference on Nuclear Power and the Public, February 26, 1979, Kansas City, Missouri.

Lyons, J. W. 1979. "Optimizing Designs of Fossil-Fired Generating Units". Power Engineering. 83(2):50-56.

Manion, W. J. and T. S. LaGuardia. 1976. An Engineering Evaluation of Nuclear Power Reactor Decommisioning Alternatives, Summary Report. AIF/NESP-009SR. Prepared by Automation Industries, Inc. for the National Environmental Studies Project of the Atomic Industrial Forum, Inc., Washington, DC.

Mooz, W. E. 1978. Cost Analysis of Light Water Reactor Power Plants. R-2304-DOE, Rand Corp., Santa Monica, California.

Murphy, T. 1980. Trends in The Capacity Utilization and Fuel Consumption of Electric Utility Power Plants, 1970-1978. DOE/EIA-0184/32. U.S. Department of Energy, Energy Information Administration, Washington, DC.

National Journal. 1980. 12(18):717.

Office of Air Quality Planning and Standards. Electric Utility Steam Generating Units. EPA-450/2-78-007a, U.S. Environmental Protection Agency, Research Triangle Park, North Carolina. 
U.S. Department of Energy, Energy Information Administration. 1979b. Annual Report to Congress 1978, Volume 3, Supplement 1. DOE/EIA-0173/3-S1, U.S. Government Printing Office, Washington DC.

U.S. Department of Energy, Energy Information Administration. 1979c. Cost and Quality of Fuels for Electric Utility Plants - 1978. DOE/EIA-0191(78), U.S. Government Printing Office, Washington DC.

U.S. Department of Energy, Energy Information Administration. 1979d. Inventory of Power Plants in the United States-April 1979. DOE/EIA-0095, U.S. Government Printing Office, Washington, DC.

U.S. Department of Energy, Energy Information Administration. 1979e.

Statistics of Privately Owned Electric Utilities in the United States - 1978, Classes A \& B Companies. DOE/EIA-0044(78), NTIS, Springfield, Virginia.

U.S. Department of Energy, Energy Information Administration. May 1980. Monthly Energy Review. DOE/EIA 0035/05(80), U.S. Government Printing Office, Washington D.C.

Uri, N. D. 1975. Towards An Efficient Allocation of Electrical Energy: An Essay in Applied Welfare Economics. D.C. Heath and Company, Lexington, Massachusetts.

Whitman, Requardt, and Associates. 1979. The Handy-Whitman Index of Water Utility Construction Costs. Bulletin No. 109. Baltimore, Maryland. 


\section{APPENDIX A}

ESTIMATES OF NEW GENERATING CAPACITY COST

PER KW FOR COAL AND NUCLEAR UNITS BY STATE 
TABLE A.1. DOE Region 1. New Generating Capacity Cost per kW for Coal and Nuclear Plants by State, 1980-1995(a)

\begin{tabular}{|c|c|c|c|c|c|c|}
\hline \multirow[b]{2}{*}{ Year } & Connecticut & Maine & Massachusetts & New Hampshire & Rhode Island $(\mathrm{b})$ & Vermont $(b)$ \\
\hline & Coal Nuclear & Coal Nuclear & Coal Nuclear & Coal Nuclear & Coal Nuclear & Coal Nuclear \\
\hline \multicolumn{7}{|l|}{1980} \\
\hline \multicolumn{7}{|l|}{1981} \\
\hline \multicolumn{7}{|l|}{1982} \\
\hline 1983 & & & & 1206 & & \\
\hline 1984 & & & 1300 & & & \\
\hline 1985 & & & & 1325 & & \\
\hline 1986 & 1378 & 656 & & & & \\
\hline \multicolumn{7}{|l|}{1987} \\
\hline \multicolumn{7}{|l|}{1988} \\
\hline \multicolumn{7}{|l|}{1989} \\
\hline \multicolumn{7}{|l|}{1990} \\
\hline \multicolumn{7}{|l|}{1991} \\
\hline \multicolumn{7}{|l|}{1992} \\
\hline \multicolumn{7}{|l|}{1993} \\
\hline \multicolumn{7}{|l|}{1994} \\
\hline 1995 & & & & & & \\
\hline
\end{tabular}

(a) $1979 \$ / \mathrm{kW}$.

(b) No plans to add coal or nuclear capacity have been announced. 
TABLE A.2. DOE Region 2. New Generating Capacity Cost per $\mathrm{kW}$ for Coal and Nuclear

Plants by State, 1980-1995(a)

New Jersey New York

\begin{tabular}{llllll} 
Year & \multicolumn{1}{c}{ Coal } & Nuclear & & Coal & Nuclear \\
1980 & & & & 1266 \\
1981 & & & & \\
\hline 1986 & & & & \\
1983 & & 1161 & & 1194 \\
\hline 1984 & & 1336 & 528 & \\
1985 & & & & \\
\hline 1986 & & 1464 & & \\
1987 & 1001 & & 551 & \\
\hline 1988 & & & 563 & 1455 \\
1989 & & & & \\
\hline 1990 & 604 & & & \\
1991 & & & & \\
\hline 1992 & & & & \\
1993 & & & & \\
\hline 1994 & & & & \\
1995 & & & & \\
\hline
\end{tabular}

(a) $1979 \$ / \mathrm{kW}$. 
TABLE A.3. DOE Region 3. New Generating Capacity Cost per kW for Coal and Nuclear Plants by State, 1980-1995(a)

\begin{tabular}{|c|c|c|c|c|c|c|c|c|c|c|}
\hline \multirow[b]{2}{*}{ Year } & \multicolumn{2}{|c|}{ Delaware } & \multicolumn{2}{|c|}{ Maryland } & \multirow{2}{*}{\multicolumn{2}{|c|}{$\begin{array}{l}\text { Pennsylvania } \\
\text { Coal Nuclear }\end{array}$}} & \multicolumn{2}{|c|}{ Virginia } & \multirow{2}{*}{\multicolumn{2}{|c|}{$\begin{array}{l}\text { West Virginia } \\
\text { Coal Nuclear }\end{array}$}} \\
\hline & Coal & Nuclear & Coal & Nuclear & & & Coal & Nuclear & & \\
\hline 1980 & 618 & & & & 473 & & & & 446 & \\
\hline 1981 & & & & & & 1086 & & & & \\
\hline 1982 & & & & & & 1145 & & & & \\
\hline 1983 & & & & & & 1246 & & 1348 & & \\
\hline 1984 & & & & & 590 & 1489 & & 1423 & & \\
\hline 1985 & & & 542 & & 591 & 1412 & & & & \\
\hline 1986 & & & & 1341 & 584 & & & & & \\
\hline 1987 & & & 641 & & & & 554 & & & \\
\hline 1988 & & & & & 653 & & & & & \\
\hline 1989 & & & & & & & & & & \\
\hline 1990 & & & & & & & & & & \\
\hline 1991 & & & & & 616 & & & & & \\
\hline 1992 & & & & & 629 & & & & & \\
\hline 1993 & & & & & & & & & & \\
\hline 1994 & & & & & & & & & & \\
\hline 1995 & & & & & & & & & & \\
\hline
\end{tabular}

(a) $1979 \$ / \mathrm{kW}$. 
TABLE A.4. DOE Region 4. New Generating Capacity Cost per kW for Coal and Nuclear Plants by State, 1980-1995(a)

\begin{tabular}{|c|c|c|c|c|c|c|c|c|c|c|c|c|c|c|}
\hline \multirow[b]{2}{*}{ Year } & \multicolumn{2}{|c|}{ Alabama } & \multicolumn{2}{|c|}{ Florida } & \multicolumn{2}{|c|}{ Georgia } & Kentucky & \multicolumn{2}{|c|}{ Mississippi } & \multirow{2}{*}{$\begin{array}{l}\text { North } \\
\text { Coal }\end{array}$} & \multirow{2}{*}{$\begin{array}{r}\text { Carolina } \\
\text { Nuclear }\end{array}$} & \multirow{2}{*}{\multicolumn{2}{|c|}{$\begin{array}{l}\text { South Carol ina } \\
\text { Coal Nuclear }\end{array}$}} & Tennessee \\
\hline & Coal & Nuclear & Coal & Nuclear & Coal & Nuclear & Coal Nuclear & Coal & Nuclear & & & & & Coal Nuclear \\
\hline 1980 & & 1138 & & & & & 497 & & & 428 & & 594 & 1084 & 925 \\
\hline 1981 & 446 & & 633 & & & & 487 & 490 & 942 & & 982 & 625 & 989 & 965 \\
\hline 1982 & 460 & & 479 & & 430 & & & & & 456 & & & & \\
\hline 1983 & 474 & 1032 & 507 & 1414 & & & 586 & & & & & 573 & 1102 & \\
\hline 1984 & & & 510 & & 452 & 1153 & 531 & & 1100 & & 1374 & & & 1108 \\
\hline 1985 & 656 & & 563 & & 463 & 1209 & 606 & 506 & 1110 & 497 & & 601 & 1129 & 1161 \\
\hline 1986 & & & 552 & & 906 & & 518 & 580 & & & 1517 & & & 1214 \\
\hline 1987 & 510 & & 548 & & 486 & & 539 & 535 & 1209 & & & 643 & 1231 & \\
\hline 1988 & 523 & & & & & & & & & & 1439 & 683 & & 1320 \\
\hline 1989 & & & 578 & & & & 572 & & & & & & 1332 & 1373 \\
\hline 1990 & 548 & & & & & & & & & & 1804 & & & \\
\hline 1991 & & & & & & & & & & & & & & \\
\hline 1992 & & & & & & & & & & & & & & \\
\hline 1993 & & & & & & & & & & & & & & \\
\hline 1994 & & & & & & & & & & & & & & \\
\hline 1995 & 835 & & & & & & & & & & & & & \\
\hline
\end{tabular}

\section{(a) $1979 \$ / \mathrm{kW}$.}


TABLE A.5. DOE Region 5. New Generating Capacity Cost per kW for Coal and Nuclear Plants by State, 1980-1995(a)

\begin{tabular}{|c|c|c|c|c|c|c|c|c|c|c|}
\hline \multirow[b]{2}{*}{ Year } & \multicolumn{2}{|c|}{ Illinois } & \multicolumn{2}{|c|}{ Indiana } & \multicolumn{2}{|c|}{ Michigan } & Minnesota & \multicolumn{2}{|c|}{ Ohio } & \multirow{2}{*}{ Wiscons in } \\
\hline & Coal & Nuclear & Coal & Nuclear & Coal & Nuclear & Coal Nuclear & Coal & Nuclear & \\
\hline 1980 & & 962 & & & 487 & & 557 & & & 532 \\
\hline 1981 & & 1010 & 610 & & & & & 532 & 1225 & \\
\hline 1982 & 571 & 1064 & 500 & 1092 & 1894 & 1040 & & & & 645 \\
\hline 1983 & & & 578 & & 548 & & & & 1167 & 728 \\
\hline 1984 & & & & 1423 & 563 & 1492 & 530 & & & \\
\hline 1985 & 845 & & 803 & & & 2410 & & 591 & 1281 & 778 \\
\hline 1986 & 925 & & & & & & 664 & 637 & & 1100 \\
\hline 1987 & 669 & 1354 & 648 & & & & 567 & 798 & & \\
\hline 1988 & & 1524 & & & & & & & & \\
\hline 1989 & 721 & & & & & & 591 & & & \\
\hline 1990 & & & & & & & & 842 & & \\
\hline 1991 & & & & & & & & & & \\
\hline 1992 & & & & & & & & & & \\
\hline 1993 & & & & & & & & & & \\
\hline 1994 & & & & & & & & & & \\
\hline 1995 & & & & & & & & & & \\
\hline
\end{tabular}

(a) $1979 \$ / \mathrm{kW}$. 
TABLE A.6. DOE Region 6. New Generating Capacity Cost per kW for Coal and Nuclear Plants by State, 1980-1995(a)

\begin{tabular}{|c|c|c|c|c|c|c|c|c|c|c|}
\hline \multirow[b]{2}{*}{ Year } & \multicolumn{2}{|c|}{ Arkansas } & \multicolumn{2}{|c|}{ Louisiana } & \multirow{2}{*}{$\frac{\mathrm{New}}{\mathrm{Coal}}$} & \multirow{2}{*}{$\begin{array}{l}\text { Mexico } \\
\text { Nuclear }\end{array}$} & \multicolumn{2}{|c|}{ Oklahoma } & \multicolumn{2}{|c|}{ Texas } \\
\hline & Coal & Nuclear & Coal & Nuclear & & & Coal & Nuclear & Coal & Nuclear \\
\hline 1980 & 436 & & 468 & & & & 429 & & 428 & \\
\hline 1981 & 450 & & 486 & 1011 & & & 456 & & 442 & 1020 \\
\hline 1982 & & & 491 & & 513 & & 494 & & 473 & \\
\hline 1983 & 478 & & 521 & & & & 484 & & 487 & 1097 \\
\hline 1984 & & & & & 701 & & & 1198 & 486 & 1130 \\
\hline 1985 & 506 & & 557 & 1356 & & & 548 & & 517 & 1220 \\
\hline 1986 & & & 534 & 1422 & & & 571 & 1316 & 531 & 1240 \\
\hline 1987 & & & & & & & 594 & & 573 & \\
\hline 1988 & & & 549 & & & & 617 & & 617 & \\
\hline 1989 & & & & & & & & & & \\
\hline 1990 & & & & & 685 & & & & & \\
\hline 1991 & & & & & & & & & & \\
\hline 1992 & & & & & 725 & & & & & \\
\hline 1993 & & & & & & & & & & \\
\hline 1994 & & & & & & & & & & \\
\hline 1995 & & & & & & & & & & \\
\hline
\end{tabular}

(a) $1979 \$ / \mathrm{kW}$. 
TABLE A.7. DOE Region 7. New Generating Capacity Cost per kW for Coal and Nuclear Plants by State, 1980-1995(a)

\begin{tabular}{|c|c|c|c|c|c|c|}
\hline \multirow[b]{2}{*}{ Year } & Iowa & \multicolumn{2}{|c|}{ Kansas } & \multicolumn{2}{|c|}{ Missouri } & Nebraska \\
\hline & Coal Nuclear & Coal & Nuclear & Coal & Nuclear & Coal Nuclear \\
\hline 1980 & & 593 & & 498 & & \\
\hline 1981 & 511 & & & 635 & & 698 \\
\hline 1982 & 1269 & 618 & & 941 & 1054 & \\
\hline 1983 & 566 & & 1138 & & & \\
\hline 1984 & & 656 & & & & \\
\hline 1985 & 649 & & & & & \\
\hline 1986 & & & & 1298 & & 612 \\
\hline 1987 & & & & 593 & 1340 & \\
\hline 1988 & & & & & & \\
\hline 1989 & & & & & & \\
\hline 1990 & & & & & & \\
\hline 1991 & & & & & & \\
\hline 1992 & & & & & & \\
\hline 1993 & & & & & & \\
\hline 1994 & & & & & & \\
\hline 1995 & & & & & & \\
\hline
\end{tabular}

(a) $1979 \$ / \mathrm{kW}$. 
TABLE A.8. DOE Region 8. New Generating Capacity Cost per kW for Coal and Nuclear Plants by State, 1980-1995(a)

\begin{tabular}{|c|c|c|c|c|c|c|c|c|c|c|}
\hline \multirow[b]{2}{*}{ Year } & Colorado & \multicolumn{2}{|c|}{ Montana } & \multirow{2}{*}{$\begin{array}{l}\text { North } \\
\text { Coal }\end{array}$} & \multirow{2}{*}{$\begin{array}{l}\text { Dakota } \\
\text { Nuclear }\end{array}$} & \multirow{2}{*}{$\begin{array}{l}\text { Dakota } \\
\text { Nuclear }\end{array}$} & \multicolumn{2}{|c|}{ Utah } & \multicolumn{2}{|c|}{ Wyoming } \\
\hline & Coal Nuclear & Coal & Nuclear & & & & Coal & Nuclear & Coal & Nuclear \\
\hline 1980 & 558 & & & 559 & & & 654 & & 559 & \\
\hline 1981 & 604 & & & 656 & & & & & & \\
\hline 1982 & 724 & 510 & & & & & & & 595 & \\
\hline 1983 & 663 & 523 & & 691 & & & 825 & & 817 & \\
\hline 1984 & 609 & & & & & & 1021 & & & \\
\hline 1985 & 611 & & & & & & 802 & & & \\
\hline 1986 & 728 & & & 703 & & & & & 703 & \\
\hline 1987 & 749 & & & & & & 560 & & & \\
\hline 1988 & & & & 743 & & & 572 & & 743 & \\
\hline 1989 & & & & & & & 584 & & & \\
\hline 1990 & & & & & & & & & & \\
\hline 1991 & & & & & & & & & & \\
\hline 1992 & & & & & & & & & & \\
\hline 1993 & & & & & & & & & & \\
\hline 1994 & & & & & & & & & & \\
\hline 1995 & & & & & & & & & & \\
\hline
\end{tabular}

(a) $1979 \$ / \mathrm{kW}$. 
TABLE A.9. DOE Region 9. New Generating Capacity Cost per kW for Coal and Nuclear Plants by State, 1980-1995(a)

\begin{tabular}{|c|c|c|c|c|c|c|}
\hline \multirow[b]{2}{*}{ Year } & \multicolumn{2}{|c|}{ Arizona } & \multicolumn{2}{|c|}{ California } & Hawa i ${ }^{(b)}$ & Nevada \\
\hline & Coal & Nuclear & Coal & Nuclear & Coal Nuclear & Coal Nuclear \\
\hline 1980 & 713 & & & 945 & & \\
\hline 1981 & 703 & & & 1002 & & 848 \\
\hline 1982 & & & & & & \\
\hline 1983 & & 1031 & & & & \\
\hline 1984 & & 1082 & & & & 956 \\
\hline 1985 & 845 & & 542 & & & 683 \\
\hline 1986 & & 1185 & 554 & & & 703 \\
\hline 1987 & 901 & & & & & 723 \\
\hline 1988 & & & & & & \\
\hline 1989 & & & & & & \\
\hline 1990 & & & 465 & & & \\
\hline 1991 & & & & & & \\
\hline 1992 & & & & & & \\
\hline 1993 & & & & & & \\
\hline 1994 & & & & & & \\
\hline 1995 & & & & & & \\
\hline
\end{tabular}

(a) $1979 \$ / \mathrm{kW}$.

(b) No plans to add coal or nuclear capacity have been announced. 
,

, 
APPENDIX B

ESTIMATES OF BUSBAR COST PER MBTU FOR ELECTRICITY FROM NEW COAL AND NUCLEAR CAPACITY BY STATE 
TABLE B.1. DOE Region 1. Busbar Cost per MBtu for Electricity from New Coal and Nuclear Plants by State, 1980-1995(a)

\begin{tabular}{|c|c|c|c|c|c|c|c|c|c|c|c|c|}
\hline \multirow[b]{2}{*}{ Year } & \multicolumn{2}{|c|}{ Connecticut } & \multicolumn{2}{|c|}{ Ma ine } & \multicolumn{2}{|c|}{ Massachusetts } & \multicolumn{2}{|c|}{ New Hampshire } & \multicolumn{2}{|c|}{ Rhode Island } & \multicolumn{2}{|c|}{ Vermont } \\
\hline & Coal & Nuclear & Coal & Nuclear & Coal & Nuclear & Coal & Nuclear & Coal & Nuclear & Coal & Nuclear. \\
\hline \multicolumn{13}{|l|}{1980} \\
\hline \multicolumn{13}{|l|}{1981} \\
\hline \multicolumn{13}{|l|}{1982} \\
\hline 1983 & & & & & & & & 13.52 & & & & \\
\hline \multicolumn{13}{|l|}{1984} \\
\hline 1985 & & & & & & 14.46 & & 14.67 & & & & \\
\hline 1986 & & 15.21 & 15.44 & & & & & & & & & \\
\hline \multicolumn{13}{|l|}{1987} \\
\hline \multicolumn{13}{|l|}{1988} \\
\hline \multicolumn{13}{|l|}{1989} \\
\hline \multicolumn{13}{|l|}{1990} \\
\hline \multicolumn{13}{|l|}{1991} \\
\hline \multicolumn{13}{|l|}{1992} \\
\hline \multicolumn{13}{|l|}{1993} \\
\hline \multicolumn{13}{|l|}{1994} \\
\hline $1995^{(t}$ & 17.47 & 19.99 & 17.64 & 19.99 & 17.47 & 19.99 & 17.47 & 19.99 & 17.37 & 19.99 & 17.47 & 19.99 \\
\hline
\end{tabular}

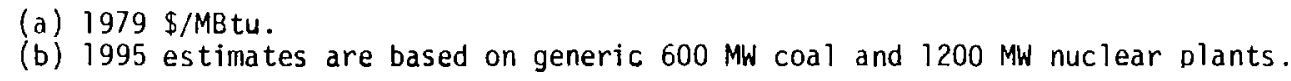


TABLE B.2. DOE Region 2. Busbar Cost per MBtu for Electricity from New Coal and Nuclear Plants by State, 1980-1995(a)

\begin{tabular}{|c|c|c|c|c|}
\hline \multirow[b]{2}{*}{ Year } & \multicolumn{2}{|c|}{ New Jersey } & \multicolumn{2}{|c|}{ New York } \\
\hline & Coal & Nuclear & Coal & Nuclear \\
\hline 1980 & & & & 13.82 \\
\hline \multicolumn{5}{|l|}{1981} \\
\hline \multicolumn{5}{|l|}{1982} \\
\hline 1983 & & 13.13 & & 13.42 \\
\hline 1984 & & 14.69 & 13.85 & \\
\hline \multicolumn{5}{|l|}{1985} \\
\hline 1986 & & 15.93 & & \\
\hline 1987 & 17.80 & & 19.52 & \\
\hline 1988 & & & 14.73 & 16.01 \\
\hline \multicolumn{5}{|l|}{1989} \\
\hline 1990 & 15.26 & & & \\
\hline \multicolumn{5}{|l|}{1991} \\
\hline \multicolumn{5}{|l|}{1992} \\
\hline \multicolumn{5}{|l|}{$\lceil 993$} \\
\hline \multicolumn{5}{|l|}{1994} \\
\hline $1995^{(t}$ & b) 17.13 & 19.99 & 17.13 & 19.99 \\
\hline
\end{tabular}

(a) $1979 \$ /$ MBtu.

(b) 1995 estimates are based on generic $600 \mathrm{MW}$ coal and $1200 \mathrm{MW}$ nuclear plants. 
TABLE B.3. DOE Region 3. Busbar Cost per MBtu for Electricity from New Coal and Nuclear Plants by State, 1980-1995(a)

\begin{tabular}{|c|c|c|c|c|c|c|c|c|c|c|}
\hline \multirow[b]{2}{*}{ Year } & \multicolumn{2}{|c|}{ Delaware } & \multicolumn{2}{|c|}{ Maryland } & \multicolumn{2}{|c|}{ Pennsylvania } & \multicolumn{2}{|c|}{ Virginia } & \multicolumn{2}{|c|}{ West Virginia } \\
\hline & Coal & Nuclear & Coal & Nuclear & Coal & Nuclear & Coal & Nuclear & Coa 1 & Nuclear \\
\hline 1980 & 12.96 & & & & 12.29 & & & & 12.04 & \\
\hline 1981 & & & & & & 12.36 & & & & \\
\hline 1982 & & & & & & 12.93 & & & & \\
\hline 1983 & & & & & & 13.86 & & 14.72 & & \\
\hline 1984 & & & & & 13.84 & 15.99 & & 15.43 & & \\
\hline 1985 & & & 13.53 & & 14.03 & 15.41 & & & & \\
\hline 1986 & & & & 14.89 & 14.17 & & & & & \\
\hline 1987 & & & 14.69 & & & & 14.09 & & & \\
\hline 1988 & & & & & 14.95 & & & & & \\
\hline \multicolumn{11}{|l|}{1989} \\
\hline \multicolumn{11}{|l|}{1990} \\
\hline 1991 & & & & & 15.11 & & & & & \\
\hline 1992 & & & & & 15.33 & & & & & \\
\hline \multicolumn{11}{|l|}{1993} \\
\hline \multicolumn{11}{|l|}{1994} \\
\hline $1995^{(t}$ & b) 16.78 . & 19.99 & 16.78 & 19.99 & 16.85 & 19.99 & 16.76 & 19.44 & 16.83 & 19.99 \\
\hline
\end{tabular}

(a) $1979 \$ / \mathrm{MBtu}$.

(b) 1995 estimates are based on generic $600 \mathrm{MW}$ coal and $1200 \mathrm{MW}$ nuclear plants. 
TABLE B.4. DOE Region 4. Busbar Cost per MBtu for Electricity from New Coal and Nuclear Plants by State, 1980-1995(a)

\begin{tabular}{|c|c|c|c|c|c|c|c|c|c|c|c|c|c|c|c|c|}
\hline \multirow[b]{2}{*}{ Year } & \multicolumn{2}{|c|}{ Alabanı } & \multicolumn{2}{|c|}{ Florida } & \multicolumn{2}{|c|}{ Georgia } & \multicolumn{2}{|c|}{ Kentucky } & \multicolumn{2}{|c|}{ Mississippi } & \multicolumn{2}{|c|}{ North Caralina } & \multicolumn{2}{|c|}{ South Carolina } & \multirow{2}{*}{\multicolumn{2}{|c|}{ Tennessee }} \\
\hline & $\operatorname{coa} T$ & Nuclear & Cod & Nuclear & Coal & Nuclear & Coal. & Nuclear. & Cod 1 & Nuclear & Coal & Nuclear & Coal & NucTear & & \\
\hline 1980 & & 12.74 & & & & & 12.29 & & & & 11.70 & & 12.74 & 12.28 & & 10.93 \\
\hline 1981 & 12.19 & & 13.48 & & & & 12.49 & & 12.49 & 11.14 & & 11.48 & 13.29 & 11.54 & & 11.33 \\
\hline 1982 & 12.54 & & 12.72 & & 12.51 & & & & & & 12.45 & & & & & \\
\hline 1983 & 12.87 & 12.04 & 13.12 & 15.28 & $\ldots$ & & 13.78 & & & & & & 13.43 & 12.04 & & \\
\hline 1984 & & & 13.37 & & 13.09 & 13.14 & 13.54 & & & 12.69 & & 15.01 & & & & 12.76 \\
\hline 1985 & 14.44 & & 13.90 & & 13.35 & 13.69 & 14.36 & & 13.57 & 12.85 & 13.35 & & 14.05 & 13.01 & & 13.28 \\
\hline 1986 & & & 14.03 & & 16.54 & & 13.85 & & 14.21 & & & 16.38 & & & & 13.81 \\
\hline 1987 & 13.90 & & 14.19 & & 13.84 & & 14.25 & & 14.11 & 13.84 & & & 14.71 & 14.02 & & \\
\hline 1988 & 14.14 & & & & & & & & & & & 15.87 & 15.15 & & & 14.86 \\
\hline 1989 & - - & & 14.71 & & & & 14.87 & & & & & . & & 15.05 & - & 15.39 \\
\hline 1990 & 14.61 & & & & & & & & & & & 19.13 & & & & \\
\hline [9]J! & & & & & & 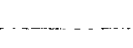 & & $\ldots$ & 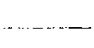 & & & 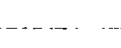 & $\ldots$ & - & 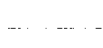 & \\
\hline 1992 & & & & & & & & & & & & & & & & \\
\hline 1993 & & & & & & & & & & & & & & & & \\
\hline $\begin{array}{l}1994 \\
1995\end{array}$ & b) 16.34 & 19.44 & .43 & 19.44 & 39 & 19.44 & .47 & 19.44 & 43 & 19.44 & 16.26 & 19.44 & .30 & 1 & 0 & 19.44 \\
\hline
\end{tabular}

(a) 1979 S/MBtu

(b) 1995 estimates are based on generic $600 \mathrm{MW}$ coal and 1200 MW nuclear plants. 
TABLE B.5. DOE Region 5. Busbar Cost per MBtu for Electricity from New Coal and Nuclear Plants by State, 1980-1995(a)

\begin{tabular}{|c|c|c|c|c|c|c|c|c|c|c|c|c|}
\hline \multirow[b]{2}{*}{ Year } & \multicolumn{2}{|c|}{ Illinois } & \multicolumn{2}{|c|}{ Indiana } & \multicolumn{2}{|c|}{ Michigan } & \multicolumn{2}{|c|}{ Minnesota } & \multicolumn{2}{|c|}{ Ohio } & \multicolumn{2}{|c|}{ Wisconsin } \\
\hline & Coal & Nuclear & Coal & Nuclear & Coal & Nuclear & Coal & Nuclear & Coal & Nuclear & Coal & Nuclear \\
\hline 1980 & & 11.24 & & & 11.78 & & 11.93 & & & & 12.03 & \\
\hline 1981 & & 11.71 & 12.90 & & & & & & 12.10 & 13.54 & & \\
\hline 1982 & 12.84 & 12.24 & 12.60 & 12.48 & 23.41 & 12.04 & & & & & 13.39 & \\
\hline 1983 & & & 13.34 & & 12.74 & & & & & 13.19 & 14.25 & \\
\hline 1984 & & & & 15.43 & 13.02 & 16.01 & 12.73 & & & & & \\
\hline 1985 & 15.46 & & 15.12 & & & 23.89 & & & 13.30 & 14.30 & 14.86 & \\
\hline 1986 & 16.24 & & & & & & 13.92 & & 14.04 & & 17.73 & \\
\hline 1987. & 14.31 & 15.07 & 14.27 & & & & 13.46 & & 15.58 & & & \\
\hline 1988 & & 16.59 & & & & & & & & & & \\
\hline 1989 & 15.06 & & & & & & 13.91 & & & & & \\
\hline 1990 & & & & & & & & & 16.33 & & & \\
\hline 1991 & & & & & & & & & & & & \\
\hline 1992 & & & & & & & & & & & & \\
\hline 1993 & & & & & & & & & & & & \\
\hline 1994 & & . & & & & & & & & & & \\
\hline $1995^{(1}$ & b) 16.29 & 19.44 & 16.33 & 19.44 & 16.10 & 19.44 & 16.00 & 19.44 & 16.03 & 19.99 & 16.31 & 19.44 \\
\hline
\end{tabular}

(a) $1979 \$ / \mathrm{MBtu}$

(b) 1995 estimates are based on generic $600 \mathrm{MW} \mathrm{coal}$ and 1200 MW nuclear plants. 
TABLE B.6. DOE Region 6. Busbar Cost per MBtu for Electricity from New Coa1 and Nuclear Plants by State, 1980-1995(a)

\begin{tabular}{|c|c|c|c|c|c|c|c|c|c|c|}
\hline \multirow[b]{2}{*}{ Year } & \multicolumn{2}{|c|}{ Arkansas } & \multicolumn{2}{|c|}{ Louisiana } & \multicolumn{2}{|c|}{ New Mexico } & \multicolumn{2}{|c|}{ Oklahoma } & \multicolumn{2}{|c|}{ Texas } \\
\hline & Coal & Nuclear & Coal & Nuclear & Coal & Nuclear & Coal & Nuclear & Coal & Nuclear \\
\hline 1980 & 10.33 & & 10.47 & & & & 10.57 & & 10.61 & \\
\hline 1981 & 10.84 & & 11.02 & 11.73 & & & 11.16 & & 11.02 & 11.80 \\
\hline 1982 & & & 11.42 & & 11.63 & & 12.07 & & 11.59 & \\
\hline 1983 & 11.69 & & 11.92 & & & & 11.84 & & 11.87 & 12.59 \\
\hline 1984 & & & & & 13.56 & & & 13.52 & 12.03 & 12.95 \\
\hline 1985 & 12.40 & & 12.70 & 14.94 & & & 12.89 & & 12.50 & 13.78 \\
\hline 1986 & & & 12.81 & 15.57 & & & 13.27 & 14.67 & 12.69 & 14.02 \\
\hline 1987 & & & & & & & 13.63 & & 13.18 & \\
\hline 1988 & & & 13.34 & & & & 13.97 & & 14.03 & \\
\hline 1989 & & & & & & & & & & \\
\hline 1990 & & & & & 14.73 & & & & & \\
\hline 1991 & & & & & & & & & & \\
\hline 1992 & & & & & 15.37 & & & & & \\
\hline 1993 & & & & & & & & & & \\
\hline 1994 & & & & & & & & & & \\
\hline $1995^{(}$ & b) 15.62 & 19.44 & 15.62 & 19.44 & 15.71 & 19.44 & 15.62 & 19.44 & 15.63 & 19.44 \\
\hline
\end{tabular}

(a) $1979 \$ /$ MBtu.

(b) 1995 estimates are based on generic $600 \mathrm{MW}$ coal and $1200 \mathrm{MW}$ nuclear plant. 
TABLE B.7. DOE Region 7. Busbar Cost per MBty for Electricity from New Coal and Nuclear Plants by State, 1980-1995(a)

\begin{tabular}{|c|c|c|c|c|c|c|c|c|}
\hline \multirow[b]{2}{*}{ Year } & \multicolumn{2}{|c|}{ Iowa } & \multicolumn{2}{|c|}{ Kansas } & \multicolumn{2}{|c|}{ Missouri } & \multicolumn{2}{|c|}{ Nebraska } \\
\hline & Coal & Nuclear & Coal & Nuclear & Coal & Nuclear & Coal & Nuclear \\
\hline 1980 & & & 12.14 & & 11.42 & & & \\
\hline 1981 & 11.80 & & & & 12.86 & & 13.21 & \\
\hline 1982 & 17.92 & & 12.82 & & 15.33 & 12.15 & & $\cdot$ \\
\hline 1983 & 12.59 & & & 12.94 & & & & \\
\hline 1984 & & & 13.48 & & & & & \\
\hline 1985 & 13.44 & & & & & & & \\
\hline 1986 & & & & & 19.13 & & 13.43 & \\
\hline 1987 & & & & & 13.48 & 14.95 & & \\
\hline 1988 & & & & & & & & \\
\hline 1989 & & & & & & & & \\
\hline 1990 & & & & & & & & \\
\hline 1991 & & & & & & & & \\
\hline 1992 & & & & & & & & \\
\hline 1993 & & & & & & & & \\
\hline 1994 & & & & & & & & \\
\hline $1995^{(b}$ & 15.57 & 19.44 & 15.93 & 19.44 & 16.01 & 19.44 & 15.73 & 19.44 \\
\hline
\end{tabular}

(a) $1979 \$ /$ MBtu.

(b) 1995 estimates are based on generic $600 \mathrm{MW}$ coal and $1200 \mathrm{MW}$ nuclear plants. 
TABLE B.8. DOE Region 8. Busbar Cost per MBtu for Electricity from New Coal and Nuclear Plants by State, 1980-1995(a)

\begin{tabular}{|c|c|c|c|c|c|c|c|c|c|c|c|c|}
\hline \multirow[b]{2}{*}{ Year } & \multicolumn{2}{|c|}{ Colorado } & \multicolumn{2}{|c|}{ Montana } & \multicolumn{2}{|c|}{ North Dakota } & \multicolumn{2}{|c|}{ South Dakota } & \multicolumn{2}{|c|}{ Utah } & \multicolumn{2}{|c|}{ Wyoming } \\
\hline & Coal & Nuclear & Coal & Nuclear & Coal & Nuclear & Coal & Nuclear & Coal & Nuclear & Coal & Nuclear \\
\hline 1980 & 9.95 & & & & 9.98 & & & & 10.64 & & 9.97 & \\
\hline 1981 & 10.53 & & & & 10.93 & & & & & & & \\
\hline 1982 & 11.64 & & 10.25 & & & & & & & & 10.71 & \\
\hline 1983 & 11.39 & & 10.53 & & 11.60 & & & & 12.66 & & 12.59 & \\
\hline 1984 & 11.23 & & & & & & & & 14.39 & & & \\
\hline 1985 & 11.48 & & & & & & & & 12.80 & & & \\
\hline 1986 & 12.37 & & & & 12.19 & & & & & & 12.20 & \\
\hline 1987 & 12.67 & & & & & & & & 11.42 & & & \\
\hline 1988 & & & & & 12.78 & & & & 11.64 & & 12.78 & \\
\hline 1989 & & & & & & & & & 11.86 & & & \\
\hline 1990 & & & & & & & & & & & & \\
\hline 1991 & & & & & & & & & & & & \\
\hline 1992 & & & & & & & & & & & & \\
\hline 1993 & & & & & & & & & & & & \\
\hline 1994 & & & & & & & & & & & & \\
\hline $1995^{\circ}$ & 13.96 & 19.44 & 14.00 & 19.44 & 13.97 & 19.44 & 13.97 & 19.44 & 13.97 & 19.44 & 13.96 & 19.44 \\
\hline
\end{tabular}

(a) $1979 \$ /$ MBtu.

(b) 1995 estimates are based on generic $600 \mathrm{MW}$ coal and $1200 \mathrm{MW}$ nuclear plants. 
TABLE B.9. DOE Region 9. Busbar Cost per MBtu for Electricity from New Coal and Nuclear Plants by State, 1980-1995(a)

\begin{tabular}{|c|c|c|c|c|c|c|c|}
\hline \multirow[b]{2}{*}{ Year } & \multicolumn{2}{|c|}{ Arizona } & \multicolumn{2}{|c|}{ California } & Hawa i i & \multicolumn{2}{|c|}{ Nevada } \\
\hline & Coal & Nuclear & Coal & Nuclear & Coal Nuclear & Coal & Nuclear \\
\hline 1980 & 12.79 & & & 11.09 & & & \\
\hline 1981 & 13.23 & & & 11.65 & & 14.36 & \\
\hline \multicolumn{8}{|l|}{1982} \\
\hline 1983 & & 12.03 & & & & & \\
\hline 1984 & & 12.54 & & & & 16.31 & \\
\hline 1985 & 15.69 & & 13.56 & & & 14.48 & \\
\hline 1986 & & 13.56 & 13.92 & & & 14.90 & \\
\hline 1987 & 16.65 & & & & & 15.29 & \\
\hline \multicolumn{8}{|l|}{1988} \\
\hline \multicolumn{8}{|l|}{1989} \\
\hline 1990 & & & 14.65 & & & & \\
\hline \multicolumn{8}{|l|}{1991} \\
\hline \multicolumn{8}{|l|}{1992} \\
\hline \multicolumn{8}{|l|}{1993} \\
\hline \multicolumn{8}{|l|}{1984} \\
\hline $1995^{(1}$ & b) 17.32 & 19.44 & 17.35 & 19.44 & & 17.35 & 19.44 \\
\hline
\end{tabular}

(a) $1979 \$ /$ MBtu.

(b) 1995 estimates are based on generic $600 \mathrm{MW}$ coal and $1200 \mathrm{MW}$ nuclear plants. 
TABLE B. 10. DOE Region 10. Busbar Cost per MBtu for Electricity from New Coal and Nuclear Plants by State, 1980-1995(a)

\begin{tabular}{|c|c|c|c|c|c|c|c|c|}
\hline \multirow[b]{2}{*}{ Year } & \multicolumn{2}{|c|}{ Alaska } & \multicolumn{2}{|c|}{ Idaho } & \multicolumn{2}{|c|}{ Oregon } & \multicolumn{2}{|c|}{ Washington } \\
\hline & Coal & Nuclear & Coal & Nuclear & Coal & Nuclear & $\operatorname{coa} 1$ & Nuclear \\
\hline 1980 & & & & & 11.71 & & & \\
\hline 1981 & & & & & & & & 12.05 \\
\hline \multicolumn{9}{|l|}{1982} \\
\hline 1983 & & & & & & & & 12.41 \\
\hline 1984 & 23.51 & & & & & & & 12.95 \\
\hline 1985 & & & & & & & & 13.54 \\
\hline 1986 & & & & & & 13.76 & & 14.02 \\
\hline \multicolumn{9}{|l|}{1987} \\
\hline \multicolumn{9}{|l|}{1988} \\
\hline 1989 & & & & & & 15.58 & & \\
\hline \multicolumn{9}{|l|}{1990} \\
\hline \multicolumn{9}{|l|}{1991} \\
\hline \multicolumn{9}{|l|}{1992} \\
\hline \multicolumn{9}{|l|}{1993} \\
\hline 1994 & & & & & & & & \\
\hline $1995^{(\mathrm{b}}$ & 16.54 & 19.44 & 15.26 & 19.44 & 16.53 & 19.44 & 16.53 & 19.44 \\
\hline
\end{tabular}

(a) $1979 \$ / \mathrm{MBtu}$.

(b) 1995 estimates are based on generic $600 \mathrm{MW}$ coal and $1200 \mathrm{MW}$ nuclear plants. 


\section{APPENDIX C}

STATE AND REGIONAL RETAIL MARGINAL COST ESTIMATES 
TABLE C.1. Derivation of Regional Retail Marginal Cost Estimates from State Electricity Cost Estimates, 1980-i995(a)

\begin{tabular}{|c|c|c|c|c|c|c|c|c|c|}
\hline Year & Connecticut & Maine & Massachusetts & New Hampshire & New Jersey & New York & Rhode Island & Vermont & $\begin{array}{c}\text { DOE } \\
\frac{\text { Region 1 } 122^{(b}}{\$ / \text { MBtu }} \\
\end{array}$ \\
\hline 1980 & & & & & & 15.72 & & & 15.72 \\
\hline \multicolumn{10}{|l|}{1981} \\
\hline \multicolumn{10}{|l|}{1982} \\
\hline 1983 & & & & 15.56 & 15.18 & 15.46 & & & 15.44 \\
\hline 1984 & & & & & 16.79 & 15.95 & & & 16.28 \\
\hline 1985 & & & 16.61 & 16.82 & & & & & 16.72 \\
\hline 1986 & 17.41 & 17.65 & & & 18.14 & & & & 17.82 \\
\hline 1987 & & & & & 20.07 & 16.79 & & & 17.64 \\
\hline 1988 & & & & & & 17.69 & & & 17.69 \\
\hline \multicolumn{10}{|l|}{1989} \\
\hline 1990 & & & & & 17.71 & & & & 17.71 \\
\hline \multicolumn{10}{|l|}{1991} \\
\hline \multicolumn{10}{|l|}{1992} \\
\hline \multicolumn{10}{|l|}{1993} \\
\hline \multicolumn{10}{|l|}{1994} \\
\hline $1995^{\prime}$ & 21.51 & 21.61 & 21.52 & 21.52 & 21.36 & 21.36 & 21.47 & 21.52 & 21.48 \\
\hline
\end{tabular}

(a) $1979 \$ /$ MBtu.

(b) Regional cost estimates are a capacity weighted average of state cost estimates.

(c) 1995 estimates are an average of generic $600 \mathrm{MW}$ coal and 1200 MW nuclear plant costs. 
TABLE C.2. Derivation of Regional Retail Marginal Cost Estimates from State

Electricity Cost Estimates, 1980-1995(a)

\begin{tabular}{|c|c|c|c|c|c|c|}
\hline Year & Delaware & Maryland & Pennsylvania & Virginia & West Virginia & $\begin{array}{c}\text { DOE } \\
\frac{\text { Region } 3^{(}}{\$ / \mathrm{MBtu}}\end{array}$ \\
\hline 1980 & 14.86 & & 14.18 & & 13.93 & 14.12 \\
\hline 1981 & & & 14.31 & & & 14.31 \\
\hline 1982 & & & 14.93 & & & 14.93 \\
\hline 1983 & & & 15.91 & 16.77 & & 16.29 \\
\hline 1984 & & & 17.02 & 17.53 & & 17.33 \\
\hline 1985 & & 15.68 & 16.87 & & & 16.51 \\
\hline 1986 & & 17.09 & 16.38 & & & 16.70 \\
\hline 1987 & & 16.95 & & 16.35 & & 16.71 \\
\hline 1988 & & & 17.27 & & & 17.27 \\
\hline \multicolumn{7}{|l|}{1989} \\
\hline \multicolumn{7}{|l|}{1990} \\
\hline 1991 & & & 17.62 & & & 17.62 \\
\hline 1992 & & & 17.90 & & & 17.90 \\
\hline \multicolumn{7}{|l|}{1993} \\
\hline $\begin{array}{l}1994 \\
1995 \text { (c }\end{array}$ & c) 21.17 & 21.17 & 21.21 & 20.89 & 21.20 & 21.13 \\
\hline
\end{tabular}

(a) $1979 \$ /$ MBtu.

(b) Regional cost estimates are a capacity weighted average of state cost estimates.

(c) 1995 estimates are an average of generic $600 \mathrm{MW}$ coal and 1200 MW nuclear plant costs. 
TABLE C.3. Derivation of Regional Retail Marginal Cost Estimates from State

Electricity Cost Estimates, 1980-1995(a)

\begin{tabular}{|c|c|c|c|c|c|c|c|c|c|}
\hline Year & Alabama & Florida & Georgia & Kentucky & Mississippi & North Carol ina & South Carolina & Tennessee & $\begin{array}{c}\text { DOE } \\
\frac{\text { Region } 4}{\text { \$/MBtu }}\end{array}$ \\
\hline 1980 & 14.63 & & & 14.19 & & 13.59 & 14.41 & 12.82 & 13.92 \\
\hline 1981 & 14.13 & 15.42 & & 14.43 & 13.76 & 13.42 & 14.36 & 13.28 & 13.67 \\
\hline 1982 & 14.56 & 14.71 & 14.50 & & & 14.44 & & & 14.54 \\
\hline 1983 & 14.49 & 16.25 & & 15.83 & & & 15.08 & & 15.06 \\
\hline 1984 & & 15.47 & 15.21 & 15.63 & 14.78 & 17.11 & & 14.85 & 15.36 \\
\hline 1985 & 16.59 & 16.06 & 15.67 & 16.51 & 15.36 & 15.50 & 15.68 & 15.43 & 15.70 \\
\hline 1986 & & 16.23 & 18.74 & 16.06 & 16.42 & 18.59 & & 16.01 & 16.75 \\
\hline 1987 & 16.16 & 16.45 & 16.10 & 16.52 & 16.24 & & 16.63 & & 16.36 \\
\hline 1988 & 16.46 & & & & & 18.19 & 17.48 & 17.19 & 17.58 \\
\hline 1989 & & 17.10 & & 17.25 & & & 17.43 & 17.78 & 17.46 \\
\hline 1990 & 17.06 & & & & & 21.58 & & & 19.54 \\
\hline \multicolumn{10}{|l|}{1991} \\
\hline \multicolumn{10}{|l|}{1992} \\
\hline \multicolumn{10}{|l|}{1993} \\
\hline \multicolumn{10}{|l|}{1994} \\
\hline $1995^{(c}$ & 20.68 & 20.72 & 20.71 & 20.75 & 20.73 & 20.64 & 20.66 & 20.56 & 20.68 \\
\hline
\end{tabular}

\footnotetext{
(a) $1979 \$ /$ MBtu.

(b) Regional cost estimates are a capacity weighted average of state cost estimates.

(c) 1995 estimates are an average of generic $600 \mathrm{MW}$ coal and 1200 MW nuclear plant costs.
} 
TABLE C.4. Derivation of Regional Retail Margina] fost Estimates from State Electricity Cost Estimates, 1980-1995(a)

\begin{tabular}{|c|c|c|c|c|c|c|c|}
\hline Year & Illinois & Indiana & Michigan & Minnesota & Ohio & Wisconsin & $\begin{array}{c}\text { DOE } \\
\text { Region } 5 \\
\$ / \mathrm{MBtu} \\
\end{array}$ \\
\hline 1980 & 13.14 & & 13.68 & 13.82 & & 13.92 & 13.55 \\
\hline 1981 & 13.65 & 14.84 & & & 14.76 & & 14.02 \\
\hline 1982 & 14.48 & 14.53 & 19.73 & & & 15.38 & 14.63 \\
\hline 1983 & & 15.38 & 14.78 & & 15.23 & 16.29 & 15.33 \\
\hline 1984 & & 17.53 & 16.62 & 14.83 & & & 16.72 \\
\hline 1985 & 17.61 & 17.27 & 26.04 & & 15.96 & 17.01 & 17.80 \\
\hline 1986 & 18.45 & & & 16.13 & 16.25 & 19.93 & 17.81 \\
\hline 1987 & 16.96 & 16.53 & & 15.72 & 17.85 & & 16.78 \\
\hline 1988 & 18.91 & & & & & & 18.91 \\
\hline 1989 & 17.45 & & & 16.29 & & & 16.76 \\
\hline 1990 & & & & & 18.77 & & 18.77 \\
\hline \multicolumn{8}{|l|}{1991} \\
\hline \multicolumn{8}{|l|}{1992} \\
\hline \multicolumn{8}{|l|}{1993} \\
\hline \multicolumn{8}{|l|}{1994} \\
\hline $1995^{\prime}$ & 20.66 & 20.68 & 20.56 & 20.51 & 20.80 & 20.67 & 20.65 \\
\hline
\end{tabular}

\footnotetext{
(a) $1979 \$ /$ Mstu.

(b) Regional cost estimates are a capacity weighted average of state cost estimates.

(c) 1995 estimates are an average of generic $600 \mathrm{MW}$ coal and 1200 MW nuclear plant costs.
} 
TABLE C.5. Derivation of Regional Retail Marginal fost Estimates from State Electricity Cost Estimates, 1980-1995(a)

\begin{tabular}{|c|c|c|c|c|c|c|}
\hline Year & Arkansas & Louisiana & New Mexico & Oklahoma & Texas & $\begin{array}{c}\text { DOE } \\
\text { Region } \\
\$ / M B \text { tu }\end{array}$ \\
\hline 1980 & 12.23 & 12.37 & & 12.46 & 12.51 & 12.44 \\
\hline 1981 & 12.78 & 13.31 & & 13.11 & 13.35 & 13.32 \\
\hline 1982 & & 13.42 & 13.63 & 14.06 & 13.58 & 13.60 \\
\hline 1983 & 13.73 & 13.97 & & 13.88 & 14.27 & 14.09 \\
\hline 1984 & & & 15.66 & 15.62 & 14.54 & 14.71 \\
\hline 1985 & 14.55 & 15.97 & & 15.04 & 15.29 & 15.42 \\
\hline 1986 & & 16.40 & & 16.18 & 15.56 & 15.90 \\
\hline 1987 & & & & 15.89 & 15.45 & 15.64 \\
\hline 1988 & & 15.66 & & 16.29 & 16.35 & 16.05 \\
\hline \multicolumn{7}{|l|}{1989} \\
\hline 1990 & & & 17.17 & & & 17.17 \\
\hline \multicolumn{7}{|l|}{1991} \\
\hline 1992 & & & 17.94 & & & 17.94 \\
\hline \multicolumn{7}{|l|}{1993} \\
\hline \multicolumn{7}{|l|}{1994} \\
\hline $1995^{\prime}$ & c) 20.32 & 20.32 & 20.36 & 20.32 & 20.33 & 20.33 \\
\hline
\end{tabular}

(a) $1979 \$ / \mathrm{MBtu}$.

(b) Regional cost estimates are a capacity weighted average of state cost estimates.

(c) 1995 estimates are an average of generic $600 \mathrm{MW}$ coal and $1200 \mathrm{MW}$ nuclear plant costs. 
TABLE C.6. Derivation of Regional Retail Marginal Cost Estimates from State Electricity Cost Estimates, 1980-1995(a)

\begin{tabular}{|c|c|c|c|c|c|}
\hline Year & Iowa & Kansas & Missouri & Nebraska & $\begin{array}{c}\text { DOE } \\
\frac{\text { Region } 7}{\text { \$/MBtu }} \\
\text { (b }\end{array}$ \\
\hline 1980 & & 14.04 & 13.32 & & 13.73 \\
\hline 1981 & 13.74 & & 14.80 & 15.15 & 14.59 \\
\hline 1982 & 19.92 & 14.81 & 15.74 & & 15.07 \\
\hline 1983 & 14.64 & 14.99 & & & 14.86 \\
\hline 1984 & & 15.58 & & & 15.58 \\
\hline 1985 & 15.60 & & & & 15.60 \\
\hline 1986 & & & 21.33 & 15.64 & 17.81 \\
\hline 1987 & & & 16.48 & & 16.48 \\
\hline \multicolumn{6}{|l|}{1988} \\
\hline \multicolumn{6}{|l|}{1989} \\
\hline \multicolumn{6}{|l|}{1990} \\
\hline \multicolumn{6}{|l|}{1991} \\
\hline \multicolumn{6}{|l|}{1992} \\
\hline \multicolumn{6}{|l|}{1993} \\
\hline \multicolumn{6}{|l|}{1994} \\
\hline $1995^{\prime}$ & 20.29 & 20.48 & 20.52 & 20.38 & 20.42 \\
\hline
\end{tabular}

(a) $1979 \$ /$ MBtu.

(b) Regional cost estimates are a capacity weighted average of state cost estimates.

(c) 1995 estimates are an average of generic $600 \mathrm{MW}$ coal and $1200 \mathrm{MW}$ nuclear plant costs. 
TABLE A.10. DOE Region 10. New Generating Capacity Cost per kW for Coal and Nuclear Plants by State, 1980-1995(a)

\begin{tabular}{|c|c|c|c|c|c|c|c|c|}
\hline \multirow[b]{2}{*}{ Year } & \multicolumn{2}{|c|}{ Alaska } & \multicolumn{2}{|c|}{ Idaho } & \multicolumn{2}{|c|}{ Oregon } & \multicolumn{2}{|c|}{ Washington } \\
\hline & Coal & Nuclear & Coal & Nuclear & Coal & Nuclear & Coal & Nuclear \\
\hline 1980 & & & & & 555 & & & \\
\hline 1981 & & & & & & & & 1050 \\
\hline \multicolumn{9}{|l|}{1982} \\
\hline 1983 & & & & & & & & 1076 \\
\hline 1984 & 1859 & & & & & & & 1130 \\
\hline 1985 & & & & & & & & 1192 \\
\hline 1986 & & & & & & 1235 & & 1240 \\
\hline \multicolumn{9}{|l|}{1987} \\
\hline \multicolumn{9}{|l|}{1988} \\
\hline 1989 & & & & & & 1424 & & \\
\hline \multicolumn{9}{|l|}{1990} \\
\hline \multicolumn{9}{|l|}{1991} \\
\hline \multicolumn{9}{|l|}{1992} \\
\hline \multicolumn{9}{|l|}{1993} \\
\hline \multicolumn{9}{|l|}{1994} \\
\hline 1995 & & & & & & & & \\
\hline
\end{tabular}

(a) $1979 \$ / \mathrm{kW}$. 
TABLE C.7. Derivation of Regional Retail Margina] fost Estimates from State Electricity Cost Estimates, 1980-1995(a)

\begin{tabular}{|c|c|c|c|c|c|c|c|}
\hline Year & Colorado & Montana & North Dakota & South Dakota & Utah & Wyoming & $\frac{\begin{array}{c}\text { DOE } \\
\text { Region } 8\end{array}}{\$ / \mathrm{MBtu}}$ \\
\hline 1980 & 11.84 & & 11.87 & & 12.53 & 11.86 & 11.96 \\
\hline 1981 & 12.47 & & 12.88 & & & & 12.73 \\
\hline 1982 & 13.64 & 12.24 & & & & 12.71 & 12.70 \\
\hline 1983 & 13.43 & 12.58 & 13.65 & & 14.70 & 14.64 & 13.61 \\
\hline 1984 & 13.32 & & & & 16.49 & & 13.72 \\
\hline 1985 & 13.64 & & & & 14.95 & & 14.02 \\
\hline 1986 & 14.57 & & 14.40 & & & 14.41 & 14.46 \\
\hline 1987 & 14.94 & & & & 13.68 & & 14.14 \\
\hline 1988 & & & 15.10 & & 13.97 & 15.10 & 14.59 \\
\hline 1989 & & & & & 14.24 & & 14.24 \\
\hline \multicolumn{8}{|l|}{1990} \\
\hline \multicolumn{8}{|l|}{1991} \\
\hline \multicolumn{8}{|l|}{1992} \\
\hline \multicolumn{8}{|l|}{1993} \\
\hline \multicolumn{8}{|l|}{1994} \\
\hline 1995 (c & c) 19.49 & 19.51 & 19.50 & 19.50 & 19.50 & 19.50 & 19.50 \\
\hline
\end{tabular}

(a) $1979 \$ /$ MBtu.

(b) Regional cost estimates are a capacity weighted average of state cost estimates.

(c) 1995 estimates are an average of generic $600 \mathrm{MW}$ coal and $1200 \mathrm{MW}$ nuclear plant costs. 
TABLE C.8. Derivation of Regional Retail Marginal Cost Estimates from State Electricity Cost Estimates, 1980-1995(a)

DOE

Region $g^{(b)}$

\begin{tabular}{|c|c|c|c|c|c|}
\hline Year & Arizona & California & Hawai i & Nevada & $\frac{\text { Region } 9}{\$ \text { /MBtu }}$ \\
\hline 1980 & 14.69 & 12.98 & & & 13.61 \\
\hline 1981 & 15.17 & 13.59 & & 16.30 & 14.32 \\
\hline \multicolumn{6}{|l|}{1982} \\
\hline 1983 & 14.08 & & & & 14.08 \\
\hline 1984 & 14.64 & & & 18.41 & 15.28 \\
\hline 1985 & 17.85 & 15.72 & & 16.63 & 16.45 \\
\hline 1986 & 15.76 & 16.12 & & 17.10 & 16.28 \\
\hline 1987 & 18.91 & & & 17.55 & 18.11 \\
\hline \multicolumn{6}{|l|}{1988} \\
\hline \multicolumn{6}{|l|}{1989} \\
\hline 1990 & & 17.09 & & & 17.09 \\
\hline \multicolumn{6}{|l|}{1991} \\
\hline \multicolumn{6}{|l|}{1992} \\
\hline \multicolumn{6}{|l|}{1993} \\
\hline $\begin{array}{l}1994 \\
1995(\end{array}$ & c) 21.17 & 21.19 & & 21.19 & 21.18 \\
\hline
\end{tabular}

(a) $1979 \$ / \mathrm{MBtu}$

(b) Regional cost estimates are a capacity weighted average of 5 tate cost estimates.

(c) 1995 estimates are an average of generic $600 \mathrm{MW}$ coal and $1200 \mathrm{MW}$ nuclear plant costs. 
Table C.9. Derivation of Regional Retail Marginal Cost Estimates from State Electricity Cost Estimates, 1980-1995(a)

\begin{tabular}{|c|c|c|c|c|c|}
\hline Year & Alaska & Idaho & Oregon & Washington & $\begin{array}{c}\text { DOE } \\
\text { Region } 10 \\
\text { \$/MBtu } \\
\end{array}$ \\
\hline 1980 & & & 13.60 & & 13.60 \\
\hline 1981 & & & & 14.00 & 14.00 \\
\hline \multicolumn{6}{|l|}{1982} \\
\hline 1983 & & & & 14.46 & 14.46 \\
\hline 1984 & 25.61 & & & 15.05 & 15.94 \\
\hline 1985 & & & & 15.69 & 15.69 \\
\hline 1986 & & & 15.97 & 16.23 & 16.10 \\
\hline \multicolumn{6}{|l|}{1987} \\
\hline \multicolumn{6}{|l|}{1988} \\
\hline 1989 & & & 17.96 & & 17.96 \\
\hline \multicolumn{6}{|l|}{1990} \\
\hline \multicolumn{6}{|l|}{1991} \\
\hline \multicolumn{6}{|l|}{1992} \\
\hline \multicolumn{6}{|l|}{1993} \\
\hline \multicolumn{6}{|c|}{1994 (c) } \\
\hline $1995^{(C}$ & 20.78 & 20.03 & 20.78 & 20.78 & 20.59 \\
\hline
\end{tabular}

(a) $1979 \$ / \mathrm{MBtu}$.

(b) Regional cost estimates are a capacity weighted average of state cost estimates.

(c) 1995 estimates are based on a generic $600 \mathrm{MW}$ coal and 1200 MW nuclear plant costs. 
4 


\section{DISTRIBUTION}

No. of

Copies

\section{OFFSITE}

A. A. Churm

DOE Patent Division

9800 S. Cass Avenue

Argonne, IL 60439

27 DOE Technical Information Center

M. Savitz

U.S. Department of Energy Washington, DC 20545

\section{J. Cable}

U.S. Department of Energy Washington, DC 20545

10 P. Back

U.S. Department of Energy Washington, DC 20545

J. Willman

U.S. Department of Energy Washington, DC 20545

C. L. McDonald

Mathematical Sciences Northwest, Inc.

P.0. Box 1887

Bellevue, WA 98009
No. of

Copies

3 J. Grossman

Energy and Environmental

Analys is

Arlington, VA 22209

Vijay Mathur

Department of Economics

Cleveland State University

Cleveland, $\mathrm{OH} 44115$

ONS ITE

DOE Richland Operations

H. E. Ransom

47 Pacific Northwest Laboratory

J. W. Currie

D. E. Deonigi

J. C. Emery

J. M. Fang

T. J. Foley

B. J. Harrer

J. B. Hask ins

L. A. Nieves (10)

R. L. Nesse

W. P. Patton

J. Tawil

Economics Library (20)

Technical Information (5)

Publishing Coordination KE(2) 